CIC. Cuadernos de Información y Comunicación ISSN: 1135-7791

http://dx.doi.org/10.5209/CIYC.60686

\title{
Respuestas internacionales al Manifiesto Académico: Informes desde 14 países $^{1}$
}

Coordinado por Willem Halffman y Hans Radder; traducción de Eva Aladro Vico

Enviado: 12 de octubre de 2917 / Aceptado: 24 de octubre de 2017

Resumen. Este conjunto de artículos discute e investiga las condiciones y situación de las Universidades Públicas de 14 países de todo el globo, por parte de importantes académicos de cada país. Analiza la productivización y mercantilización de la universidad pública en una era de recortes y falta de apoyo político e institucional. Discute la pérdida de criterios y horizontes de valoración de los académicos y sus escuelas y universidades, su sometimiento al sistema de evaluación cuantométrico que es inadecuado e injusto, y propone la necesidad de organizar una acción conjunta global de los académicos conscientes de esta pérdida de criterios para defender y situar en su puesto la enseñanza superior universitaria y su función vital en el desarrollo social.

Palabras clave: Manifiesto Académico, Informe internacional, universidad productivista, gerencialismo, condiciones de producción, internacional académica.

\section{[en] International responses to the Academic Manifesto: reports from 14 countries}

Abstract. This set of articles discusses and investigates the conditions and situation of Public
Universities in 14 countries around the globe. It analyzes the productivist model created for the public
university in an era of withdrawal and lack of political and institutional support. It discusses the loss
of self-assessment criteria of the academics and their universities, their submission to the quantometric
evaluation system that is inadequate d unfair, and it proposes the organization of a global academical
joint action to defend and restore in their position the public university and higher education, fighting
for its essential role in social development Keywords: Academic Manifesto, International Report on 14 Countries, productivist university, managerial model for public education, academic international movement.

Sumario. Introducción al informe, por Willem Halffman and Hans Radder. Referencias. El lobo y la oveja en Quebec, por Michel Lacroix. El Lobo está por todas partes. ¿Las ovejas devuelven

1 Este Informe es una traducción del Informe aparecido en SERRC Social Epistemology Reply and Review, plataforma online de la publicación Social Epistemology, (Social Epistemology Review and Reply Collective, Special Report (2017): 1-76. http://wp.me/p1Bfg0-3FV dirigida por Jim Collier, a quien agradecemos su gentil permiso para realizar esta versión en español, así como a todos los coautores del Informe desde 14 países de todo el mundo. El original se publica en verano de 2017 como International Responses to the Academic Manifesto: Reports from 14 Countries Ningún esfuerzo hubiera fructificado si los profesores Willem Halffman, de la Radboud University, y Hans Radder, profesor en VU University Amsterdam no hubieran publicado previamente, en 2013 y en 2015 el Academic Manifesto: en la revista Minerva, que Cuadernos de Información y Comunicación CIC tradujo y publicó en español en su número 22 de 2017 y que fue clave en el movimiento contra la reestructuración de la Universidad Complutense de Madrid en el año 2016. Agradecemos a todos ellos su colaboración. 
el golpe? Referencias. Más allá de la privatización en la educación superior en USA, por Mark B. Brown. Privatización y gerencialismo. ¿Qué hacer? Referencias. Los efectos perversos de la dirección empresarial: la experiencia brasileña, por Renato Dagnino and Marcos Barbosa de Oliveira. Referencias. La crisis de la academia japonesa. Breve informe de los últimos acontecimientos, por Makoto Katsumori. Referencias. Australia: ¿Reclamar la Universidad Pública?, por Simon Batterbury y Jason Byme. Similitudes y Diferencias. Reformas en la Educación Terciaria. El Lobo en Australia. Evaluación de resultados individuales. Conclusión. Referencias. Sobre lobos, ovejas y pastores: Una comedia bosnia de los errores, por Mario Hibert y Andrea Lešić-Thomas. Referencias. Al lado del lobo hay también un horrible pulpo gigante que está devorando la libertad académica en Hungría, por Anna Wessely. 1. ¿Cuáles son las similitudes y diferencias más significativas con la situación en nuestro país? 1.1. Resumen de los cambios legislativos y su impacto en la CEU. 2. ¿Cómo se relacionan las afirmaciones hechas en el Manifiesto con la situación en Hungría? 3. ¿Qué posibilidades hay en Hungría de cambiar la situación a mejor? Referencias. La lucha por la autenticidad académica: la posición eslovaca en el contexto del Manifiesto Académico por Jozef Hvorecky, Emil Višňovsky y Matúš Porubjak. Referencias. Ansiedades y tensiones en el modelo nórdico -Finlandia y Escandinavia- por Anita Välikangas. Referencias. Activismo contra acritud: Sin mejoría pero más allá del Marco de Excelencia Investigadora en Reino Unido, por Richard Watermeyer. Referencias. El Manifiesto Académico: La situación en los territorios flamencos por Koen Bogaert, Valerie De Craene, Anton Froeyman, Karen Stroobants y Sigrid Vertommen. Las afirmaciones del Manifiesto. Acción y posibilidades de cambiar la situación a mejor. La Universidad Complutense de Madrid y el Manifiesto Académico: Rasgos comunes de una crisis global de la educación superior, por Eva Aladro Vico. Referencias. Problemas en las universidades francesas, por Christophe Charle. Financiación desigual. Especialización prematura. El espejismo de los reconocimientos internacionales. Pérdida de Independencia. La lucha por la universidad pública en Holanda, por Willen Halffman y Hans Radder. Resistencia y acción reformista. Movimientos críticos. Los Sindicatos. Protestas de estudiantes y personal. El gobierno y los partidos políticos. Consejeros de políticas. ¿Cambio de régimen? Activismo: ¿qué funciona? Valoración: ¿hacia una universidad pública? Referencias. La Universidad productivista se hace global: (y también la Resistencia), por Willem Halffman y Hans Radder. El productivismo contextualizado. Cómo resistir a la universidad productivista. Intervención democrática. Sindicalización. Manifestaciones y acciones críticias. Huelgas y rechazo colectivo. Contra-ocupaciones. Salida. Contraindicaciones y el poder del Humor. Conclusión. Referencias.

Cómo citar: Halffman, W.; Radder, H. (2018). Respuestas internacionales al Manifiesto Académico: Informes desde 14 países, en CIC. Cuadernos de Información y Comunicación 23, 25-103.

\section{Introducción al informe}

\section{Willem Halffman and Hans Radder}

En abril de 2015, publicamos nuestro Manifiesto Académico, una versión inglesa levemente actualizada de nuestro artículo previo en holandés (Halffman y Radder 2013, 2015a). El él se describía cómo las universidades están siendo ocupadas por una dirección de ideología empresarial, en un régimen obsesionado con "el reconocimiento de méritos" mediante la cuantificación profesional, que ha dado paso a una creciente competitividad, al dominio de la supuesta eficiencia, "excelencia" y a una equivocada idea de salvación económica. Dados los absurdos efectos de esta ocupación, examinamos cómo la colonización de la universidad se hacía real y por qué sigue todavía presente. Más allá, bosquejamos una visión alternativa de la universidad pública, más cercana a un bien común de conocimiento socialmente comprometido, que a una empresa. Dimos una lista de veinte medidas concretas para llegar a esa universidad pública. Visto el hecho de que los directivos universitarios parecen ignorar los argumentos de peso, concluimos que solamente podría darse un cambio 
si los académicos mismos pasan a la acción. Así, exploramos diferentes estrategias para renovar la política universitaria.

El artículo ha causado, parece, agitación en estos años recientes. Hemos recibido reacciones de apoyo de académicos de muchos países. Ahora hay una versión húngara, una española, una bosnio/croata, y una portuguesa, y la traducción al francés se publicará en breve ((Halffman and Radder 2015b, 2015c, 2016, 2017). Todas las traducciones se han hecho en el contexto de protestas académicas en sus países respectivos, y como llamada a la acción. Finalmente, en este momento, la página web de la revista Minerva tiene 19K de descargas del Manifesto, lo que es excepcional para este tipo de revistas.

Por nuestra parte estos hechos sugerían la necesidad de un seguimiento del tema. Aparentemente, los problemas académicos que analizamos desde una perspectiva holandesa no se limitaban a Holanda. Así pues, parecía importante tener una visión más en detalle de la situación actual de la Educación Superior en una gama de países diferentes. Para este fin, invitamos a algunos colegas que previamente nos habían enviado una reacción, a que escribieran una breve respuesta al Manifiesto. Estas respuestas debían contemplar los análisis, evaluaciones y las soluciones propuestas al Manifiesto desde la perspectiva nacional de cada uno de los investigadores.

El objetivo era triple. Primero, esta visión general mostraría la dimensión internacional de la situación y podría defendernos de los intentos de acallar nuestras críticas con el argumento de que los problemas descritos son meramente locales e incidentales. En segundo lugar, constituiría un acto de solidaridad internacional y con ello serviría para motivar y apoyar futuras formas de resistencia. Tercero, ayudaría a diseñar estrategias eficaces de acción política al permitirnos aprender los unos de los otros.

En resultado, hemos recibido los Informes que se verán a continuación. Algunos son relativamente breves, otros se extienden más en detalle. Se originan desde un amplio grupo de países: Australia, Bélgica, (área flamenca), Bosnia-Herzegovina, Brasil, Canadá (Quebec), Finlandia, (y Escandinavia), Hungría, Japón, España, Eslovaquia, Reino Unido y los Estados Unidos. Hemos añadido a este inventario una breve pieza de lo ocurrido en Holanda desde que publicamos la primera versión del Manifiesto en 2013. Como los Informes no pueden agruparse en conjuntos temáticos claramente diferenciados, los hemos ordenado de acuerdo con el área geográfica y las regiones de los autores. Concluimos esta colección de Informes con un bosquejo de nuestra perspectiva de lo que denominamos "universidad productivista", tanto en sus rasgos globales como en sus igualmente globales formas de resistencia, que estamos viendo surgir en los 14 países que contribuyen a este Informe.

\section{Referencias}

Halffman, Willem and Hans Radder. 2013. "Het Academisch Manifest: Van een Bezette Naar een Publieke Universiteit.” Krisis: Tijdschrift Voor Actuele Filosofie (3): 2-18.https://goo. gl/ZV79Jp.

Halffman, Willem and Hans Radder. 2015a. "The Academic Manifesto: From an Occupied to a Public University." Minerva 53 (2): 165-187.

Halffman, Willem and Hans Radder. 2015b. “A Megszállt Egyetemből Legyen Újra Közintézmény!" [In Hungarian.] Translated by Anna Wessely. Budapest Review of Books, 6 (July): 114-120. 
Halffman, Willem and Hans Radder. 2015c. “Akademski Manifest: Od Okupiranog dso Javnog Univerziteta." [In Bosnian/Croatian/Serbian.] Translated by Mario Hibert and Andrea Lešić. Pregled: 173-203. https://www.academia.edu/11955254.

Halffman, Willem and Hans Radder. 2016. "Manifiesto Académico: De la Universidad Ocupada a la Universidad Pública.” [In Spanish.] Translated by Eva Aladro Vico. https://goo. gl/VSEQp6 CIC Cuadernos de Información y Comunicación, 22, 2017).

Halffman, Willem and Hans Radder. 2017. "Manifesto Acadêmico: De uma Universidade Ocupada a uma Universidade Pública." [In Portuguese.] Translated by Amires Cianci von Atzingen, Carlos Machado and Marcos Barbosa de Oliveira. Revista ADUSP. (60): 6-25. https://goo.gl/QTepxW.

Halffman, Willem and Hans Radder. Forthcoming. "Le Manifeste Académique." [In French.] Translated by Michel Lacroix. 


\section{El lobo y las ovejas en Quebec}

Michel Lacroix ${ }^{2}$

\section{El Lobo está por todas partes}

A un profesor de universidad canadiense, leer el Manifiesto Académico le causa una muy intensa sensación de "preocupación extrañamente familiar". Sin duda, el lobo de mil cabezas de la dirección empresarial nos ha colonizado a nosotros también. Podemos reconocer en el sistema de la universidad de Québec la mayoría de los síntomas de esta ocupación. El nuevo régimen de "fetichismo de los indicadores" domina las prácticas y los discursos de la administración universitaria, de las instituciones de concesión de ayuda a la investigación, así como al gobierno de la universidad y a las organizaciones de financiación privada. En todos estos frentes, la presión es para producir "más": más estudiantes en cada aula, en cada programa de estudios, más estudiantes internacionales en cada universidad, más publicaciones, y más proyectos de investigación para cada académico. La ratio profesor/estudiante ha subido un $40 \%$ entre 1995 y 2005 , pero el número de bajas por sobre-esfuerzo en las facultades también se ha multiplicado (en torno a 6 veces, en Laval University, vid. Leclerc, Bourassa y Macé 2016).

La intensidad del vacío intelectual de la competencia entre estudiantes, entre profesores y entre instituciones ha alcanzado niveles muy altos y ha creado un circuito de sistemática ratificación de decisiones precedentes: la mayoría de las becas de Doctorado para estudiantes las reciben alumnos que ya recibieron beca para hacer su Máster, y lo mismo ocurre con las becas Posdoctorales, con las plazas de docencia, y en toda la gama de "puestos de investigación en Canadá", en los que los académicos que reciben mayor financiación son los que ya la recibieron anteriormente, tanto ellos como sus estudiantes asociados. La concentración de becas en unas pocas manos ha generado un oligopolio investigador de enorme desigualdad: el 10\% de la llamada élite de los académicos recibe un $80 \%$ del dinero de ayudas (Larivière 2013). Todo esto devalúa permanentemente la enseñanza: las "estrellas" académicas no imparten más que un seminario de grado por año, los profesores que tienen la carga de la docencia "regular" deben asumir cuatro cursos anuales de grado, y son los "pobres hombres" entre sus compañeros, mientras que en torno al 50\% de los cursos de grado son impartidos por contratados precarios. Todo ello socava el valor de la comunidad de servicio, y con ello el espíritu colegiado, hasta el punto de que los puestos de director de Departamento, de coordinador de Grado, e incluso, hasta los de los responsables sindicales, son considerados como obstáculos o vías muertas para la carrera académica "de élite". El efecto Mateo diagnosticado por el Manifiesto Académico afecta a las universidades de Québec tanto como a las holandesas o a las europeas.

Aquí también, la desviación de la meta de preservar, transmitir y alimentar el conocimiento nuevo, de desarrollar un análisis crítico de las ideas y las prácticas, para competir más eficazmente, se cambia por una absurda ideología de la excelencia que sugiere que cada institución, cada académico, puede y debe estar "en la cima

Michel Lacroix es Profesor de Estudios Literarios en el Departamento de Estudios Literarios de la Universidad de Québec en Montréal. Sus actuales investigaciones se centran en las Publicaciones Periódicas Literarias y Académicas, Sociología de los Grupos Literarios y las Redes de Intelectuales Transatlánticos. Es también representante sindical en la UQAM. 
del $1 \%$ de su campo", incluso aunque ello agrave las desigualdades estructurales, "naturalizándolas" en un sistema piramidal. El sistema constantemente aumenta la competencia por captar estudiantes, y conduce a la construcción de nuevos campus en otros territorios y a buscar extensiones en países extranjeros. La misma lógica guiada por el mercantilismo empuja a multiplicar los gabinetes de comunicación y las relaciones públicas internacionales en todos los niveles. Al mismo tiempo, las continuas exigencias gubernamentales de un mayor control de beneficios han internalizado en las administraciones universitarias la doctrina de la "nueva dirección empresarial pública", que no ha hecho mermar en nada la tendencia burócrata: cada vez más tiempo y dinero se dedica a la producción de Informes y Memorias (cada universidad debe enviar en torno a 200 Informes Anuales al gobierno). Entre 1997 y 2008 , la nómina total de personal administrativo ha crecido un $154 \%$, tres veces más que el crecimiento de la nómina de profesorado (FQPPU 2013).

El lobo, tal y como aparece en nuestras universidades, tiene dos características extras respecto a las descritas en el Manifiesto. La primera es la tendencia de los gobiernos a poner la financiación de la investigación al servicio de ellos mismos, a través de financiación temática, que recibe cada vez mayor porción de las ayudas. Además de romper la autonomía de los campos académicos para escoger y evaluar el interés relativo de los temas de investigación, el menor escrutinio y revisión crítica en este asunto contrasta con la amplia financiación que se obtiene del sector privado (el estudio de Lajoie (2009) ha sido severamente criticado, vid. Gingras 2010). La segunda característica concierne a la cuestión del gobierno de las universidades, o por usar otro lenguaje, la distribución del poder dentro de las universidades. Se han producido reiterados esfuerzos, por parte del gobierno y de la administración de las universidades, para dar más poder a sus rectores y a sus equipos rectorales, a costa de los órganos colegiados de la universidad. Un decreto de 2009 daba al menos el $60 \%$ de la representación en los órganos de poder universitarios a los gerentes y administradores externos a la universidad. Una oposición unificada consiguió echar abajo el proyecto, pero la lucha continúa. De hecho, en los últimos meses, en la Université à Montréal y en la Université de Quèbec à Montréal, se han elaborado dos propuestas de restructuración que plantean nuevos modelos de toma de decisiones, con menos poder para los estamentos colegiados en los que profesores, asociados y estudiantes son mayoría. Otro aspecto de las reformas administrativas inspirado en el Lobo es la denominada "devolución de presupuesto" adoptada por algunas universidades, de la administración central hacia las facultades y servicios. En sus efectos (si no en sus objetivos), estas reformas consideran a los estudiantes "ingresos" y los profesores y clases como "gastos", coloreando casi todas las decisiones de una perspectiva estrictamente económica.

Debo añadir también que el mundo estudiantil, organizado en asociaciones, es en Québec una importante fuerza de oposición a la transformación elitista y gerencial de las universidades. Su fuerza puede florecer o estar latente, pero conduce a movilizaciones masivas, como se vio en la reciente "primavera estudiantil" de 2012, en la que una huelga general contra la subida de tasas del $75 \%$ duró varios meses y coaligó a 300.000 estudiantes.

A pesar de estas diferencias, la importancia y magnitud de las similitudes entre la situación en Québec, Holanda, Europa, y diría, Norteamérica, nos enseña que, independientemente de cada contexto económico, cultural o político respectivo, hay sin duda un movimiento transnacional de presión hacia una universidad gerencial, que 
se basa en una ideología compartida, desarrollada y hecha dominante por las instituciones de gobierno, con la ayuda benevolente de los gobiernos universitarios. Esto es mucho más que una "crisis de las Humanidades"(incluso aunque el primer objetivo sean las Humanidades) y más que la consecuencia de años de políticas de austeridad. Veinte años atrás, Bill Readings analizaba el surgimiento y dominio de la idea de excelencia como síntoma de un movimiento globalizador que estaba transformando la universidad en un complejo comercial internacional. El Manifiesto Académico demuestra que este movimiento no solamente ha cambiado la concepción de la universidad, sino su completa estructura, de las interacciones diarias entre colegas a las organizaciones universitarias. Lo que en el libro de Readings era tan solo una descripción verbal se ha materializado ahora en procedimientos, modelos de informe, hojas de cálculo y bajas por agotamiento.

De lo que un profesor quebequés puede deducir del Manifiesto, parece incluso que la situación es peor en los sistemas "públicos" europeos. Excepto los decanos, hasta los más estelares profesores deben aquí dar clase anualmente, y se ofrecen años sabáticos a todos los profesores titulares, siendo la titularidad accesible a la gran mayoría de docentes, tras cuatro o cinco años de carrera, y aunque las universidades publican informes anuales (aunque sus planes estratégicos son prosa administrativa de nuevo cuño desprovista de todo valor intelectual), no hemos experimentado ninguna presión hacia las fusiones, y la introducción de criterios de financiación privada, aunque sea un problema, aún es limitada y se muestra abierta a soluciones creativas.

\section{¿Las ovejas devuelven el golpe?}

Hay un paso muy importante, entre el Manifiesto y La universidad en ruinas (o cualquiera de las críticas esenciales a la universidad gerencial, que se produjeron en bastante cantidad en el contexto de las huelgas estudiantiles de 2012 (por ejemplo Baillargeon 2013; Martin y Ouellet 2011; Seymour 2013)) y es la investigación activa en busca de movimientos de contraataque. También es clara la apelación a un movimiento internacional de lucha, como el Manifiesto incita en su conclusión: " ¡Trabajadores de todas las universidades, uníos!". Algunos académicos seguramente se han reído con sorna de una llamada a las armas como ésta, aunque presuman siempre de su conciencia utópica. Pero sin duda es una de las vías que los profesores universitarios, los docentes asociados y los estudiantes deben examinar, para sacudirse el sentimiento de ser una retaguardia desesperada (la mentalidad de la "aldea gala"). El estudio y la crítica del "sistema mundial" universitario, en su naturaleza burócrata, elitista y mercantilista, no debe convertirse en otro campo especializado de estudio más, sino que debe engendrar, a través de redes de discusión y movilización, una heterogénea pero combativa república de académicos rebeldes. La lógica de los sistemas actuales (conferencias, revistas académicas, seminarios) puede ser utilizada contra sí misma, para ayudar a alimentar una reflexión y acción académicas, y sin embargo militantes.

En cuanto a las diferentes estrategias pergeñadas en el Manifiesto, algunas pueden ofrecer importantes vías para conseguir objetivos específicos y construir la solidaridad local. El rechazo colectivo y la oposición comunitaria a algunos protocolos administrativos, sistemas de documentación, o propuestas, puede ser muy útil. En mi propia universidad, se introdujo un nuevo Programa de Evaluación, que exigía la evaluación anual, trianual y decenial para cada programa, todas ellas con cuestiona- 
rios prefabricados. Tras dos años de experimentación con los Informes Anuales, que sistemáticamente concluían con un "nada que declarar" a aquellas preguntas, los directores de programa de una facultad decidieron negarse a cumplimentarlo, y justificaron su decisión en las propias aplicaciones del Informe, con copia a sus colegas de la misma facultad. Unos meses más tarde, la universidad abandonó este Informe Anual.

Las acciones sindicales pueden ser muy efectivas dependiendo de la historia local y el contexto legal. En la Université de Québec à Montréal y en las otras ramas de la Université du Québec, un acuerdo colectivo especifica la estructura esencial de la universidad. Ello significa que la administración no puede cambiar su estructura mediante un acuerdo colectivo sin previamente tener un acuerdo pactado con la mayoría de los profesores. Consecuentemente, el sindicato tiene un papel estructural en los asuntos universitarios, desde el proceso de contratación de nuevos profesores hasta la creación de nuevos grados, incluso en el control de la ratio profesor/alumno.

Otros sindicatos universitarios no tienen esta capacidad (algunos centros como McGill, no tienen sindicatos, sino solamente asociaciones), pero la posibilidad de una huelga y que las estructuras colegiadas tengan voz y voto, es real. Sin embargo, incluso si muchos de los problemas que se encuentran los profesores en su trabajo provienen de una misma ideología gerencialista, y “de excelencia”, la mayoría de los conflictos son locales, con escaso eco en el exterior. Tenemos una Federación Provincial de Profesores (FQPPU) con un espíritu muy combativo, que publica estudios bien documentados sobre el estado de las universidades quebequesas. Una de las proposiciones que plantearon, que podría detener e incluso revertir la concentración de fondos y de prestigio en unas pocas manos, es la provisión de una beca de investigación anual de 10.000 dólares canadienses para cada profesor de universidad (FQPPU2016). Sin embargo, no hay una "consciencia" real, de parte de los profesores universitarios, de lo que está pasando realmente, y más concretamente en las universidades de sus colegas. Esto limita seriamente la posibilidad de un contraataque colectivo. La imposibilidad legal de una "huelga social" es otra limitación importante. Las huelgas podrían tener un papel importante, en alimentar la solidaridad así como para estructurar un movimiento organizado en favor de los "contraindicadores", via en la que la pericia en muchos campos (relaciones laborales en la ciencia, sociometría y cienciometría en este sector) podría favorecerse conjuntamente. Esto es tanto más necesario, bajo mi punto de vista, en el nivel internacional (y podría darle sentido a una Internacional Educativa (2017)), o mejor incluso, crear una Internacional de la Educación Superior, dado que la primera parece muy distante y más enfocada a los niveles primarios y secundarios de enseñanza.

\section{Referencias}

Baillargeon, Normand. 2013. Je ne Suis Pas Une PME. Montréal: Poètes de Brousse. Education International/Internationale De L'éducation. 2017. "Education International-Latest News on Education.” Accessed March 24 2017. https://www.ei-ie.org/.

FQPPU_Fédération Québécoise Des Professeurs et Professeures D’université. 2016. "Pour Une Subvention De Recherche Annuelle De Base." https://goo.gl/sGKqwD.

FQPPU—Fédération Québécoise Des Professeurs et Professeures D’université. 2013. "Ouvrir Ensemble Une Voie Pour L’université Québécoise.” https://goo.gl/Nqf4cf. 
Gingras, Yves. 2010. “Qu'est-ce Que la Recherche Libre? Review of Vive la Recherche Libre!by Andrée Lajoie.” Recherches Sociographiques 51(1-2): 160-173.

Gingras, Yves. 2016. Bibliometrics and Research Evaluation: Uses and Abuses. Cambridge: MITPress.

Giroux, Aline. 2006. Le Pacte faustien de L'université. Montréal: Liber.

Lajoie, Andrée. 2009. Vive la Recherche Libre! Montréal: Liber.

Larivière, Vincent. 2013. "La Concentration des Fonds de Recherche et ses Effets." Décou$\operatorname{vrir}(9)$. https://goo.gl/SVMFaj.

Larivière, Vincent, Benoit Macaluso, Éric Archambault, and Yves Gingras. 2010. "Which Scientific Elites? On the Concentration of Research Funds, Publications and Citations." Research Evaluation 19 (1): 49-53.

Leclerc, Chantal, Bruno Bourassa, and Christian Macé. 2016. "Dérives de la recherche et détresse psychologique: Une recherche qualitative." Découvrir, no 6. Retrieved from https://goo.gl/yP5i3Q.

Martin, Éric, and Maxime Ouellet. 2011. Université Inc. Montréal: Lux.

Readings, Bill. 1997. The University in Ruins. Cambridge: Harvard University Press.

Seymour, Michel. 2013. Une Idée de L'université. Propositions d'un Professeur Militant. Montréal: Boréal. 


\section{Más allá de la privatización en la educación superior en los Estados Unidos Mark B. Brown ${ }^{3}$}

En el Manifiesto Académico Willem Halffman y Hans Radder (2015) resumen hábilmente muchas de las tendencias que están socavando a la universidad pública en Holanda y otros países. Los autores ven lo "público" de la universidad pública no primariamente como una forma de financiación, sino como una filosofía de desarrollo y de objetivos. Incluso una universidad privada, como muchas de las más prestigiosas universidades en los Estados Unidos, puede ser "pública" en este sentido, de distintas maneras: educa e informa al público, proporciona beneficios no solamente privados sino bienes públicos con un beneficio social y no mercantil, y trabaja para establecerse como comunidad autogobernada plenamente transparente para sus miembros, y para los amplios colectivos que puedan estar implicados en sus actividades.

Como miembro de facultad en una universidad pública regional de California, mucho de lo que Halffman y Radder describen me es muy familiar. Por supuesto, el paisaje de la educación universitaria norteamericana está muy diferenciado y es complejo, y no puedo ofrecer una comparación general con Holanda. Aquí quiero simplemente bosquejar unos pocos puntos relacionados con la situación presentada por Halffman y Radder.

\section{Privatización y gerencialismo}

Halffman y Radder pintan un retrato decepcionante y, desde el punto de vista de USA, muy parecido al estado actual de la educación secundaria norteamericana:

- Una cultura de la competencia cada vez mayor socava el espíritu colegiado y la cooperación académica. Las facultades compiten por las plazas académicas y por el reconocimiento, en tanto las universidades compiten por conseguir la financiación pública, los donantes privados, los estudiantes y las estrellas académicas.

- La investigación comercializable tiene prioridad tanto sobre la docencia de grado como sobre la investigación fundamental.

- Los docentes no estables constituyen la mayoría de los miembros de las facultades e imparten la mayoría de los cursos. Trabajan con contratos de corta duración con bajísimos salarios, escasa seguridad laboral, pocas oportunidades de acceder a la investigación académica, ninguna o muy débil voz en los órganos de gobierno, y falta sempiterna de respecto y de reconocimiento académicos.

- Los estudiantes tienden a verse a sí mismos como consumidores que se preocupan más de los deportes en el campus y de las oportunidades de ocio y entretenimiento que de la calidad académica. Ante la perspectiva de verse atrapados en altas deudas y un mercado de trabajo precario, ven en la educación universitaria no primariamente el mundo de la búsqueda intelectual o de la compren-

Mark B. Brown es Profesor en el Departamento de Gobierno en la California State University de Sacramento. Autor del texto Science in Democracy: Expertise, Institutions, and Representation (MIT Press, 2009), y de varias publicaciones sobre expertos, representación política, bioética, cambio climático y temas relacionados, Imparte cursos en Teoría Política Moderna y Contemporánea, Teoría Democrática, y Política de la Ciencia, de la Tecnología y del Medioambiente. 
sión de uno mismo, sino un medio para adquirir las credenciales académicas y las conexiones profesionales para un trabajo que pueda estar bien pagado.

- Los administradores y gerentes cada vez se vuelcan más en los recuentos de impacto o en otros mecanismos de la cuantificación gerencial para monitorizar la calidad del medio académico. Estos mecanismos fracasan en registrar el valor social de la investigación y de la enseñanza, crean tareas inútiles y burócratas sin valor alguno, y alimentan una cultura de la desconfianza. Los gerentes y directivos proclaman que estas medidas disminuyen los costes de la universidad y aumentan su eficiencia, pero generalmente lo que ocurre es lo contrario.

Cada uno de estos problemas podemos encontrarlos por todas las universidades y academias en los Estados Unidos. Desde aproximadamente 1980, las universidades norteamericanas tienden a definir la Educación Superior no como un bien público sino como una empresa de lucro privado. En su reciente libro The Great Mistake: How we wrecked public universities and how we can fix them, Christopher Newfield (2016) muestra que la privatización, que se ha convertido en la respuesta más común a los problemas que tiene la educación superior, es precisamente la causa de dichos problemas.

La privatización cobra muchas formas en los Estados Unidos: el aumento de las tasas de matrícula y cursos traslada el esfuerzo de financiación, de los ciudadanos en sus impuestos, a los estudiantes y sus familias; la externalización de los sistemas de apoyo a la enseñanza, como la tecnología educativa, el análisis financiero, los seguros sanitarios estudiantiles, y los servicios de restauración, a compañías comerciales; la cada vez mayor dependencia de donantes privados y de fundaciones que a menudo ejercen sutil (o no tal sutil) influencia sobre la investigación y la docencia; el descuido tanto de la retórica como de la política de lo social y de los beneficios no comerciales de la Educación Superior (por ejemplo, el avance en la salud pública, en la felicidad, y en las habilidades para solucionar problemas), y una redefinición de los estudiantes y profesores como capital humano, centrada en la continua auto-inversión con el propósito de conseguir seguridad económica (vid. también Brown 2015).

Lo más importante que señala Newfield es que tanto los conservadores como los liberales en USA tienden a no comprender la dinámica básica de la privatización universitaria. Los conservadores ven las universidades como gasto de fondos públicos, y por ello exigen la vigilancia gerencial, la disciplina fiscal, y una orientación hacia modos empresariales de gobernanza. Los liberales tienden a ver la privatización como una necesaria aunque lamentable respuesta a los recortes en la financiación pública. En los dos casos asumen equivocadamente que no hay dinero suficiente para financiar la educación superior, como un genuino bien público. Y en ambos casos ven la privatización como un modo de ahorrar dinero, cuando en realidad lo que ocurre es lo contrario.

La subida de tasas, por ejemplo, no empezó como respuesta a los recortes en la financiación pública, como se asume comúnmente, sino que en realidad precedió a los recortes. Como Newfield (2016: 42) explica, "las universidades públicas subieron las tasas un $50 \%$ durante los años 80 y otro $38 \%$ en los 90 , cuando la financiación pùblica realmente se incrementaba ligeramente. Cuando los parlamentos estatales conocieron que las universidades iban a incrementar las tasas universitarias, se sintieron con valor para recortar la financiación pública. Entre 1990 y 2012, las ma- 
trículas de todos los centros y universidades en conjunto aumentaron de coste un 297 por ciento, dos veces el coste de los servicios de salud". De acuerdo con un estudio reciente, (Newfield et al. 2017) en 2016 California ha gastado un 39\% menos por universidad que en los 15 años precedentes, mientras la matrícula de los cursos y tasas se han duplicado y más tanto en la Universidad de California como en la California State University, y triplicado en los dos años en ambas comunidades académicas del estado.

Uno de los cambios más trascendentes y sorprendentes ha sido el producido en la alteración de la composición de la fuerza académica de trabajo. De acuerdo con un Informe de 2014, (AAUP 2014, Figura1), entre 1976 y 2011 ha habido un incremento de un $369 \%$ en las plazas a tiempo completo para profesionales externos a la universidad ("gestores y agentes mercantiles, recursos humanos, formadores, especialistas en relaciones laborales, analistas gerenciales, consejeros de financiación, abogados, y otros puestos no académicos"). Los profesores no titulares, se incrementaron en un $259 \%$, en tanto los titulares y los académicos estables crecieron solamente un $23 \%$, a pesar de la masiva matriculación de alumnos. De acuerdo con un Informe de 2016 (AAUP 2016, 13), "la mayoría (70\%) de las plazas académicas hoy en día no solamente son para puestos externos a la carrera docente, sino a tiempo parcial, con plazas a tiempo parcial para docentes en formación que constituyen casi el $41 \%$ de la fuerza académica de trabajo, y asistentes a la docencia, graduados, llevando el peso de otro restante $13 \%$. El informe también muestra que el gasto en educación en las universidades estadounidenses no constituye ni un tercio de todo el presupuesto general en Educación Superior.

En estas circunstancias, el escepticismo hacia el apoyo público a colegios y universidades empieza a parecer completamente razonable. Los contribuyentes se preguntan con razón si están pagando por investigaciones que terminan beneficiando a los inversores tecnológicos que no repercuten en beneficio público. Los padres se preguntan ciertamente por qué los educadores de sus hijos están tan saturados que no pueden proporcionar el adecuado retorno de información sobre su aprendizaje, y por qué los profesores más prominentes dedican tan poco tiempo y esfuerzo a la enseñanza de calidad (Brown 2015:197).

Por supuesto, el público escepticismo con las universidades norteamericanas tiene también otras causas, incluyendo una larga tradición de anti-intelectualismo. Muchos conservadores en USA ven las universidades como bastiones de inmoralidad sexual y de ideología marxista, repletos de profesores izquierdistas que intentan adoctrinar a sus hijos. En un reciente discurso, la recién nombrada Secretaria de Educación del presidente Donald Trump, Betsy DeVos (2017) repetía un tema familiar a los conservadores cuando afirmaba "La facultad, de los profesores adjuntos a los decanos, te dice lo que tienes que hacer, lo que tienes que decir, y lo que es más vergonzoso, lo que tienes que pensar".

Finalmente, es importante señalar una causa más insidiosa del público desapego a la Educación Superior en USA. De 1950 a 1970, las universidades públicas eran vistas muy ampliamente como una fuerza para reducir las desigualdades de raza, clase y género. A pesar de varios retrocesos, los Estados Unidos extendieron la garantía de educación superior a una sección amplia y diversa de la sociedad, como nunca en ningún país en la historia. En los pasados cincuenta años, los programas, los estudiantes, y (hasta cierto punto) las Facultades, han sido los organismos más representativos del desarrollo democrático de América (Newfield 2008). Pero el 
compromiso con una educación superior pública como instrumento para reducir las desigualdades sociales y rectificar las injusticias históricas ha ido gradualmente cayendo en la cuneta. En su lugar, tenemos un vago compromiso liberal con la tolerancia, el pluralismo, y el multiculturalismo, movidos por una apelación a la "inclusión". Sin duda que la inclusión creciente de grupos históricamente marginados es un logro importantísimo, pero no deshace los efectos acumulados de las pasadas injusticias, ni elimina las actitudes racistas y sexistas. Sin duda, como la historia es compleja, no es casualidad que la voluntad de la mayoría blanca de financiar la universidad pública haya caído justo en el porcentaje en el que se ha incrementado el número de estudiantes no blancos.

\section{¿Qué hacer?}

Halffman y Radder (2015:166) señalan que los críticos a esta evolución de la universidad han producido "una inacabable corriente de artículos de opinión, lamentaciones, cartas de presión y apelaciones" -y jesta es una más!- todo ello con muy escaso impacto discernible. Y se culpan muy significativamente a sí mismos o a sus (propios) compañeros de centro. "El profesor radical especialista en Literatura francesa posmoderna que al mismo tiempo que se queja usa el panóptico de las citas para imponer su disciplina sobre los profesores temporales". "Los filósofos críticos publican duros artículos contra las políticas de burocracia absoluta, pero se conforman mansamente cuando se introducen en su propia institución. Hoy publicamos un manifiesto, mañana tiramos de la alfombra bajo algún colega en la esperanza de conseguir fondos para un becario de investigación. Divide y vencerás funciona porque todos estamos en ello" (173).

Un mensaje similar aparecía en un texto reciente de Kevin Birmingham (2017), el primer miembro precario de una Facultad en recibir un prestigioso galardón de crítica literaria en la Universidad de Iowa. "Si eres titular (o tienes carrera docente como tal) en un Departamento de Humanidades junto a otros Doctores candidatos en la universidad", escribe Birmingham, "eres tanto el instrumento, como el directo beneficiario de la explotación".

Halffman y Radder continúan con una serie de estrategias de resistencia potenciales, que van desde los brazos caídos o el sabotaje ejecutivo, hasta las protestas, las huelgas, y la lucha judicial. En muchos aspectos, los Estados Unidos son la zona cero de la privatización neoliberal, y los recientes procesos ofrecen poco margen al optimismo en todo ello. Pero también hay prometedores ejemplos de una lucha eficaz por los valores e instituciones de la Educación Superior pública.

Quizás el mayor cambio en los años pasados sea la creciente conciencia pública respecto a los profesores precarios. Ha habido un numeroso grupo de informes en los medios sobre las condiciones indignantes de trabajo de los profesores precarios (p. ej. Fredrickson 2015). La universidad precaria ha promovido sus intereses mediante la investigación y los grupos de defensa profesional como el New Faculty Majority (2017), la Coalition on the Academic Workforce (2017) y el Delphi Project (2017), la Coalition of Contingent Academic Labour (2017) y la AAUP (2016). Y en muchos campus, la universidad precaria ha ganado pequeños pero significativos avances en pagas, beneficios, seguridad laboral y derechos de participación en el autogobierno académico.

Muchos sindicatos universitarios en USA se han comprometido y luchan eficazmente por los valores de la educación superior pública en general, y por los profesores contratados en precario en particular. Halffman y Radder escriben que los sindi- 
catos en las universidades holandesas tienden a representar tan sólo los intereses de los profesores estabilizados y no a los precarios. En la Universidad de California, el caso es el contrario, y el sindicato del profesorado precario (UCAFT) ha conseguido subidas salariales y beneficios, derechos para el proceso de contratación adecuado, y una mínima cantidad de seguridad laboral para los docentes con más de 6 años de antigüedad. En la California State University, donde yo enseño, muchos profesores precarios se han sindicado en los últimos años gracias a la campaña del Sindicato Internacional de Empleados de la Universidad. De acuerdo con un informe reciente (Herbert 2016), desde 2012 ha habido un incremento del $25.9 \%$ en socios de los sindicatos universitarios en universidades privadas, y un 2.1 de crecimiento en las públicas. Y la sindicación universitaria arroja claros beneficios: los profesores temporales con representación sindical tienen una media de salario un $25 \%$ superior al resto. (Flaherty 2013).

Finalmente, el activismo estudiantil parece estar en auge, y tiene el potencial para transformar el debate sobre la Educación Superior. Por supuesto, algunos comentaristas ridiculizan hoy a los estudiantes como niños ansiosos y frágiles de unos padres muy sobreprotectores (Lukianoff y Haidt 2015). Los estudiantes actuales, dicen, demandan mimos de las facultades universitarias en forma de códigos de voz, alarmas, espacios seguros, y sistemas para informar de las micro-agresiones y otras formas de acoso a las mujeres o las minorías étnicas y raciales, o a otras identidades vulnerables. Pero esos informes exageran una serie de casos muy selectivos, y descuidan las evidencias en contra que son muy considerables.

Las encuestas indican que hay altos porcentajes de estudiantes actualmente muy implicados en las causas políticas de todo tipo. Por ejemplo, una encuesta de 2015 (Eagan et al. 2015) en UCLA, mostraba que en torno al 9\% de los estudiantes del primer curso (y un 16\% de los estudiantes negros de primer año) declaran que es "muy probable" que participen en las protestas del campus. En torno a un $22 \%$ indican que para ellos influir en las estructuras políticas es "muy importante" o "esencial". Y más del 40\% indican que es "muy importante" o "esencial" promover el entendimiento entre razas, influir en los valores sociales y estar informado de los asuntos políticos.

Durante la pasada década, miles de estudiantes americanos se han implicado en las campañas políticas de todo tipo, incluido el movimiento estudiantil contra la explotación laboral, campañas contra la violencia sexual, la campaña para evitar la inversión universitaria en combustibles fósiles, y las protestas antirracistas y sexistas en el campus. En mi propia universidad, los Estudiantes por la Calidad Educativa han estado luchando por una verdadera Educación Superior Pública desde 2007. Ya es hora de que más de nosotros nos unamos a su lucha.

\section{Referencias}

AAUP -American Association of University Professors. 2014. "Losing Focus: The Annual Report on the Economic Status of the Profession. 2013-14." https://goo.gl/Yjrjzg.

AAUP-American Association of University Professors. 2016. "Higher Education at a Crossroads: The Annual Report on the Economic Status of the Profession, 2015-16." https:// goo.gl/SWPAUr.

Birmingham, K. 2017. "The Great Shame of Our Profession: How the Humanities Survive on Exploitation." The Chronicle of Higher Education, February 12.http://www.chronicle. com/issue/2017/02-17. 
Brown, W. 2015. Undoing the Demos: Neoliberalism's Stealth Revolution. New York: Zone Books.

Coalition of Contingent Academic Labour. 2017. "About COCAL.” http://cocalinternational. org/aboutus.html.

Coalition on the Academic Workforce. 2017. "Coalition on the Academic Workforce." http:// www.academicworkforce.org.

Delphi Project. 2017. "The Delphi Project on the Changing Faculty and Student Success." https://www.aacu.org/delphi.

DeVos, B. 2017. "U.S. Secretary of Education Betsy DeVos' Prepared Remarks at the 2017 Conservative Political Action Conference, February 23, U.S. Department of Education." https://content.govdelivery.com/accounts/USED/bulletins/189306a.

Eagan, K., E. B. Stolzenberg, A. K. Bates, M. C. Aragon, M. R. Suchard, and C. Rios-Aguilar. 2015. The American Freshman: National Norms Fall 2015. Los Angeles: Higher Education Research Institute, UCLA. https://goo.gl/pYDnje.

Flaherty, C. 2013. "Union Raises for Adjuncts." Inside Higher Ed, July 26. https://goo.gl/ E6Hgsy.

Fredrickson, C. 2015. "There is No Excuse for How Universities Treat Adjuncts." The Atlantic, September 15. https://goo.gl/7vnbhA.

Halffman, W., and H. Radder. 2015. "The Academic Manifesto: From an Occupied to a Public University." Minerva 53 (3), 165-187.

Herbert, W. A. 2016. "The Winds of Changes Shift: An Analysis of Recent Growth in Bargaining Units and Representation Efforts in Higher Education." Journal of Collective Bargaining in the Academy 8 (December). https://goo.gl/RN6WAf.

Lukianoff, G., and J. Haidt. 2015. "The Coddling of the American Mind." The Atlantic (September). https://goo.gl/ngAaiC.

New Faculty Majority. 2017. "Faculty working conditions are student learning conditions." http://www.newfacultymajority.info.

Newfield, C. 2008. Unmaking the Public University: The Forty-Year Assault on the Middle Class. Cambridge, MA: Harvard University Press.

Newfield, C. 2016. The Great Mistake: How We Wrecked Public Universities and how We Can Fix Them. Baltimore, MD: Johns Hopkins University Press.

Newfield, C., C. Hansen, J. Polansky, E. Hays, A. Hines-Shaikh, and S. A. Glantz. 2017. "The \$48 fix: Reclaiming California's Master Plan for higher education.” Berkeley, CA: Reclaim California Higher Education. http://www.reclaimcahighered.org/48dollars. 


\section{Los efectos perversos de la dirección empresarial: la experiencia brasileña Renato Dagnino and Marcos Barbosa de Oliveira ${ }^{4}$}

Para situarnos en una perspectiva adecuada, debemos decir que la educación superior en Brasil está financiada por el sector privado tanto como por el público. El sector privado es con mucho el más importante, soportando en torno al 75\% de las carreras de los estudiantes. Con unas pocas honrosas excepciones, que siempre se mencionan, en las universidades privadas prácticamente no existe investigación. No son propiamente universidades en el sentido estricto del término, que se aplica solo a instituciones en las que la investigación es una de las funciones principales. Hablando con rigor, no pertenecen al mundo académico, y por ello, aquí las consideraremos solamente en un aspecto, para mostrar las diferencias entre las situaciones en Holanda y en Brasil; toda otra consideración se referirá solamente al sector público. Vamos primero con las similitudes.

La principal similitud es que en Brasil, como en Holanda, el espíritu gerencialista domina, con casi todos sus rasgos: el predominio de las evaluaciones cuantitativas sesgadas ideológicamente, sobre las evaluaciones cualitativas, la presión intensamente productivista, la competitividad exacerbada, la sobre-evaluación de los artículos publicados en detrimento de los libros, y sobre otras formas de producción, especialmente las actividades de docencia, el gran valor otorgado a las publicaciones en inglés, en detrimento de las publicadas en otras lenguas (incluida, obviamente, la portuguesa), el fetichismo de los indicadores, particularmente el factor de impacto y el índice h, la asunción de que escalar en los ránkings de las universidades es el objetivo principal de la administración académica, el acento en las invenciones como propósito de la investigación científica, etc.

Los efectos colaterales venenosos de los métodos gerencialistas, que hacen tan disfuncional a la administración, son también los mismos: daño a la calidad de vida de los académicos, problemas de salud debidos a la presión competitiva, conducentes en algunos casos al agotamiento por estrés, sobreproducción de artículos, con la consecuente caída de su calidad, incremento en la frecuencia de casos de mala praxis (falsificación y fabricación de datos, plagio, publicaciones duplicadas, etc.), erosión del concepto de autoría, pérdida de tiempo y de energía para los académicos a la hora de reflexionar sobre su trabajo, y a la hora de poner en acción su responsabilidad social y académica, etc.

$4 \quad$ Renato Dagnino es profesor en el área de Análisis de Políticas de Innovación y en Gestión Pública en la Facultad de Políticas Científicas y Tecnológicas en la Universidad Estatal de Campinas (UNICAMP), de la que fue uno de los miembros fundadores en 1970. Ha sido profesor visitante en varias universidades hispanoamericanas. Sus libros más importantes son Science and Technology in Brazil: The Decision-Making Process and the Research Community; Neutrality of Science and Technological Determinism; Social Technology: Conceptual and Methodological Contributions; The Defense Industry in the Lula Government and Strategic Public Management.rdagnino@ige.unicamp.br.

Marcos Barbosa de Oliveira es Licenciado en Ciencias Físicas (Universidad de São Paulo (USP), 1970); Doctor en Historia y Filosofía de la Ciencia (University of London, 1981). Profesor Asociado en la Facultad de Educación en la USP, hasta su jubilación en 2014. Actualmente es Profesor Asistente en el Programa de Grado en Filosofía(USP). Investigador en el Instituto de Estudios Avanzados (IEA-USP), miembro del grupo de investigación en Filosofía, Historia y Sociología de la Ciencia y de la Tecnología. Miembro de la Asociación Filosófica Scientiae Studia. Algunas publicaciones recientes en inglés son "On the Commodification of Science: The Programmatic Dimension” and "Technology and Basic Science: The Linear Model of Innovation.” mbdolive@ usp.br; http://paje.fe.usp.br/ mbarbosa. 
El último punto de esta lista citado en el no menos importante último párrafo merece una mención especial. En torno al año 2000, se inició un impulso vigoroso en Brasil para promover el innovacionismo, es decir, el establecimiento de la producción de innovaciones como primer objetivo de la investigación científica, definiéndose innovación como una invención que puede adoptarse por una empresa, para incrementar con ella sus beneficios. Esta tendencia implica un gran número de medidas, como favorecer, en las agencias financiadoras, a los proyectos con potencial para generar aplicaciones lucrativas, incentivar proyectos conjuntos entre universidades y empresas, realizar campañas para favorecer la "cultura de la innovación", incrementar el valor atribuido a la obtención de patentes en la evaluación de los investigadores, etc. La conclusión ineludible, basada en estadísticas oficiales, es que la completa movilización en este sentido ha sido un fracaso completo. Este no es lugar para explicar en detalle las causas de dicho fracaso. Lo que en dos palabras podemos decir, es que resulta de adoptar acríticamente políticas de los países coloniales y sus metrópolis, sin tener en cuenta las diferencias en la estructura de la economía, entre las metrópolis y Brasil. El efecto colateral negativo en este caso es el dispendio de los recursos, y la falta de consideración de las otras funciones posibles de la investigación científica, no necesariamente dependientes del mercado.

Vamos ahora con las diferencias. La figura central del Manifiesto es un lobo de mil cabezas gerencial, que ha ocupado la academia "con un ejército de administradores profesionales". En Brasil (así como en otros países iberoamericanos) los agentes no son administradores profesionales, sino antiguos académicos o los que se incorporan ahora; no es un ejército mercenario, sino, podemos decir, una quinta columna, extraída de estratos altos de la jerarquía académica, la mayoría proveniente del campo de las Ciencias Experimentales. No solamente eso, sino que en una parte considerable de los casos, en el Ministerio responsable de la Ciencia y la Tecnología, en organismos análogos (Secretarías) de cada estado, y en las agencias de evaluación de investigación, los puestos directivos también los ocupan los académicos -a ese nivel, se trata en su mayoría de académicos consolidados en el pasado-. Estos han adoptado el espíritu gerencial no solamente por las presiones del gobierno, o del sector privado, o de la sociedad en general; su actitud es básicamente resultado de una imitación acrítica, a menudo caricaturesca, de las prácticas de los países desarrollados y sus metrópolis. El primer movimiento que puede interpretarse como un paso más en la dirección de situar a ejecutivos profesionales al mando de la administración es el contrato firmado por la Universidad de Sâo Paulo (nuestra universidad más grande e importante entre las públicas) y McKinsey \&Company, la conocida firma consultora y ejecutiva. El contrato otorga a McKinsey un proyecto de "creación de un modelo de financiación y de la mejora de la administración y dirección empresarial" de la universidad, así como "el fortalecimiento de la relación de la universidad con la sociedad y con el sector productivo (es decir, las empresas privadas)".

La segunda diferencia tiene que ver con la competencia entre universidades por captar a los estudiantes. En Brasil, la educación superior que el sector privado proporciona tienen que pagarla los estudiantes; en el sector público, debido a la legislación de provisión educativa en todos los niveles (con unas pocas excepciones, en algunos cursos de Máster), es gratuita. Otra diferencia crucial es que en un nivel superior, la educación proporcionada por las universidades públicas es de mucha mejor calidad (sean cuales sean los criterios de evaluación), que la de las "universi- 
dades" privadas. El resultado es que en el sector público la demanda siempre es mayor que la oferta educativa, y la selectividad para acceder es muy exigente. La competición para los estudiantes, y todas las estrategias de márketing que la acompañan, se restringen al sector privado.

La reacción a los avances gerencialistas por parte de los miembros de la comunidad académica no implicada en la administración o gestión ha sido débil. Entre los veteranos, la insatisfacción con los nuevos métodos, especialmente con el productivismo, y con las formas de evaluación cuantitativa, es bastante fuerte, pero se manifiesta solamente en conversaciones privadas. Los nuevos académicos, por otra parte, comienzan sus carreras ya completamente adaptados al espíritu gerencial, que conciben de una manera totalmente naturalizada, como algo dado de la vida académica. Además, el "publica o perece" y su presión deja a todo el mundo con muy poco tiempo y energía para reflexionar sobre el significado de su trabajo y del sistema. Así pues, actúa como una droga adictiva, que no solamente es dañina, sino que afecta a las facultades cognitivas, impidiendo a sus usuarios reconocer su acción maligna. La única acción concertada contra el gerencialismo es la de los sindicatos de profesores precarios. A este respecto, debemos mencionar que la publicación de ADUSP (asociación de profesores asociados y ayudantes de la Universidad de Sâo Paulo, afiliada a un sindicato nacional), tiene un número temático sobre el productivismo, que contiene una traducción en portugués del Manifiesto Académico (número 60 de la Revista de la ADUSP).

En cuanto concierne a las posibilidades de cambiar las cosas para mejor, debemos reconocer que la situación no ha hecho sino empeorar, debido a la severa crisis económica que Brasil está atravesando. El programa de austeridad adoptado por el gobierno de derechas que asumió el poder tras el golpe parlamentario que destituyó a la presidenta Dilma Rousseff, implica drásticos recortes a la investigación científica y las universidades. Por ejemplo, comparado con el año cumbre de 2013, los fondos proporcionados al Ministerio de Ciencia, Tecnología, Innovación y Comunicaciones han sufrido una reducción del 40\%. Hay algunos casos dramáticos, como el de la Universidad Estatal de Rio de Janeiro que, debido a la absoluta falta de recursos, no ha conseguido hasta ahora concluir el segundo semestre académico del año pasado, que quedó interrumpido por una huelga. En esta situación, la comunidad académica concentra sus energías en luchar contra los recortes (mediante manifiestos y pronunciamientos de los líderes de las sociedades académicas, hasta ahora con escaso efecto) y adaptándose a la impuesta penuria. Mientras la crisis persista, quedará poca energía para enfrentarse a la ocupación gerencialista.

El último párrafo de este relato se escribió en febrero de 2017. El 30 de marzo, el gobierno decretó otro recorte de un $44 \%$ del presupuesto federal para la ciencia. $\mathrm{La}$ comunidad científica cae en la desesperación. En palabras de Luiz Davidovich, presidente de la Academia Brasileña de Ciencias, el nuevo presupuesto es una bomba atómica para la ciencia en Brasil (Nature, 3/3/2017). Considerando todo, creemos que este nuevo trabajo a partir del Manifiesto Académico debe ser un movimiento importante en la lucha contra los avances del gerencialismo, y en favor de una verdadera universidad pública. Además, dado que, como hemos indicado, el espíritu del gerencialismo ha llegado a Brasil por un proceso de imitación, creemos que la internacionalización de esta lucha será de hecho más importante para nosotros, que para Holanda y los demás países desarrollados. 


\section{Referencias}

Barbosa de Oliveira, M. 2013. "On the Commodification of Science: The Programmatic Dimension." Science \& Education 22 (10): 2463-2483. https://goo.gl/3qvD3e. R.

Dagnino and M.B. de Oliveira 18 Barbosa de Oliveira, M. 2014. "Technology and Basic Science: The Linear Model of Innovation.” Scientiae Studia 12 (Special Issue): 129-146. https://goo.gl/2hRj6N. 


\section{La crisis de la academia japonesa: breve informe de los acontecimientos recientes}

Makoto Katsumori ${ }^{5}$

Los problemas actuales de la academia, analizados críticamente por Willem Halffman y Radder en su Manifiesto Académico, son de lo más común con la situación que se da en Japón. Una serie de cambios estructurales introducidos en las universidades japonesas en la última veintena de años pueden considerarse parte de una reestructuración neoliberal de los sistemas académicos. Al mismo tiempo, sin embargo, parece que existen rasgos específicos en la situación japonesa. Es notable, en particular, que el gobierno nacional, y especialmente el Ministerio de Educación (oficialmente el Ministerio de Educación, Cultura, Deportes, Ciencia y Tecnología) tiene un papel central a la hora de imponer reformas a las universidades -reformas que, bajo la apariencia de querer promover la autonomía de las universidades, de hecho son diseñadas para fortalecer el control gubernamental sobre ellas-. En este breve informe, me limitaré estrictamente a una "descripción casi periodística" de esta evolución reciente que afecta seriamente a la vida académica en Japón.

En 2004 tuvo lugar un punto de inflexión, cuando todas las universidades nacionales japonesas se "incorporaron" es decir, se les dio el status, de "corporaciones universitarias nacionales". Dicha incorporación, que era ostensiblemente para impulsar "la independencia y autonomía" de cada universidad (MEXT 2003) en realidad ha funcionado para todo lo contrario. Con ella, la "beca operacional" del Ministerio de Educación, que constituye la mayor fuente de financiación para las universidades nacionales (en torno al $48 \%$ de sus ingresos totales en el año fiscal de 2004), empezó a recortarse un 1\% anual (vid. Oba 2006). Esta reducción de la beca operacional se acompañó de la introducción y expansión de varios tipos de fondos que se adjudicaron selectivamente a partir de un criterio competitivo. Además, en su momento, la beca operacional asumió ella misma un carácter competitivo, es decir, se adjudicaba a las universidades de acuerdo con su "productividad" sometida a la evaluación de "un tercero". Este conjunto de mecanismos ha causado una enorme presión en las universidades, que han debido reorganizarse y ponerse en sintonía con las intenciones del gobierno. De esta manera, como una serie de críticos han señalado, la corporización de las universidades nacionales ha ayudado a intensificar su control estatal, que sirve para reorientar la actividad académica cada vez más hacia la lógica empresarial de la eficiencia y de la mensurabilidad combinada con una competición perpetua.

La corporización de las universidades nacionales también conlleva medidas que refuerzan el poder jerárquico y su estructura dentro de la universidad. Particularmente, con el nuevo sistema, el rector no es ya elegido por el voto de los miembros de la comunidad académica, sino seleccionado por un comité formado por un conjunto de representantes internos y de expertos externos (aunque se pueda tener en consideración la opinión de los académicos), y la toma de decisiones en la universidad no se basa ya en el sistema colegiado, sino en un régimen centrado en un rector y un consejo de administración (vid. Oba 2006). De este modo, en tanto el gobierno sigue hablando oficialmente de mejora de la autonomía universitaria bajo el liderazgo de

Makoto Katsumori is Profesor de Filosofía en la Facultad de Educación y Estudios Humanos en la Akita University, de Japón. katsumor@gipc.akita-u.ac.jp 
un rector poderoso, el nuevo sistema de gobierno universitario de hecho ayuda al gobierno a controlar las universidades mediante el poder del rector para controlar las protestas internas.

En este nuevo escenario interno, se han dado una serie de desarrollos posteriores en la universidad japonesa, En 2014, impulsadas por el gobierno conservador de Abe, dos leyes educativas relevantes para la universidad fueron modificadas. Específicamente, la revisión de la Ley de Educación Escolar, que concierne no solo a las nacionales, sino a todas las universidades del país, ha restringido el derecho de la comunidad académica a deliberar en asuntos concernientes a la universidad. Las Juntas de Facultad, formadas en su mayoría por profesores a tiempo completo, tenían hasta esa fecha el derecho de discutir temas mayores relativos a la universidad, incluidos los relativos a la dirección y la administración, aunque, como indicamos antes, la decisión final en las universidades nacionales ya ha sido centralizada en las manos del rector. La reforma de la Ley de Educación estipula, sin embargo, que las Juntas de Facultad solamente discutirán temas concernientes a la "enseñanza y la investigación", y que "expresarán opiniones" en estas materias, que el rector considerará si es necesario (MEXT 2014).

Uno de los pasos "pioneros" para llevar a la práctica este nuevo modo de gobernanza fue asumido por mi propia Universidad de Akita, una universidad nacional situada al noreste de Japón. A comienzos de 2014 - un poco antes de la revisión de la Ley de Educación -la Universidad de Akita, muy apoyada por el gobierno, abrió una nueva facultad denominada Facultad de Ciencias de Recursos Internacionales de Investigación. En esta Facultad, la mayoría de los académicos son sistemáticamente excluidos de la discusión de los temas básicos de la universidad, lo que ha dejado a los recién creados "Consejos" en reuniones de unos pocos miembros ejecutivos con algunos representantes de otras universidades y de las finanzas privadas. Este nuevo sistema de gobierno, completamente desprovisto de autonomía académica y de libertad universitaria, fue en su superficie voluntariamente diseñado y propuesto por la universidad misma, pero su objetivo era obtener subsidios adicionales del gobierno. Como era de esperar, el sistema fue altamente elogiado por el gobierno y en los círculos de negocios como modelo que debía imitarse en las otras universidades. Poco después de la revisión de la Ley de Educación, la Universidad de Akita de nuevo tomó la iniciativa extendiendo el nuevo sistema de gobernanza a toda su universidad, aunque no se realizó completamente dada la resistencia de parte de la comunidad académica y de los sindicatos.

En 21015, el Ministerio de Educación hizo público un decreto para las universidades nacionales que las llamaba a restructurarse en sus facultades de Humanidades y de Ciencias Sociales, así como en las de facultades de habilitación del profesorado: las universidades nacionales debían "dar pasos activos hacia la abolición de dichas organizaciones, y para modificarlas de modo que sirvieran a áreas que encajaran mejor con las necesidades de la sociedad". Este hecho levantó una ola de protestas en la academia y en los medios, y fue tratada con duras críticas por parte de los medios internacionales también. Específicamente, los rectores de algunas de las universidades nacionales expresaron su intención de no cumplir con el mandato indicado, y el Consejo de la Ciencia de Japón criticó al ministro de Educación por su "falta de respeto a las Humanidades y las Ciencias Sociales y su estrecha visión de las "necesidades de la sociedad"' (Consejo de la Ciencia de Japón, 2015). Enfrentado a estas reacciones adversas, el ministro de Educación moderó verbalmente su posición, afirmando 
que en ningún modo se despreciaba a las humanidades y ciencias sociales y que no tenía intención de forzar a las universidades a acabar con dichas áreas. Como algunos críticos han señalado, la reacción pública a las medidas ministeriales fue en parte causada por una cobertura mediática de impacto, que dio la impresión de que el gobierno quería de repente abolir facultades que consideraban socialmente inútiles (Yoshimi 2016). De hecho, mucho de dicha reestructuración ya había sido llevada a cabo por el ministerio, y más esencialmente, la misma lógica ya se había instalado en la política general gubernamental para la universidad desde el año 2014, con la conversión de las universidades nacionales en corporaciones. Es decir, que esta reconversión corporativa -particularmente la desigual distribución de los fondos, basada en la evaluación de resultados - sistemáticamente estaba ya funcionando en detrimento de la ciencia social y especialmente de las humanidades, que generalmente están menos concebidas que los campos de las ciencias naturales para producir resultados mensurables o cuantificables a corto plazo. En estas circunstancias, un número de universidades nacionales han dado una serie de pasos para reducir las facultades de Humanidades y Ciencias Sociales y/o para cerrar algunos departamentos de humanidades en las Facultades de Ciencias de la Educación. De este modo, la universidad japonesa de hoy en día, especialmente en las áreas consideradas de menor provecho y beneficio financiero, se encuentra en una crisis seria y sin precedentes (vid. Muroi 2015).

Con seguridad, como puede verse en esta descripción hasta este punto, los recientes desarrollos en las universidades japonesas no se han dado del todo sin un disenso interno y públicas críticas a los mismos. Desafortunadamente, empero, no ha habido una resistencia fuerte en suficiente medida como para reorientar la situación general, y no vemos perspectivas de que dicha resistencia vaya a surgir en un futuro próximo. Esto parece ser en parte resultado de la obediencia de la gente y del conformismo arraigado en la sociedad japonesa, academia incluida, y también es efecto de la lógica de la eficacia y del gerencialismo controlador que ha sido en parte internalizado por los mismos miembros de la comunidad universitaria. Yo personalmente rechazo en todo lo posible cooperar con sistemas de control introducidos uno tras otro (como la evaluación y auto-evaluación de los miembros de la academia individuales) y en ciertas ocasiones, me uno a algunos colegas para organizar protestas, pero siempre encuentro difícil apelar a la "mayoría silenciosa" para que ponga en brete las normas impuestas. En estas circunstancias, el intercambio internacional y el diálogo entre países, estimulado por el Manifiesto Académico, son de un enorme valor, porque nos dan una perspectiva más amplia que es necesaria para continuar en nuestro compromiso crítico con la situación.

\section{Referencias}

MEXT [the Ministry of Education, Culture, Sports, Science and Technology]. 2003. "FY2003: White Paper on Education, Culture, Sports, Science and Technology." https:/goo.gl/ bCTvua.

MEXT. 2014. “Gakkō Kyōiku hō Oyobi Kokuritsu Daigaku Hōjin hō no Ichibu wo Kaisei Suru Hōritsu.” https://goo.gl/QyHjby.

Muroi, Hisashi. 2015. Bunkei Gakubu Kaitai [The Disbandment of Humanities Faculties]. Tokyo: Kadokawa.

Oba, Jun. 2006. "Incorporation of National Universities in Japan and its Impact Upon Institutional Governance.” https://goo.gl/YuhQ3s. 
The Science Council of Japan. 2015. "Korekara no Daigaku no Arikata ni Kansuru Giron ni yosete." https://goo.gl/SY2UWv.

Yoshimi, Shun'ya. 2016. Bunkei Gakubu Haishi' no Shōgeki [The Impact of 'Scrapping Humanities Faculties ']. Tokyo: Shūeisha. 


\section{Australia: ¿Reclamando la Universidad Pública?}

Simon Batterbury and Jason Byrne ${ }^{6}$

En su provocativo artículo, Halffman y Radder discuten los mundos kafkianos que los académicos en Holanda tienen en su entorno, en un sector universitario infrafinanciado que se devora a sí mismo y a su fuerza de trabajo $(2015,165-166)$. Su Manifiesto Académico hace notar que muchas universidades en Holanda han sido "invadidas" por un "ejército de administradores profesionales" que usan sus enfoques gerencialistas para forzar sus objetivos basados en la productividad. Las instituciones terciarias del país, escriben, se han vuelto obsesivas con la "mensurabilidad" y persiguen imperativos de estilo neoliberal de "eficacia y excelencia". Retratan un cuadro de académicos acosados, de quienes se desconfía, y que son constantemente controlados a micro-escala. La prosecución de la así llamada eficacia ha supuesto sistemas de reconocimiento que en sí mismos son deleznables, y que llevan a una parece que inacabable reestructuración institucional. Además, las instituciones, acusan los autores, se han vuelto obsesivas con los investigadores estrella, guiadas por objetivos competitivos que se blindan en los ránkings globales. La cienciometría -resultados en publicaciones, medición de la calidad de las revistas, citas, impacto e ingresos por financiación- producen una cultura de la competición y a veces, comportamientos mercenarios, de parte de los académicos y de los gestores.

Cambios profundos en todo el sector terciario se dan en muchos otros países, como este Informe muestra. Muchos de ellos pueden identificarse como cambios de modelo de financiación universitaria. En los países de la OCDE, en los últimos treinta años, se ha reconceptualizado la Enseñanza Superior como un bien de consumo (Watts 2016). De acuerdo con ello, los estudiantes son ahora clientes, los académicos son proveedores de servicios al cliente y de ingresos, y muchas universidades públicas se han convertido en negocios en todo, menos en su nombre (Connell 2013). Contra este retroceso, Haffman y Radder (2015) apuntan seis grandes cambios que han reconfigurado la educación superior:

i) Procesos de fijación de objetivos, auditoría, y "fetichismo de los indicadores" (p. ej. objetivos, cuotas);

ii Un nuevo panorama competitivo (p. ej. competición entre estudiantes, por la financiación de la investigación y la docencia, por los profesores "estrella", etc.).

iii) La precarización de la fuerza de trabajo universitaria con puestos cada vez peor pagados;

iv) Múltiples capas de gerencia y de administración, con comisiones crecientes para la administración, y relaciones públicas, marketing, apoyo a los estudiantes, etc.

v) Una incansable persecución de la excelencia -como sea que se defina, y

Simon Batterbury es Profesor de Ecología Política en la Lancaster University y Principal Fellow de la School of Geography en la University of Melbourne. Ha sido docente durante 24 años en UK, USA y Australia (incluidos 3 años en gestión universitaria). Ha editado la publicación abierta online Journal of Political Ecology desde 2003.simonpjb@unimelb.edu.au.

Jason Byrne is Profesor asociado de Planificación Urbana y Medioambiental en la Griffith University, Australia. jason.byrne@griffith.edu.au. 
vi) La estandarización - en los curricula, en los objetivos docentes, en los modelos de carga de trabajo, en las solicitudes de becas y en la gestión de personal-.

Estos cambios en Holanda han conducido a un sistema que es aislante, anónimo, burocratizado y universalizante, dañado por la ambición, la avaricia, la incompetencia y una obsesión constante con la eficiencia y con el ascenso en el estatus. Aunque puedan darse algunos rayos de luz, en el artículo se ven pesadamente ocultos, lo que lleva a la depresión tras la lectura. La provocación de Halffman y Radder arroja dos preguntas, a las que nosotros intentaremos dar respuesta. ¿Hay alguna comparación con Australia? Y ¿qué pueden hacer las universidades australianas ante todo esto?

\section{Similitudes y Diferencias}

Las instituciones del sector terciario en Australia han experimentado cambios similares en los últimos treinta años. Ha habido recortes en la financiación, una reorganización de prioridades en la Educación Superior, y para los académicos, nuevas formas de evaluación de la investigación y de la docencia mediante medición de resultados. Como académicos que hemos trabajado en Australia durante una década, y con experiencia en los Estados Unidos e Inglaterra, nos encontramos con los mismos temas. Uno de nosotros trabaja en una de las universidades en el "top 40" de Australia, en una de las más antiguas y mejor dotadas del país, y el otro imparte docencia en una de las universidades más influyentes, en una red de instituciones que tienen menos de 50 años de antigüedad. Enfrentándose a diferentes desafíos, ambas instituciones han experimentado los mismos recortes de personal, las mismas reorganizaciones departamentales, los sistemas burocráticos de gestión y los objetivos impuestos desde el exterior.

Australia tiene varias universidades que están reconocidas internacionalmente, y una población mayoritaria con educación superior (situándose en los ránkings por encima de la media de los países de la OCDE (OCDE 2017)). Hasta hace bien poco tiempo no se ha visto afectada por las debacles internacionales que empiezan a alterar la educación superior, como las restricciones a la inmigración impuestas por el presidente Trump en USA, el Brexit en Inglaterra, las grandes amenazas a la seguridad o los agujeros financieros en algunos países europeos. Australia entró en la Crisis Financiera Global de 2007 con superávit en sus presupuestos. Sus gobiernos nacionales tienden al conservadurismo, visto históricamente a nivel federal, y son votados por una población mayoritariamente suburbana. Los estudiantes internacionales aspiran a estudiar en Australia, y hasta que han llegado restricciones importantes a la inmigración, han tenido también buena posibilidad de quedarse en el país si así lo deseaban. Muchos de los problemas que identificamos pueden relacionarse con el funcionamiento actual de las universidades como instituciones mercantiles, con menor financiación pública. El gobierno nacional no es proclive a subvencionar los costes de un sector universitario voluminoso, incluso aunque haya crecido la matriculación de los estudiantes sustancialmente.

\section{Reformas en la Educación Terciaria}

Desde 1974 (bajo el gobierno laborista de Whitlam) hasta los finales de los 80, asistir a la universidad en Australia era gratuito o tenía un coste simbólico. La Educación 
Superior se consideraba parte esencial de la construcción de la nación, para desarrollar una fuerza de trabajo competitiva, incluso se consideraba un "derecho". Sin embargo, en 1987, las universidades comenzaron a implementar tasas universitarias, y en los dos años siguientes empezaron a pagarse las tasas completas. Bajo la Reforma Dawkins (Sharrock 2013), el gobierno laborista de Hawke introdujo legislación para permitir a los estudiantes que contrataran créditos a bajo interés a través del Sistema de Contribución para Educación Superior (HECS). Estos créditos se pagaban mediante impuestos, una vez que se alcanzaba una renta determinada en la vida posterior. Esta es la situación hoy en día.

Las reformas Dawkins reestructuraron también dos grandes sectores de 19 universidades y 46 colegios universitarios o institutos creando un sector "unificado", con cerca de 40 universidades públicas - muchas creadas a partir de fusiones-. Las restantes instituciones educativas técnicas o de educación continua (TAFE) quedaron financiadas por los gobiernos estatales. Estas reformas destrozaron también el crecimiento en la captación de estudiantes internacionales, dado que subieron sus tasas de matrícula. Las universidades comenzaron a competir por los fondos de investigación federales -basándose en los resultados y éxito en el logro de objetivos nacionales económicos y sociales. El Consejo Investigador Australiano (ARC) desde 1988 (independiente desde 2001), sigue premiando las investigaciones competitivas en sus ayudas.

Un bombardeo de reformas profundas trajeron el dominio creciente de los principios de libre mercado en los primeros años de los 90. Los gobiernos laboristas de Rudd y Gillard introdujeron un sistema de financiación basado en la demanda. Se fundamentaba en el Informe Bradley (Dow y Kempner 2010) de la Educación Superior en 2008, que recomendaba elevar los objetivos de matriculación, para el año 20125 , en un $40 \%$ para estudiantes de 25 a 34 años, con vistas a obtener un grado universitario (dirigido a las clases socioeconómicas más bajas). El Informe igualmente reubicaba las plazas de matrícula con beca de la Commonwealth (federales), basadas en la demanda, y establecía una Agencia de Calidad y Standards para la Educación Terciaria (TEQSA) para regular la calidad de la docencia.

Se pretendía que las universidades reorientaran sus grados para centrarse más en el "desarrollo de competencias", para encajar supuestamente con las necesidades de la economía global contemporánea. En 2014, una Ley de Educación Superior fue desechada por muy pocos votos - hubiera permitido a las universidades ser "desreguladas", es decir cobrar las tasas que les convinieran, a los estudiantes nacionales. Universidades de Australia, el organismo más general en la gestión de dichos centros, de hecho apoyaba la Ley de 2014, para espanto de los estudiantes. Solamente hubo un disidente -el Rector de la pequeña Universidad de Canberra, Stephen Parker, quien consideraba que las matrículas desreguladas eran antiéticas e injustas (Parker 2014). Pero en 2017, hay nuevas propuestas gubernamentales para subir las tasas estudiantiles, para recortar la financiación a la docencia, introducir nuevos criterios de evaluación, y para endurecer las condiciones de devolución de créditos.

Raewyn Connell $(2013,2015)$ atribuye las medidas financieras y burocráticas en Australia a las reformas Dawkins de los años 80. Argumenta la autora que tras rediseñar el sector terciario como hemos indicado, 
"el siguiente paso era encontrar alguien que pagara (financiando la educación) y la solución neoliberal surgió en sus manos: las tasas de matriculación. El subsidio del gobierno federal a la universidad comenzó un colapso sorprendente, del 90 por ciento aproximado de subvención que se daba al presupuesto de las universidades en los comienzos de los 90 , a un $45 \%$ en estos momentos. Las tasas estudiantiles han subido año tras año, para compensar esa retirada." (Connell 2015:24).

Los resultados son desoladores. Por ejemplo, un estudiante internacional de doctorado en la Universidad de Melbourne paga alrededor de 36.000 dólares australianos (unos 24.555 euros) por año en 2017 (los descuentos son discrecionales); un estudiante de graduado en Ciencias debe pagar anualmente 39.680 dólares australianos (27.065 euros) y 20.277 euros en el Grado en Artes. En Griffith, un estudiante de grado en Artes pagará como poco 18.075 euros. Estas tasas, que en algunos casos son un poco más bajas a las equivalentes en la universidad pública norteamericana, no son lucrativas o usureras, son esenciales. Las instituciones se ven obligadas a subsidiar con ellas su investigación y su docencia utilizando el dinero de las tasas de estudiantes internacionales o no internacionales. El alza del dólar australiano y la dificultad de sostener las matriculaciones internacionales están complicando todavía más esta tarea.

La solución obvia, como Connel (2015) argumenta, es financiar las universidades adecuadamente mediante fondos públicos, con los presupuestos y subvenciones adecuadas, dado que esta nación tiene en las universidades un elemento económico vital. Pero ningún gobierno, desde los 80 , ha escogido este camino, y ni siquiera han compensado la inflación en su financiación. La cascada de presiones presupuestarias se vuelca sobre los académicos y el personal profesional. Las Universidades, atrapadas en la Nueva Gestión Pública con su obsesión por la"cuantificación de la calidad" (Lorenz 2015:7) ahora tienen que competir entre sí, y atraer a los estudiantes nacionales e internacionales mediante sus reputaciones. Las universidades australianas han abrazado completamente los ránkings universitarios internacionales. Los rectores y vicerrectores se afanan en publicitar mediante su maquinaria de marqueting cualquier logro (online y en el campus). Las reputaciones se alicatan mediante mejoras de infraestructura en los campus (aunque sea a costa de mantener menos personal), como por ejemplo en las infraestructuras y espacios de recreación y restauración, en las de alojamiento de estudiantes, y demás. Algunas de estas infraestructuras generan más gastos. La expansión de capital es en parte para alojar a más estudiantes, pero la "calidad" de las instalaciones y la"experiencia de los alumnos" cuentan en los ránkings, de modo que afectan a los costes mediante las matriculaciones.

\section{El Lobo en Australia}

La mayoría (o un porcentaje significativo) de los académicos tienen algún tipo de contrato permanente o de varios años. La mayoría reciben sueldos adecuados porque se trata de una fuerza de trabajo cualificada y son potenciales captadores de ingresos. Con el declive de la financiación pública central, la generación de ingresos se ha convertido en algo tan esencial como la generación de "conocimiento" e ideas, y es el centro de las evaluaciones anuales de resultados en la mayoría de las universidades. Más aún, no existe ningún tipo de titularidad académica, lo que hace que los 
recortes en empleos puedan ser posibles si las finanzas se complican (para un debate sobre la desaparición de la titularidad docente (vid. Batterbury 2008). El Sindicato de Educación Superior Nacional (NTEU) representa y lucha para proteger a los académicos y personal profesional, mediante acuerdos colectivos económicos con cada institución. Esos acuerdos se consiguen duramente. La NTEU es cada vez más importante en las universidades porque las universidades están respondiendo a la austeridad fiscal con presupuestos más restrictivos, recortes de personal, transformaciones de cursos presenciales en online y conversión de la fuerza de trabajo en un alto porcentaje de profesores e investigadores temporales o estacionales (baratos), con contratos por corto tiempo. Actualmente los profesores temporales imparten la mitad de la docencia en Australia, aunque no disponemos de datos (Connell 2015). Gracias a la NTEU, los precios por hora de enseñanza, por calificaciones y por tutorías son generalmente buenos (muchos mejores que en Norteamérica), pero como en Holanda y en otros países, los académicos temporales están atrapados con una carga de docencia masiva y muy poco tiempo para realizar investigación.

La gerencia neoliberal se basa en un equipo de ejecutivos de altísimos sueldos, lo que sugiere que el ahorro en los gastos no se distribuye equitativamente. Los Rectores de las universidades australianas reciben ahora unos salarios anuales de cerca de 1 millón de dólares (unos 709.000 euros). Son asesorados por abogados gestores y una plétora de cargos -los Vicerrectores, los Asesores de Rector, los Decanos y Vicedecanos, y Secretarios de Facultad,- que tienen sueldos que van de 200.000 dólares australianos hasta 500.000. La situación varía en el sector pero la ironía de una escala de gerentes y gestores sobre-pagados que les piden a los sobrecargados académicos que "trabajen mejor" no es infrecuente entre el personal académico y profesional. Conforme se agota la financiación, aumenta la diferencia entre clases, estalla la carga docente y los procesos burocráticos se multiplican, con los colegas siendo despedidos o solicitando la baja por el alto nivel de estrés, ansiedad y depresión, lo que deja el interrogante de por qué se pagan millones a los gerentes. La disputa sobre las condiciones de trabajo se debe trasladar a gran escala con huelgas y protestas -en parte, porque los bajos salarios no son tema que preocupe a una cohorte de académicos estabilizados que es más numerosa que en otros países-.

Otro factor de la reducción de costes es la "restructuración". Ésta es menos visible en las universidades en la cima de los ránkings (el grupo de las Ocho). Las reestructuraciones no siempre son exitosas. En La Trobe University en los primeros años de los 2010, una gran reducción de personal en Humanidades y Ciencias Sociales hubo de retirarse por las protestas e intensa acción de rechazo (Bode y Dale 2012). El despido de la profesora Judith Bessant de la RMIT University en Melbourne, fue un caso de prueba del poder de los gestores y ejecutivos -fue rechazado en los tribunales pues se estableció que esta universidad había violado la Ley de Trabajo Justo, sin apelación de la otra parte-. (Bessant 2015). Pero nosotros dos hemos experimentado reorganizaciones de Departamentos y de Facultades, perdiendo cada cierto tiempo, o ganándolos, a colegas, grados e infraestructuras bajo un nuevo "Plan Financiero" cada vez. En las universidades más nuevas, algunos Departamentos han sido "fusionados" en SúperDepartamentos que se consolidan en Facultades más grandes, -lo que siempre requiere el control de una clase gerencial y ahorra en los puestos administrativos básicos-. La investigación y la docencia se bifurcan en algunos casos, pues la enseñanza es controlada por los Decanos o Secretarios de Facultad, y la investigación depende de los Directores de las Unidades de Investigación. 
Esto crea más capas de burocracia y más fragmentación, aunque hay excepciones. Melbourne ha creado una única Facultad de Geografía para la investigación y la enseñanza, pero solamente después de que una Facultad completa (la de la Tierra y el Medioambiente) fuera partida y fusionada con otras dos.

Dado que la función de los académicos es ser recursos de captación de ingresos, el personal profesional es usualmente el primero que sufre recortes en los ajustes presupuestarios. En todo el sector, las universidades de Australia han recortado hasta la saciedad funciones como el apoyo a los estudiantes. Por ejemplo, el Programa de Mejora Financiera de la Universidad de Melbourne (2013-2016) anunció un recorte financiero importante. Unas 540 plazas de administrativos iban a amortizarse en enero de 2016. (Fioritti y See-Tho 2014). No sabemos actualmente qué ha pasado con el proceso, pero sabemos que muchas personas perdieron su puesto de trabajo, otros fueron a un proceso de recontratación compitiendo con compañeros por una cantidad pequeña de puestos de trabajo, y muchas funciones se trasladaron a la versión online (Campbell y Morrissey 2015). La Universidad de Griffith también ha sufrido oleadas de recortes de puestos laborales, bajas incentivadas prematuras y otras por redundancia de puestos. Los centros de apoyo a estudiantes de ambas universidades y en el resto del país, que en su dia eran numerosos y personalizados en su atención para la matriculación y otras necesidades, se han visto cerrados o reemplazados, en una de nuestras instituciones, por un sistema de "teleoperadores" de Inteligencia Artificial, como el de IBM Watson Support, de manera que se centraliza y por tanto reduce la atención humana. El apoyo de operadores automáticos se ha centralizado y externalizado en muchos casos, con pérdida sustancial de puestos de trabajo y a menudo con beneficios financieros marginales. Las oficinas de correos han cerrado, los sistemas reconducen a robots o aplicaciones de móvil, y el marqueting y el seguimiento en el campus se consolida y centraliza en formas empresariales. El objetivo es ahorrarse costes salariales. La eficiencia resulta en ciertas áreas, pero muy a menudo produce la sobrecarga laboral de quienes soportan el resto del sistema, y sustancialmente generan menos contacto humano y con ello menor humanidad en el trato universitario.

Las dos universidades que conocemos mejor han seguido caminos diferentes. Melbourne es una universidad de prestigio y tiene gran éxito y preferencia entre los estudiantes. El resultado más importante de la Nueva Gestión Pública en Melbourne consiste en las luchas internas sobre cómo repercutir las tasas de matrícula. Las Facultades han recibido unos objetivos financieros que deben cumplir. Pero desde hace unos años, las facultades compiten para "capturar" matrículas de estudiantes. Hay unas disputas por la "propiedad" de las clases o de los grados completos, con temor a que se produzcan "fugas de matrículas" a otras Facultades. Esto afecta a la elección posible de los estudiantes, a menudo reduciendo las clases más "elegibles", a las que se imparten en un Grado de una Facultad principal. Las disputas sobre la "propiedad" de los grados universitarios han sido constantes desde la gran reestructuración de mediados de los 2000, llamada el "Modelo de Melbourne". Un Consejo Académico es el que adjudica los mismos, pero en 2017 se estableció un nuevo Grado, con la mayoría de matrículas destinadas a una sola Facultad, de manera que se reubicaban los ingresos que antes se daban en otras.

En Griffith una gama de ofertas de Grado se ha consolidado en grandes unidades -como el genérico Licenciado en Ciencias. Similar a las facultades de Melbourne, las de Griffith se ven cada vez más preocupadas por la fuga de matrículas 
y por los ingresos. A diferencia de Melbourne, Griffith a menudo se ve forzada a generar medidas para atraer a suficientes estudiantes y "cumplir la cuota". Los académicos, para este fin, tienen que apoyar y rebuscar estudiantes para sus centros, con un número creciente de alumnos (a menudo de proveniencia no tradicional) que pueden carecer de las habilidades básicas para estudiar en la universidad. Esto ha incrementado las ratios de abandono, que son vigiladas muy de cerca por los evaluadores, y supone una carga más a las espaldas de los académicos, que deben cambiar sus programas e incluso el modo de desarrollar su docencia, para mejorar los resultados y las experiencias de los estudiantes, con tutorías personalizadas, o esfuerzos "pastorales" para maximizar el aprendizaje. Mucho de todo esto podemos atribuirlo a la "competición permanente" en el sector que Halffman y Radder detectaron (2015).

\section{Evaluación de resultados individuales}

En las Facultades se han establecido ahora objetivos de resultados individuales cuantificables. Se trata de algo relativamente reciente. Los profesores deben publicar en revistas, "captar ayudas" e incluso superar evaluaciones docentes. Los objetivos son un rasgo proveniente del mundo profesional comercial, y conllevan siempre estrés. Los resultados individuales podrían manejarse de manera mucho más humana y más en apoyo del profesor si no existieran objetivos drásticos, mediante una retroalimentación constante. Los objetivos incumplibles significan, en última instancia, individuos que no los cumplirán y que o son sancionados o son despedidos. El éxito en la investigación se define ahora de acuerdo con el logro de los Proyectos Nacionales Competitivos o de los contratos con consultoras externas, como en el caso de las publicaciones. Las ayudas nacionales del ARC o las ayudas de la asociación médica NHMRC son muy difíciles de conseguir, con ratios de menos del 15\% para diversas disciplinas (ARC Descubrimientos tiene un $17.8 \%$, en 2017 (ARC 2017a), NHMRC para 2016 otorgó un 15.2\% de las ayudas). Los que consiguen un Proyecto pueden aislarse sin tener que afrontar grandes cargas de docencia, que recaen en los académicos jóvenes o en aquellos que no han sido distinguidos con estas ayudas. La "captación de ayudas" y las publicaciones en revistas de alto índice de impacto son los criterios que deciden a menudo la contratación, en detrimento de la excelencia en la enseñanza o la capacidad comunicativa (no olvidemos que las ayudas de investigación son un input-dinero para desarrollar investigación- pero no son un output, y muchos investigadores no necesitan de ellas precisamente).

Investigar de manera barata no se recompensa en absoluto (Martin 2011). Tampoco la publicación ética y barata -el acceso abierto y fuera de las editoriales comerciales que están destrozando el presupuesto bibliográfico de las universidades-. Dedicar muchos años para producir un libro editado de manera excelente, por ejemplo, fuera de los artículos de las revistas indexadas, se castiga porque no granjea suficientes puntos a la universidad en el sistema de evaluación de la excelencia investigadora (ARC 2017b). En sus peores formas, los criterios sobre input y output están empezando a crear brechas en la libertad académica, y han empeorado profundamente en los últimos decenios. Críticos como Lorenz argumentan que "los profesores necesitan autonomía profesional para poder trabajar adecuadamente y el control cuantitativo lo hace imposible" (20015:7). 
La docencia también está sometida a escrutinio y a la métrica de resultados,-añadiendo más estrés-. La vigilancia de la calidad es necesaria, pero el Marco de Calidad de Australia ha estandarizado los currícula. "Los resultados del aprendizaje" son los que controlan ahora mismo el proceso. Se los requiere en los perfiles y programas de los cursos, que son contratos entre académicos y estudiantes para proporcionar un servicio. Los académicos son distribuidos anualmente para la programación docente a partir de las evaluaciones administradas desde recursos centrales, de acuerdo con las evaluaciones obligatorias de los estudiantes y las experiencias sobre el curso, como ocurre en muchos países. Si se reitera el fracaso en el cumplimiento de los objetivos docentes, ello tiene efecto en la promoción y en las perspectivas de empleo, aun cuando existan alarmas internacionales al respecto de cómo los valores numéricos no pueden usarse para evaluar la "calidad" (Stark 2013).

El apoyo internacional para investigación y asistencia a conferencias ha caído en las instituciones que conocemos. Hoy en día es raro el derecho a un año sabático para investigar. Se espera que los académicos (o se les fuerza) lleven un buen lote de investigación aparte de las 40 horas de trabajo semanales -y al mismo tiempo se les exhorta a tener un buen equilibrio de vida y trabajo-. Los que caen en el estrés y la depresión no reciben demasiado consuelo, aconsejándoseles que llamen por teléfono a un sistema de asesoría externalizado o que asistan a tres sesiones gratuitas de terapia anual.

Todo esto sería soportable si existiera algún apoyo, oposición o protestas por parte de los trabajadores universitarios. La lucha constante contra la desigualdad y la presión es material y simbólicamente importante, y una clave para que las plazas de trabajo mantengan su calidad y salud. Pero muchos académicos australianos, y personal administrativo, se mantienen en silencio. El disenso real es mudo porque todos se preocupan por las consecuencias del disenso. La esperanza está en las "estrellas", los catedráticos cuyos servicios son demasiado buenos o demasiado lucrativos para perderlos. Pero incluso ahí, la acción colectiva es rara. Muchos profesores no están acostumbrados a luchas como estas, y tristemente comparten quizá algunos de los valores de la dirección gerencial -su éxito, después de todo, es porque encajan en los objetivos requeridos, o porque han tenido la suerte de escalar la cadena de la alimentación antes de que las reformas estructurales en la educación terciaria comenzaran a morder-.

Muchos académicos senior reproducen las exhortaciones de los gestores para publicar en revistas en el top de los índices, obtener financiación y lanzar los departamentos al éxito. Sin embargo entre ellos hay muchísimos ejemplos de "académicos top" y gestores de nivel ejecutivo que jamás serían capaces de conseguir los mismos indicadores de resultado que exigen y con el que el personal por debajo de ellos debe dejarse las uñas y las ilusiones. Además si estos tuvieran "sueldos normales, y realmente dieran más importancia al contenido intelectual y tuvieran menos interés público en su reputación" (Halffman y Radder entonces quizás hubieran sido más proclives a ponerse del lado de los colegas sobreexplotados. Esto hubiera solucionado muchos problemas de una vez.

\section{Conclusión}

En suma, muchos de los temas de Halffman y Radder (2015) son igualmente verdad en Australia. Pero los académicos no están bajo un asedio desesperado en nuestras 
mejor soportadas universidades, incluso aunque la reestructuración y la búsqueda de más altos ránkings esté resultando onerosa. Hay muchos núcleos de trabajadores decentes, esforzados y educados, que socializan y que tienen incluso tiempo para reflexionar libremente y sin prisas, y para investigar. Australia tiene muchos académicos extranjeros que aún encuentran nuestras universidades mucho mejores, y más tolerantes, que las de sus propios países. Pero muchos otros se ven aplastados por el intento de cumplir con el siguiente objetivo o mérito con fecha de caducidad, y creemos que esto es cada vez más común conforme la cienciometría de los resultados y los índices van teniendo mayor importancia. Se trata del personal de nivel medio o bajo, predominantemente mujeres, que son las que lo han sufrido más.

Conforme el sistema de acreditación de igualdad de género British Athena-Swan (SAGE 2017) llega a Australia, este y otros temas están empezando a ser vigilados. Esfuerzos hercúleos nos están permitiendo mantener alta la calidad docente y seguir atrayendo a estudiantes, pero quizás a demasiados de ellos, y ciertamente con matrículas que son realmente caras cuando tenemos en cuenta el coste de la vida. En las instituciones menos valoradas en los índices, la vida académica puede llegar a ser casi insoportable. Hay gran tensión en los profesionales, muchísimos abandonos de personal, baja moral, y cierres de facultades o departamentos así como despidos. De nuevo hay excepciones y nichos de buena voluntad, pero las condiciones estructurales de persistente infrafinanciación pueden terminar cerrándolos todos.

Estamos de acuerdo con Halffman y Radder (2015) en su Manifiesto, con sus 20 puntos precisos para aliviar la tortura de la burocracia en la universidad neoliberal y sus resultados antiéticos. Pero los problemas australianos empiezan fuera del sector universitario. Con su riqueza en recursos naturales y su pequeña población, Australia está muy enraizada en la mentalidad neoliberal y hay muy poca voluntad de apoyar las universidades públicas. Muchos estudiantes quieren un Grado que los posicione en una nación que está enfocada a los negocios y a la ideología neoliberal a ultranza. Aunque estamos de acuerdo en que la universidad debe ser un "bien común" (175), la versión australiana indica que los estudiantes (o quizás la industria) deben pagarla, y no el estado. Connel (2015) pide el fin de las tasas de matrícula en el país y aboga por el retorno a un adecuado apoyo a las universidades desde el mundo público. Incluso aunque consigamos que los profesores "estrella" protesten contra la cuantificación métrica y las altas tasas de matrícula, una condición previa para el cambio es un gobierno nacional que esté mucho más comprometido con la universidad pública.

Retornamos al punto de partida, -el problema es sistémico, y financiero-- Desarrollar una universidad significa controlar un gran presupuesto, pagar a cientos o miles de profesionales, y mantener la actividad en marcha. Una universidad ética, si podemos retornar a ella, no será algo fácil de conseguir, no podemos ignorarlo (Bode y Dale, 2012). Acabar con la competición entre las Facultades, y silenciar la competencia entre universidades, es algo que solo puede hacerse mediante acuerdos (posiblemente mediante una distribución de ingresos centralizada, con condiciones del personal entre los criterios de aplicación utilizados, y quitándole énfasis a los ránkings y a la cuantificación métrica). Restaurar la autonomía académica es también esencial: ello no será fácil, porque la cuantificación empieza en la cima, donde se distribuyen los fondos de investigación y las becas y ayudas restantes.

Parece que F.J. Foakes Jackson le dijo una vez a un académico novel en Cambridge: "No sirve de nada intentar ser inteligente -todos somos inteligentes aquí-; inten- 
te usted solo ser amable, ¡un poco amable!" (la cita exacta es difícil de documentar). Hay que restaurar la cultura de la convivencia académica, el respeto y la cooperación que puedan hacer crecer el poder de resistencia colectiva y la resistencia a pequeña escala. Todos los estudiantes y el personal se beneficiarían de ello. Necesitamos académicos que puedan "devolvernos" la universidad, y que no acepten quejumbrosos las desigualdades laborales -ahora mismo éstos son una minoría.

Una universidad debe confiar en su personal y sus estudiantes. Y los académicos quieren algo más que una palmadita en la espalda por sus logros. Si pueden poner en práctica un academicismo "slow", relajado (Berg y Seeber 2016), hacer coincidir las responsabilidades prácticas y las éticas, y apoyar más a sus colegas académicos o profesionales, con ello se sentirán más seguros para contribuir al futuro de la universidad en Australia. Para ello, necesitamos disminuir la vigilancia burocrática de gente que no está cualificada, ni conoce la experiencia ni es capaz de desarrollar culturas del trabajo, del apoyo y de la convivencia. De nuevo, se trata de una afirmación compleja porque compete a un conjunto de diferencias sustanciales en todo el sector educativo. Pero Australia necesita menos Nueva Gestión Pública, y más "confianza de su gobierno" como ha reconocido Suecia (Myklebust 2017).

De un modo muy turbador, Connell(2015:24) apunta que en Australia

"las universidades están ahora repletas de una contabilidad falsa. Al mismo tiempo, recurren a técnicas de relaciones públicas para atraer a los estudiantes potenciales y a los donantes y para maquillar la imagen de la organización. La universidad empresarial proyecta ahora al mundo una fantasía reluciente de praderas anchas, estudiantes relajados, personal feliz, edificios espaciosos, y una eterna puesta de sol australiana. El imperativo cultural racional de las universidades, como sustentadoras de la verdad, del pensamiento riguroso, se está viendo muy seriamente amenazado"

Esta fantasmagórica imagen esconde un lado preocupante y a veces desagradable, como mucha gente decente está esforzándose por señalar, manteniendo al Lobo fuera de la casa. Y ese esfuerzo es realmente doloroso.

\section{Referencias}

ARC—Australian Research Council. 2017a. "Discovery Projects Selection Report for Funding Commencing in 2017." https://goo.gl/UeZuc7.

ARC-Australian Research Council. 2017b. "Excellence in Research for Australia." http:// www.arc.gov.au/excellence-research-australia.

Batterbury, S.P.J. 2008. "Tenure or Permanent Contracts in North American Higher Education? A Critical Assessment. Policy Futures in Education 6 (3): 286-297.

Berg, M., and B. Seeber. 2016. The Slow Professor: Challenging the Culture of Speed in the Academy. Toronto: University of Toronto Press.

Bessant, J. 2015. "Smoking Guns: Reflections on Truth and Politics in the University." Through a Glass Darkly: The Social Sciences Look at the Neoliberal University, edited by M. Thornton, 229-258. Canberra: ANU Press. https://goo.gl/ASdC5b.

Bode, K., and L. Dale. 2012. "'Bullshit'? An Australian Perspective. Or, What can an Organisational Change Impact Statement Tell Us about Higher Education in Australia". Australian Humanities Review 53: 1-15. https://goo.gl/H2fShp. 
Campbell M., and P. Morrissey, eds. 2015. The People's Tribunal: An Inquiry into the 'Business Improvement Program' at the University of Melbourne. Melbourne: Discipline.

Connell, R. 2013. Neoliberalism and Higher Education: the Australian Case. Universities in Crisis-Blog of the International Sociological Association (ISA). https://goo.gl/1fGHB9.

Connell, R. 2015. “Australian Universities Under Neoliberal Management: The Deepening Crisis." International Higher Education 81: 23-25.

Dow, Coral, and Carol Kempner. 2010. "Meeting the Need for Higher Level Skills Through Tertiary Education Reform.” https://goo.gl/UUfLMJ.

Fioritti, Nathan, and Michelle See-Tho. 2014. "Inside the Business Improvement Program." UMSU/Farrago, July 23. https://goo.g1/F35bmZ.

Halffman, W., and H. Radder. 2015. The Academic Manifesto: From an Occupied to a Public University. Minerva 53(3): 165-187.

Lorenz, C. 2015. "The Metrification of 'Quality' and the Fall of the Academic Profession." Oxford Magazine Hilary week, Trinity term: 7-11. https://goo.gl/wfDXSz.

Martin, B. 2011. "ERA: Adverse Consequences.” Australian Universities'Review 53 (2): 99102. http://www.bmartin.cc/pubs/11aur2.pdf.

Mountz, A., A. Bonds, B. Mansfield, J. Loyd, J. Hyndman, M. Walton-Roberts, R. Basu, R. Whitson, R. Hawkins, T. Hamilton, and W. Curran. 2015. "For Slow Scholarship: A Feminist Politics of Resistance through Collective Action in the Neoliberal University." ACME: An International Journal for Critical Geographies 14 (4): 1235-1259. https://ojs. unbc.ca/index.php/acme/article/view/1058/1141.

Myklebust, Jan Petter. 2017. "In Search of a New Form of University Governance." University World News (450), July 6. https://goo.gl/9w4a8b.

OECD. 2017. “OECD Better Life Index: Australia.” https://goo.gl/UKvtrh.

Parker, Stephen. 2014. "Higher Education Changes a 'Fraud on the Electorate'." The Conversation, December 2. https://goo.gl/v8JkDT/.

SAGE-Science in Australia Gender Equity. 2017. "Athena SWAN Principles." https:// www.sciencegenderequity.org.au/athena-swan-principles/.

Sharrock, Geoff. 2013. "Book Review: The Dawkins Revolution, 25 Years On.” Review of The Dawkins Revolution, 25 Years On, by Simon Marginson, Gwilym Croucher, Andrew Norton, and Julie Wells. The Conversation, October 23. https://goo.gl/3gm9ZB.

Stark, Philip. 2013. "What Exactly Do Student Evaluations Measure?” Berkeley Blog, October 21. https://goo.gl/oqdjAa.

Watts, R. 2016. "The Idea of 'Marketising' the University: Against Magical Thinking." In Public Universities, Managerialism and the Value of Higher Education, edited by R. Watts, 147-179. Basingstoke: Palgrave Macmillan. 


\section{Sobre lobos, ovejas y pastores: una comedia bosnia de los errores} Mario Hibert and Andrea Lešić-Thomas ${ }^{7}$

Hay un dicho según el cual la oveja se pasa toda la vida temiendo al lobo, para ser al final devorada por el pastor. El leitmotiv fundacional del Manifiesto Académico ilustra el actual estado de hambre gerencial en el sistema académico corporativo. Sin embargo, en el caso de Bosnia Herzegovina, el tema suscita cuestiones de la transición post-comunista a la universidad neoliberal, y la ambición es salvaguardar a sus "niños inmaduros" en el camino hacia el ideal de la educación moderna. De todos modos quién es el pastor y quién es el lobo es un tema muy poco claro en el caso bosnio (y argumentaremos también, en el área post-yugoslava e incluso post-comunista en general).

De los dos autores de este Informe, Andrea ha experimentado directamente algo similar al sistema universitario que el Manifiesto describe y pone de relieve. Ella estudió y enseñó Literatura en el Reino Unido (el campo de pruebas originario en Europa para testar el enfoque gerencial de las universidades) y ha experimentado tanto las delicias de un acceso temprano a la investigación y docencia globales, como las frustraciones de verse forzada a justificar la existencia de las Humanidades no lucrativas en unas universidades cada vez más obligadas a funcionar de acuerdo con la lógica neoliberal. Una vez de vuelta a Bosnia Herzegovina en 2007, se quedó asombrada de las libertades casi surreales que encontró entre los docentes universitarios de Bosnia, que podían enseñar lo que quisieran, publicar cualquier cosa en cualquier lugar deseado, y esperar un estatus social casi automático sobre la base del título académico grabado junto a su nombre. Esas libertades, sin embargo, provienen de un caos no resuelto, y múltiple, en una transición post-comunista que busca una solución a partir de una ensordecedora cacofonía de prácticas académicas enfrentadas, de tendencias y de ideologías a la búsqueda de una base común. En dicha situación caótica, el Manifiesto proporcionó un bálsamo de calma y claridad. Si ahora tenemos un espacio en el que conformar nuestro futuro, es mejor mirar de frente cuáles puedan ser esos posibles futuros que se ofrecen.

Hay claramente cuatro sistemas coexistiendo y en contradicción en la práctica e ideología académica implicadas en el funcionamiento de nuestra universidad (Sarajevo): su fundamento y su legado socialista; la ideología nacionalista posterior a 1992; el presente deseo ardoroso de "ponerse a la altura del mundo moderno" y adaptarse al "proceso Bolonia" (el proyecto pan-europeo de convergencia de las estructuras de

Mario Hibert, Doctor en Filosofía, desde 2006 imparte docencia en Departamento de Literatura Comparada y Biblioteconomía en la Facultad de Filosofçia de la UNiversidad de Sarajevo. Es además Doctor en Ciencias de la Información y la Comunicación, en la Facultad de Humanidades y Ciencias Sociales en la Universidad de Zagreb, Croacia. Imparte un Master en Derechos Humanos y Democracia en el Centro de Estudios de Posgrado Interdisciplinares de la U. de Sarajevo/Università di Bologna. Estudia temas críticos de Biblioteconomía, la Sociedad en Red, la cultura digital, y la Ética informativa. mario.hibert@ff.unsa.ba.

Andrea Lešić-Thomas, Doctora en Filosofía, ha estudiado en Belgrado y Londres, impartido docencia en la Escuela de Estudios Eslavos y de Europa del Este y en la Queen Mary, ambas en la Universidad de Londres, y actualmente es docente en la Facultad de Filosofía en la Universidad de Sarajevo, en Bosnia Herzegovina. Ha escrito sobre Literatura comparada (Literaturas rusa, francesa y eslava del sur), Teoría literaria (en particular estructuralismo, narratología y Bajtin, así como Estudios de la memoria).

Actualmente enseña Teoría Literaria en la Universidad de Sarajevo, y desarrolla investigaciones sobre Estudios de la Memoria, Poética cognitiva, Narración romántica y vampiros. Es autora del libro Bajtin, Bart, strukturalizam: književnost kao spoznaja i mogućnost slobode Beograd: Službeni Glasnik, 2011. andrea.lesic-thomas@ ff.unsa.ba. 
grado, créditos para asegurar la movilidad de estudiantes y profesionales -que en la interpretación local, se reduce a una burocracia inflada y al retorno de la manía de la estandarización, y que ha causado con ello una igualmente apasionada oposición entre la mayoría de los docentes; vid EUA 2017; EHEA 2017), y finalmente, un vago anhelo de la "torre de marfil" (de la que hay realmente poca experiencia local, pero que funciona como el obvio contraste a las penalidades del "proceso Bolonia"·).

Aunque un par de facultades de la Universidad de Sarajevo se fundaron justo después o durante la Segunda Guerra Mundial (Agricultura y Forestales en 1940, y Medicina en 1944), la universidad en sí misma se funda en 1949. Nuestra propia Facultad de Filosofía (que inicialmente enseñaba no solamente Humanidades, sino Ciencias Sociales y Naturales) se funda en 1950, constituyendo el logro del primero de los objetivos más representativos y más legendarios de la universidad, que es proporcionar formación para las profesiones socialmente significativas ${ }^{8}$. La Universidad de Sarajevo, así como otras tres universidades más, fundadas a mediados de los años 70 en Bosnia (en Banja Luka, Tuzla y Mostar) se crean para proporcionar educación gratuita (sea en Leyes, Medicina, Ingeniería o para las enseñanzas en Educación Secundaria o Primaria) a personas con talento, para el avance de la sociedad en su conjunto, con el sistema de demandas morales y políticas que esto conlleva. ${ }^{9}$ Este legado es aún evidente en el hecho de que nuestra facultad, así como la Facultad de Ciencias Naturales y Matemáticas, o las Academias de Arte y de Música, ofrecen programas de Grado que incluyen un conjunto de cursos de Pedagogía tanto teóricos como prácticos, y así habilitan a sus graduados a ser profesores en el tema que están estudiando sin una formación adicional. En algunos casos, el componente pedagógico es opcional, pero en muchos (y particularmente en nuestro caso) el único modo de estudiar, por ejemplo, Literatura Bosnia, es convertirse también en profesor de escuela.

A este primer nivel operativo se añade el contexto ideológico de la Posguerra. Durante los últimos 20-25 años, el nacionalismo sistémico, que proporciona el fondo básico de ruido, si no la partitura, para todo lo que se hace en las ciencias sociales y las humanidades en el país, domina sobre las instituciones educativas socialistas (como en todo lo demás). Igual que al estudiante socialista se le proporcionaba un conjunto de habilidades para que fuera un trabajador socialmente útil, al estudiante post-socialista de la Bosnia en transición se le lleva por un camino procedimental casi idéntico, y sin embargo ideológicamente modificado, en el sistema educativo, para que el tema nacionalista y el engranaje en la máquina que lo promueve sigan funcionando (un simple "trabajador", sea él o ella, tiene menos probabilidad de so-

8 La página oficial de la Universidad de Sarajevo, sin embargo, en la sección que detalla la historia de la universidad, viene a indicar que la universidad es el legado de la Biblioteca de Gazi Husrev-Bey's del siglo XVI con su fundación de varios Seminarios (aunque las Facultades de Teología -islámica, católica y ortodoxa -sean miembros oficiales de la Universidad solamente desde hace unos pocos años y formaron parte del Museo Nacional en el siglo XIX. Esta confusión cronológica es en sí signo del confuso estado de estos temas (Universidad de Sarajevo 2017)

$9 \quad$ La carrera del padre de Andrea es un buen ejemplo de esto: unos años después de la Guerra Mundial, era uno de los estudiantes más dotados de la Facultad de Gramática, que el gobierno reclutó por decreto para formar parte del profesorado en las escuelas; con 18 años, fue destinado a la Escuela de Gramática de la pequeña localidad de Keševo; dos años más tarde, un inspector de enseñanza decidió que estaba siendo desperdiciado en la pequeña ciudad y ordenó que cursara una carrera universitaria, así que de nuevo por decreto, se situó entre los mejores alumnos universitarios de la Facultad de Filosofía, donde ahora enseñan Mario y Andrea. Este tipo de ingeniería social personalizada no se ha podido sostener por mucho tiempo pero sobrevive una lógica de fondo que lleva a toda la gente a asistir a la universidad en primera instancia. 
brevivir en un país económicamente moribundo que mantienen a flote los créditos internacionales y que se mantiene unido por una corrupción generalizada). Añádase a esto la proliferación tanto de nuevas universidades privadas como de propiedad estatal, todas las cuales tienen como objetivo creciente el número de estudiantes matriculados, y la competencia entre ellas en el mercado de la Educación Superior.

La tercera capa, la que clama por la modernización y la adopción de los niveles de calidad internacionales, y desea sacarnos de un pasado retrógrado hacia un futuro brillante y global, es la capa en la que la comedia de los errores empieza a resultar algo serio. Esta capa es en la que la ideología nacionalista (tradicionalista, conservadora, pre-moderna) se muestra como el socio perfecto de la práctica neoliberal postsocialista. En Bosnia y Herzegovina, así como en toda la zona y región, el Lobo aparece pintado como una bestia de bandera roja rugiente, utópica y engañosa, con sus dientes acechando a las libertades académicas, mientras que la salvación neoliberal actual es el Pastor que nos rescata con su agenda de economía de consumo, y que nos protegerá con éxito de los males del pasado si nos sometemos como es debido a las estandarizaciones, cuantificaciones, y controles de calidad en un nivel puramente administrativo.

Nuestro pastor rara vez se implica verdaderamente en lo mejor de esos estándares de calidad internacional (como por ejemplo la evaluación por pares, el debate robusto, y el constante cuestionar el conocimiento establecido). Le interesa más replicar los efectos cosméticos, siguiendo las normas de otros con evidente mala fe, pontificando sobre los niveles de calidad internacionales y la necesidad de un control de calidad, en tanto favorece la propaganda nacionalista envuelta en una apariencia de discurso académico. También muestra una falta de respeto absoluta a las tradiciones académicas (que han sido desechadas junto a todo el legado socialista) mientras al mismo tiempo proclama que regresa a las tradiciones nacionales, que fueron masacradas por el lobo socialista. Sí, nuestra pequeña comedia de los errores es así de divertida.

Añadida a ésta va la cuarta capa: la instrumentalización de la creencia en la santidad de la autonomía académica, y un anhelo por una imaginaria (e ilusoria) "torre de marfil" del pasado. Este anhelo, con sus airadas proclamaciones de autonomía universitaria, se acompaña de una mezcla mareante de altanería intelectual e irresponsabilidad académica, diletantismo y soberbia, y sirve principalmente de pantalla y de coartada para una enseñanza e investigación muy mediocres, así como para la corrupción y el clientelismo.

Cuando presentamos el Manifiesto Académico en una mesa redonda sobre el futuro de las universidades públicas organizada por la Universidad de Sarajevo, centramos nuestra charla en el hecho de que la competitividad en nuestros entornos parece más bien una caricatura de la salvación, puesto que nosotros no tenemos ni una dirección administrativa propia que pueda acercarse siquiera a una reorganización propiamente dicha ${ }^{10}$. Nuestras universidades pueden exigirnos que publiquemos sola-

10 Nuestra traducción de Manifiesto Académico se publicó en Pregled (Halffman and Radder 2015), principal revista académica en Ciencias Sociales de nuestra universidad, en un número que editó las Actas de las discusiones sobre el tema del "Papel y Situación de las Universidades Públicas en Bosnia Herzegovina". La mesa redonda representaba todo tipo de puntos de vista (de los académicos veteranos defendiendo la universidad humboldtiana, a los doctorandos defendiendo las encuestas de satisfacción de los clientes/estudiantes que indican que los clientes/estudiantes abogan por que sus universidades tengan un plan de desarrollo estratégico, de la calidad de la enseñanza al acceso a buenas bibliotecas o laboratorios, e incluso del precio de la cerveza en la 
mente en revistas indexadas (como hizo este verano a sus académicos la Universidad de Tuzla) pero para muchos de nosotros en Humanidades y Ciencias Sociales en Bosnia, sencillamente no hay ninguna revista que esté indexada en nuestra comunidad académica, y nuestras editoriales y revistas académicas (que una vez fueron pujantes, en los días del Lobo socialista), sobreviven a duras penas con una publicación u otra, sin inversiones a largo plazo y sin esperanzas de un futuro sostenible. Tenemos colegas que se desesperan pensando en un futuro en el cual no tendremos incentivo alguno para publicar en las revistas locales (tal y como son) y cómo nos hundiremos en el caos actual en el que prácticamente nadie tiene realmente posibilidad de ser evaluado por pares de manera auténtica (algo opuesto tanto a la denigración ideológica como al amable apoyo psicofántico, ambos dos abundantes en los procesos actuales).

Es claro que nada puede continuar así para siempre, y que en algún momento deberemos decidir qué futuro queremos tener. Para nosotros dos, (y, parece, para un número importante de colegas jóvenes) opinamos que haber sido niños de la Yugoslavia socialista no es algo de lo que avergonzarse, y que quizás las tradiciones de solidaridad y de cooperación, junto a un legado académico perfectamente sólido heredado de aquellos días, pueden proporcionarnos una base común y compartida desde la cual construir una visión de la universidad pública en el futuro de Bosnia. Para nosotros, el Manifiesto Académico ha sido un recordatorio (y un aviso a nuestros colegas implicados con el lobo liberal disfrazado de pastor) de que podemos simplemente abrazar nuestra posición marginal en la comunidad académica global, abandonar el proyecto de auto-colonización en el que nuestras universidades se embarcan justo en estos instantes, y usar este momento de caótica libertad para compartir la fuerza que las bases de nuestra Universidad nos proporcionan, y evitar los errores que cometieron aquellos que no los iban a pagar tan caro como nosotros. Al menos esto es lo que estamos intentando argumentar aquí. Deseadnos suerte pues, con seguridad, estamos siendo forzados a liberarnos de las garras del Lobo para ir a ser servidos de cena al Pastor de la Granja Académica.

\section{Referencias}

EUA-European University Association. 2017. "European Research Area and the Bologna Process." Accessed May 8 2017. https://goo.gl/zYVen6.

EHEA-European Higher Education Area. 2017 "How does the Bologna Process work?" Accessed May 8 2017. https://goo.gl/QL1LfW.

Halffman, Willem and Hans Radder. 2015. “Akademski Manifest: Od Okupiranog Do Javnog Univerziteta." [In Bosnian/Croatian/Serbian.] Translated by Bosnian/Croatian/Serbian. Translated by Mario Hibert and Andrea Lešić. Pregled: 173-203. https://www.academia.edu/11955254.

University of Sarajevo. 2017. "History of University.” Accessed May 8 2017. https://goo.gl/ wmL7Rm.

cafetería de estudiantes); y resultó, hasta donde sabemos, completamente ineficaz en términos de cualquier impacto político, benéfico o maléfico, y al mismo tiempo sirvió fundamentalmente para hacer ostentación ritual y vana de todas las perspectivas. 


\section{Al lado del lobo hay también un pulpo gigante hambriento comiéndose la libertad académica en Hungría}

Anna Wessely ${ }^{11}$

La Red de Profesores Contratados de Hungría (OHA) celebró una reunión en Budapest el 21 de febrero de 2017 para discutir la relevancia en Hungría de las denuncias del Manifiesto Académico. Este Informe resume los puntos principales de sus discusiones referentes a tres cuestiones centrales.

\section{1. ¿Cuáles son las similitudes y diferencias más significativas con la situación en nuestro país?}

Las situaciones son engañosamente similares en la superficie, en el nivel de las actuaciones del día a día, pero hay diferencias subyacentes significativas, que conciernen al constante cambio de contexto legal en el que las universidades húngaras se ven autorizadas o animadas a existir. La estrategia del Lobo y su retórica, así como los instrumentos del Lobo, se usan de una manera oportunista y claramente selectiva por el gobierno o el Ministerio de Recursos Humanos (jsic!) para justificar reorganizaciones específicas de estructura o financiación, todas dirigidas a reforzar el control estatal -financiero, administrativo, político- de las universidades.

Podemos apreciar interferencias con, y restricciones de objetivos de, la autonomía universitaria a todos los niveles.

- Una ley nueva de Educación Superior en 2012 recortó los poderes del rector (y, en consecuencia, de todos los niveles inferiores a éste, de las unidades administrativas, directores de departamentos, etc.) creando el puesto de Consejero nombrado por el gobierno que debía aprobar todas las decisiones del rector antes de que se lleven a efecto.

- Un nuevo órgano administrativo se insertó entonces en la organización de las universidades para garantizar el constante control gubernamental. Se le denomina Consistorio, tiene una mayoría asegurada pro-gubernamental, y se le encomienda la vigilancia, la aprobación y el veto de las decisiones del Claustro de la Universidad.

La legislación parece vincular solamente a las universidades, no a la administración del estado. La extensión de la financiación, los fondos del presupuesto nacional para enseñanza e investigación, el permiso para participar en proyectos internacionales, el lanzamiento de nuevos programas educativos y formativos, el nombramiento de catedráticos, el número de estudiantes que se admiten en todos los niveles de estudios, los requisitos para acceder a los diversos grados y títulos, etc., son todo cuestiones que dependen de la aprobación gubernamental que, a su vez, depende de la lealtad al gobierno de quien está al frente del gobierno universitario.

11 Anna Wessely, Doctora en Filosofía, es Historiadora del Arte y socióloga. Es Profesora en la Eötvös Loránd University y en la Universidad de Bellas Artes en Budapest, y Presidenta de la Hungarian Sociological Association, y Editora Jefe de la revista BUKSZ (Budapest Review of Books). 
Evadiéndose o no teniendo en cuenta las decisiones del Consejo de Acreditación Académica, mediante legislación o mediante regulación administrativa, el gobierno de Hungría ha conseguido destruir la autonomía de las instituciones de educación superior incluso en asuntos académicos. El ejercicio de su autonomía nominal y de su autogobierno tiende a depender de los cambiantes objetivos del gobierno nacional y de las igualmente volátiles relaciones de poder a varios niveles de las organizaciones de la administración pública.

El gobierno húngaro actual (desde 2010) se define orgullosamente como una "democracia aliberal". Intenta centralizar todos los recursos y controlar todas las instituciones y procesos sociales. Las instituciones privadas de educación superior son, al igual que todas las ONG, amenazadas de la misma manera, excepto si ocurre que tienen el favor particular del primer ministro o de los partidos políticos dominantes. Los mecanismos de este gobierno y sus tácticas mixtas de combinación o alternancia de falsas acusaciones, etiquetas derogatorias o argumentos legalistas con mayor o menor coerción encubierta y propaganda engañosa, han llevado a los analistas políticos a definirlo como un estado mafioso y a comparar su funcionamiento con la avaricia y mortífero abrazo de un gran depredador: "el Pulpo Húngaro" (Magyar and Vásárhelyi 2017; Magyar 2016). Su presa más reciente son las iglesias libres, las ONG y la Universidad Central Europea (CEU).

Las tácticas mixtas en el caso de la CEU significan que el estado no prohíbe o disuelve esa universidad, sino que busca destruir las condiciones de su funcionamiento presionando al parlamento para aprobar un decreto que modifique de cierta manera la Ley de Educación Superior, que justamente concierne a una única institución, la Universidad Central Europea. No importa que los cambios legislativos del decreto que se ha redactado, debatido y aprobado con el voto de la mayoría en tres días, resulten ser inconstitucionales. Cuando los tribunales de Hungría o incluso los de Estrasburgo hayan decidido que la "Lex CEU" es inconstitucional y está en conflicto con la ley europea y con el acceso a los documentos de la UE, el gobierno húngaro habrá causado ya tanto perjuicio a la CEU con la nueva ley que será difícil que sobreviva. La oficina del Rector en la CEU resumía los cambios legislativos y su impacto esperado de la siguiente manera:

\section{Resumen de los cambios legislativos y su impacto en la CEU}

La Universidad Central Europea es una institución de educación superior con una identidad legal dual que opera en un solo campus en Budapest. CEU está concertada con la Universidad Estatal de Nueva York, donde todos sus programas de grado se registran. En los Estados Unidos, CEU es evaluada por la Comisión de los Middle States en Educación Superior. La CEU también se instituye como una universidad húngara por parte del Parlamento de Hungría bajo el nombre de Közép-európai Egyetem ('KEE') y está acreditada por el Comité de Acreditación Húngaro.

La identidad dual de la CEU/KEE permite a la universidad cumplir con las leyes de Hungría y las de USA y ofrecer títulos tanto húngaros como homologados en USA. La CEU no tiene operaciones en USA. Es un modelo común. La CEU es una de las muchas universidades acreditadas en América que no operan ningún programa académico dentro de Estados Unidos pero ofrecen un nivel educativo internacional que es accesible a los estudiantes locales. Las modificaciones exigidas a la CEU afectan a los programas que esta universidad ofrece al Estado de Nueva York. Forzar 
a dicha universidad en este sentido no tiene ningún beneficio educativo e incurre en costes innecesarios tanto en recursos financieros como humanos.

La parte de las modificaciones que más claramente ilustra la discriminación sufrida por la CEU es la provisión que impide que las universidades acreditadas en Hungría (en este caso, la KEE) impartan programas o grados de universidades de países no europeos miembros de la OCDE. La legislación existente permite que funcionen programas universitarios y grados de países de la OCDE (incluido USA) en colaboración con las universidades húngaras, como hace actualmente la CEU/KEE. Hungría misma es miembro de la OCDE desde 1996, y como tal, no debería discriminar estas disposiciones para otros miembros de la OCDE.

Otro claro ejemplo de discriminación en la modificación propuesta es la eliminación de la claúsula de buena fe que actualmente permite a los académicos de terceros países trabajar en la KEE sin necesidad de un permiso de trabajo. El cambio crea barreras adicionales e innecesarias para la contratación y acceso de dichos docentes. El gobierno húngaro puede denegar esos permisos basándose en consideraciones políticas o restringir burocráticamente los mismos. Dado que la CEU se basa en particular en la docencia de profesorado de fuera de la EU, la nueva regulación coloca a esta universidad en una posición de desventaja, si no directamente imposibilita su actuación.

La modificación propuesta también prohíbe que las instituciones tengan nombres iguales o similares. Esto requiere que la CEU se dote de dos entidades legales -con programas que se dan conjuntamente- o que cambie sus nombres que se han utilizado desde hace décadas o deje de operar en Hungría.

Finalmente, la modificación requerirá un acuerdo vinculante internacional entre Hungría y USA tanto a nivel federal como estatal para permitir operar a la CEU como universidad extranjera en Hungría. Además, la ley ha sido modificada 24 horas antes de que fuera aprobada, lo que requiere un acuerdo internacional vinculante que debe ser implementado en los seis meses desde la publicación de la ley y en menos de nueve meses debe registrar los programas en la institución de Educación Superior extranjera del país de origen. Esto es punitivo y no deja el suficiente tiempo para que estas instituciones puedan cumplir las provisiones recién adoptadas" (Ignatieff, 7 April 2017).

Este resumen se publicó hace tres semanas. Desde entonces, se han producido manifestaciones masivas, sentadas y clases en la calle, protestas, etc. en las instituciones académicas, entre científicos, escritores en Hungría y en el extranjero. Ayer (27 de abril) la Asamblea Parlamentaria del Consejo Europeo exigió a Hungría suspender el debate parlamentario sobre la ONG Fidesz, y detener la implementación de la Lex CEU (Novak 2017). Y la historia no ha terminado todavía.

\section{2. ¿Cómo se relacionan las afirmaciones hechas en el Manifiesto con la situación en Hungría?}

Desde la perspectiva de la situación en Hungría, la descripción de los procesos en marcha que aparece en el Manifiesto está plenamente justificada. Como indica el título de este artículo, el Lobo se ve ayudado por el Pulpo en nuestro país. Esto significa que incluso si la interferencia política directa está ahora en el punto de mira, el lobo sigue trabajando en nuestros centros de educación superior, exigiendo y desarrollando regulaciones, informes, hojas de cálculo, etc. Si somos persistentes o afortunados y conseguimos librarnos del Pulpo, el Lobo seguirá ahí. No porque los profesores o los estudiantes echemos de menos sus servicios, o nos sintamos perdidos 
sin su guía, sino porque la condición de Hungría, de miembro del área de Educación Superior Europea, implica una similaridad en las principales tendencias evolutivas en toda Europa. El siguiente gobierno del país puede, y afortunadamente también lo hará, ser liberal, democrático y transparente, pero sin duda ni querrá ni podrá luchar contra el Lobo.

\section{3. ¿Qué posibilidades hay en Hungría de cambiar la situación a mejor?}

Nadie ha optado por hacer de la universidad una "torre de marfil", en la que sus supuestos habitantes nunca se sintieron cómodos. En cualquier caso, la torre de marfil es un eslogan combativo usado por los opositores a la libertad académica, más que el deseo o la experiencia vivida de nadie. La universidad pública como bien de conocimiento es una idea atractiva pero arriesgada en una era de medios controlados por el comercio, sean impresos o electrónicos, que monopolizan la transmisión de información sobre temas tópicos. Conforme las universidades caen bajo el control político, las estrategias para cambiar su situación y su papel social tienen que enfrentarse al gobierno. Por eso nuestra pequeña organización, la Red de Profesores Contratados, intenta actuar, presentándose a sí misma en las distintas plataformas de protesta política. Desafortunadamente, estas acciones son insuficientes en un país en el que los grandes medios están bajo el directo o indirecto control gubernamental. Desde esta perspectiva, la política de reformas universitarias parece muy secundaria y una tarea bien sencilla. Cuando realmente tratamos el tema, descubrimos lo difícil que es: los trabajadores de (todas) las universidades difícilmente se unirán para luchar.

\section{Referencias}

Ignatieff, M. 2017. “'Lex CEU' Now in Force, is Contested in Hungary, US, EU.” E-mail Message to supporters of CEU by Michael Ignatieff, CEU President and Rector. April 13, 2017.

Magyar, B. 2016. Post-Communist Mafia State: The Case of Hungary. Budapest: Central European University Press.

Magyar, B., and J. Vásárhelyi, eds. 2017. Twenty-Five Sides of a Post-Communist Mafia State. Budapest: Central European University Press.

Novak, B. 2017. "Council of Europe Calls on Hungary to Suspend Debate on NGO Law, Rescind Lex CEU.” Budapest Beacon, 28, April 2017. https://goo.gl/TunSuC. 


\section{En lucha por la autenticidad académica: la posición eslovaca en el contexto del Manifiesto Académico}

Jozef Hvorecky, Emil Višňovsky, and Matúš Porubjak ${ }^{12}$

El texto del Manifiesto Académico (Halffman and Radder 2015) captura exactamente no sólo la situación holandesa. Una plaga similar está devastando la cultura académica en todo el mundo. Naturalmente, hay también especificidades nacionales que arraigan en la historia de cada país. Un ejemplo es la educación secundaria en Eslovaquia -que de hecho es algo muy reciente y consecuentemente, inmaduro. La universidad más vieja que existe se fundó en 1919, y la segunda en 1940. En 1990, tras la Revolución de Terciopelo, solo existían 12 centros de educación universitaria en el país, muchos de ellos de pequeñas dimensiones. A pesar de la gran demanda, la proporción de población con estudios universitarios era solamente un $10 \%$ del total.

Los números demuestran que el sistema fundado para la educación superior en Eslovaquia se estableció en su mayoría bajo el régimen comunista. Básicamente representa una variación del modelo tradicional humboldtiano (como herencia de la Checoslovaquia del pasado) combinado con el soviético. En cuanto al primero, su idea clave es la unidad de docencia e investigación que se respeta, incluidas algunas porciones de libertad académica que algunos, no todos, disfrutan. Respecto al segundo modelo, establece el control no solamente de los estudiantes que pertenecen a la "clase trabajadora" (incluyendo la posibilidad de admitirlos), y también el contenido de todos los programas de estudio (que extiende la presión política a las Humanidades). Los académicos aprendieron que su obediencia a las autoridades era la mejor manera de sobrevivir y de promocionar.

Tras la revolución de 1989, surgió la oportunidad de revitalizar el sistema. El resultado no puede considerarse un éxito, debido fundamentalmente a tres razones:

1. En el régimen comunista los salarios en todos los puestos de trabajo eran más o menos iguales. Sin embargo, el sector privado emergente empezó a ofrecer mayores sueldos a su personal cualificado. Muchos académicos (en principio jóvenes) dejaron rápidamente sus universidades para ir a la empresa privada. Este agujero aún es muy notorio.

2. El personal remanente consistía tanto en entusiastas devotos de la educación (y preparados para continuar sus carreras académicas independientemente del dinero) o aquellos que no conseguían encontrar plazas mejor pagadas fuera de la universidad. Conforme los entusiastas eran normalmente una minoría, los académicos con una actitud pasiva y formal respecto a docencia e investigación empezaron a dominar muchos Departamentos.

12 Jozef Hvorecky, Doctor en Filosofía, es Profesor en Informática en la High School of Management/City University of Seattle en Trenčín, Eslovaquia, y Profesor Honorífico en la Universidad de Liverpool, UK. jhvorecky@vsm.sk.

Emil Višňovsky, PhD, es Profesor de Filosofía en la Comenius University en Bratislava, Eslovaquia, e Investigador Senior en la Academia Eslovaca de Ciencias. emil.visnovsky@savba.sk. Matúš Porubjak, PhD, es Profesor Asociado de Filosofía en la Universidad de St. Cyril and Methodius in Trnava, Slovakia. matus.porubjak@ ucm.sk. 
3. Hubo también un intento de incrementar la calidad de las universidades. Se organizó en su origen por parte de investigadores de Matemáticas, Ciencias Naturales y Ciencias Técnicas, porque estos campos habían sufrido menor opresión en el pasado. Desafortunadamente empezaron a aplicar sus propios criterios de calidad a todos los campos. Como en estos precisos campos de investigación la cuantificación describe la calidad del resultado bastante bien, se pensó que sería la mejor herramienta y que se podía aplicar a todos los campos.

El desarrollo de los años 90 y sus primeros frutos están bien descritos en Bakoš (2011). La evolución posterior no ha hecho sino reforzar las tendencias iniciales. La generación senior, acostumbrada a obedecer órdenes del superior, está seleccionando a los nuevos que son igualmente sumisos a la jerarquía. Los sueldos en las universidades son aún mucho más bajos comparados con la empresa. Los jóvenes académicos con potencial emigran del sistema -algunos fuera del país, otros a los negocios-. La cuantificación y sus criterios están distorsionando el sistema del modo exacto que se describe en el Manifiesto. El camino a este estado indeseable fue diverso, pero el estado actual es más o menos el mismo: "los académicos no son de fiar, y por tanto deben ser evaluados y monitorizados, bajo la amenaza permanente de reorganización, cese o despido" (Halffman and Radder 2015: 166).

El "Lobo de mil cabezas de la dirección empresarial" tiene un rostro ligeramente diferente comparado con el del Manifiesto. Una parte sustancial del poder de decisión sigue estando centralizado y en las manos del Ministerio de Educación. Desafortunadamente, "el ejército de gestores profesionales, armados con sus hojas de Excel" no consiste aquí en ejecutivos solamente. La Comisión de Acreditación le sirve como aliada de primer orden (Porubjak 2015). Su esfuerzo inicial para mejorar la calidad de las universidades mediante la intensificación de la investigación ha resultado una copia exacta de una serie de criterios de calidad como éstos: "el número de publicaciones primero, luego solamente el de las publicaciones internacionales, después tan solo las editadas en lengua inglesa, y después los artículos en inglés en revistas de alto impacto..." (Halffman y Radder 2015:167). En este momento, la Comisión para la Acreditación no solamente posibilita el tipo de presión necesaria, sino que se opone a los intentos de cambiar dichos criterios y discutirlos. Tenemos que admitir además que dos tercios de los miembros de la Comisión de Acreditación son académicos de las universidades eslovacas. Un enfoque similar ha sido seguido por una organización auditora cívica independiente llamada la Agencia Académica de Ranking y Rating (ARRA). Esta agencia viene intentando establecer la calidad de las instituciones de educación superior eslovaca desde hace más de diez años. Sus criterios de evaluación son todos ellos formales, poco trasparentes y en algunos aspectos conducen a error, como se muestra en Sykora (2015).

Si hay alguna diferencia comparando con la situación holandesa, reside en el lado oscuro del trabajo académico. Como la constelación inicial del sistema educativo post-comunista era peor comparada con los países democráticos tradicionales, probablemente hay más casos de violaciones de la integridad académica (por ejemplo, plagio) y un menor deseo de solucionar esos problemas. Sus consecuencias y posibles soluciones se analizan en Hvorecky (2015).

No importa lo paradójico que resulte, el sistema académico actual y la situación en Eslovaquia es un resultado muy poderoso de dos cosas: el modelo solviético/ humboldtiano y el modelo post-comunista/neoliberal. Los dos han hallado uno en el 
otro a su hermano ideológico. En los países post-comunistas, los Lobos gerenciales y burocráticos han encontrado probablemente el mejor terreno para su misión neoliberal, apoyados por el general "giro cultural" hacia Mammón. Boyadjieva e IlievaTrichkova (2015) y Sabic (2015) muestran que la misma situación se da en otros países postcomunistas.

Desde el punto de vista práctico, esto significa simplemente: lo que no se puede medir, no existe, y lo que se puede medir, debe convertirse en un valor pecuniario. En resultado, una nueva generación de académicos junior ha crecido en el entorno que ha adoptado estos valores y principios académicos inauténticos. En su mente y en sus ideas, estos valores son los que hay que seguir y son "los correctos". La generación más joven ha adoptado la idea de la universidad como una máquina, una fábrica, un negocio o una agencia cuya misión es producir artículos que, al final del día, produzcan dinero. Todo -el conocimiento, la educación, las publicaciones, las citas, las aplicaciones, etc.- debe ser medido y evaluado y/o convertido en dinero (Višňovsky 2014). Estos pseudo-académicos y directivos pseudo-académicos no hablan de ciencia, sabiduría, significado, revelación, comprensión, valores, etc. Simplemente ellos aceptan mediciones, inputs, outputs, resultados, excelencia, acreditación, evaluación, auditoría, y demás.

De todos modos, la aplicación de la mayoría de los métodos para el cambio que poponen Halffman y Radder puede conducirnos al desastre. En el futuro cercano, protestas masivas o manifestaciones en las universidades son algo poco probable. La comunidad ha aprendido a obedecer. Los desobedientes se han ido por su propio pie, debido a la atmósfera irrespirable, o han sido "apartados".

Por tanto, el cambio solamente puede venir mediante una "educación para la democracia académica". Su objetivo debe ser enseñar a la comunidad que la libertad académica y la integridad son claves para mejorar la universidad. Ello requiere un trabajo lento y paciente, pausado. Y la inevitable comunicación internacional entre académicos que, contra todos los pronósticos, no desean rendirse en su determinación de lo que consideran el significado de su vida y de su trabajo: la alegría de investigar y del pensar. La crisis actual de los académicos no es el "apogeo" de la crisis de la humanidad, al menos si la comparamos con la corrupción de la política global. Sin embargo, el modo como consigamos combatirla puede arrojar luz fuera de los muros de la "torre de marfil". El papel global de la Universidad es trabajar duro para detener la situación actual de estupefacción de la humanidad, y convertirse ella misma en un "rayo de luz", en la esperanza de que eso sea todavía posible.

\section{Referencias}

Bakoš, O. 2001. Katedra Paupológie [Department of Pauperology]. Bratislava: L.C.A.

Boyadjieva, P., and P. Ilieva-Trichkova. 2015. "Institutional Diversity and Graduate Employability: The Bulgarian Case." In Diversity and Excellence in Higher Education: Can the Challenges be Reconciled?, edited by R.M.O. Pritchard, M. Klumppand, and U. Teichler, 153-171. Rotterdam: Sense Publishers.

Halffman, Willem, and Hans Radder. 2015. "The Academic Manifesto: From an Occupied to a Public University." Minerva 53 (3): 165-187.

Hvorecky, J. 2015. Testament Vedca [Testament of a Researcher]. Bratislava: Premedia. Porubjak, M. 2015. "Mráz Prichádza Odvšadial” [Freeze Comes from Everywhere]. Ostium 11(3). http://www.ostium.sk/sk/mraz-prichadza-odvsadial/ . 
Sabic, N. 2015. "Governance Through Transparency Tools: The Case of Romanian Higher Education Reforms." In Diversity and Excellence in Higher Education: Can the Challenges be Reconciled?, edited by R.M.O Pritchard, M. Klumpp, and U. Teichler, 217-230. Rotterdam: Sense Publishers.

Sykora, P. 2015. "Robí si ARRA Srandu z Filozofickych Fakúlt?” [“Does ARRA Poke Fun at Faculties of Arts?"]. Accessed March 25 2017. https://goo.gl/SBVyik.

Višňovsky, E., ed. 2014. Univerzita, Spoločnost', Filozofia: Realita Verzus Hodnoty [University, Society, Philosophy: Reality Versus Values]. Bratislava: Iris. 


\section{Ansiedades y tensiones en el modelo nórdico-Finlandia y Escandinavia Anita Välikangas ${ }^{13}$}

En diciembre de 2016 Willem Halffman y Hans Radder llamaron a responder al Manifiesto Académico: De la Universidad ocupada a la Universidad Pública”. Yo prometí describir los recientes desarrollos en Finlandia, y comentar cómo dichos desarrollos se comparan con otros países nórdicos. A una primera mirada, la tarea parecía bastante clara: muchos puntos del Manifiesto me eran muy familiares. En Finlandia venimos viendo recortes en la financiación de la universidad, y un cambio en la dirección de la investigación universitaria hacia un tipo "orientado a las soluciones" y "relevante para las políticas". Los nuevos indicadores cuantitativos que miden el impacto de la investigación universitaria se desarrollan constantemente. Hay presiones para monitorizar y para incrementar la empleabilidad de los graduados universitarios, y una gran proporción de la financiación universitaria se basa en dichos números. Más que basarse en el ideal humboldtiano, el nuevo ideal parece provenir de las agencias de empleo. Dentro de las universidades, la extensión tipo de contrato de trabajo es bastante breve, y los investigadores tienden a pasar mucho de su tiempo escribiendo (y leyendo) solicitudes de ayudas. Hay cada vez menos razones para publicar en las revistas en las lenguas nacionales: esto tiene impacto sobre todo en las comunidades y disciplinas científicas específicamente relacionadas con la cultura local y los fenómenos locales (Koskinen 2016). Por estas razones, el Manifiesto resonó mucho con mis experiencias personales, pero al mismo tiempo existían algunas diferencias significativas.

Comparada con muchos países europeos, la educación superior en Finlandia se encuentra todavía en un buen estado. Incluso aunque los niveles de financiación para estudiar hayan decrecido muy notoriamente en los últimos años, no hay que pagar tasas de matrícula por parte de los estudiantes nacionales en su educación universitaria. En Finlandia, como en otros países nórdicos, las universidades reciben la mayor parte de su financiación del gobierno central. Incluso aunque las universidades se enfrentan a presiones para encontrar nuevas fuentes de financiación, han emergido muy pocas acciones nuevas de este tipo, exceptuando las universidades de tipo técnico. Mi visión personal es que en estos momentos, los políticos y la gente que trabaja en transferencias tecnológicas quieren presentar estas iniciativas empresariales como algo que los investigadores "deberían" considerar interesante para llevarlo a cabo. En la práctica, sin embargo, la mayoría de los investigadores de las ciencias y disciplinas "no aplicadas" prefieren seguir con su investigación normal, con su docencia, y con las actividades de alcance social general. En este sentido, la estimación del Manifiesto de que los países nórdicos siguen siendo todavía más públicos que ocupados, es cierta.

Incluso aunque las universidades nórdicas sean financiadas con el dinero público, y los estudiantes no tengan que pagar carísimas matrículas, eso no implica que la comunidad universitaria sea pública en un sentido amplio. El concepto de lo público, tal y como implica la palabra latina populus, abarca en ella al "pueblo". Las universidades no solamente son escuelas que tienen que formar a jóvenes con capacidades adecuadas y orientadas al trabajo. Las universidades son también comunidades so-

13 Anita Välikangas es Investigadora predoctoral en la Facultad de Ciencias Sociales de la Universidad de Helsinki. Realiza actualmente su tesis doctoral sobre la Conexión entre investigación científica y Políticas en la Academia del Finland Centre of Excellence in the Philosophy of the Social Sciences (TINT).

anita.valikangas@helsinki.fi. 
ciales, y para cumplir propiamente su responsabilidad, deben atraer y retener a investigadores con talento. Como hemos mencionado antes, el trabajo de los investigadores universitarios en Finlandia es bastante breve, de solamente unos pocos años. La competición es dura a todos los niveles. En las Humanidades, la ratio típica de aceptación para un investigador de Doctorado en sus solicitudes de ayuda es de en torno un 10 a un $20 \%$, y definitivamente no mejora en estadios posteriores de la carrera. Cuando las oportunidades de investigar a tiempo completo son tan limitadas, muchas personas solo sueñan con la estabilidad financiera. Un típico escenario es una persona que pasa un periodo de varios meses o incluso hasta un par de años en un proyecto de investigación, y luego, en el mejor de los casos, pasa a otro proyecto. Lo que permanece constante es la necesidad de buscar nuevas ayudas y un sentido de vulnerabilidad que no desaparece. Esta situación no ayuda a crear unas buenas comunidades científicas o lugares donde la enseñanza sea real.

El año pasado fue especialmente malo para las instituciones de educación superior en Finlandia y Dinamarca. En Finlandia, el gobierno decidió recortar la financiación para la investigación en 600 millones de euros para los próximos cuatro años. En Dinamarca, la situación era igual de negra: se dieron los mayores recortes en el presupuesto de educación de la historia de este país, en el 2016. Estos recortes sumaron un total de 8,7 billones de Coronas Danesas (1,17 billones de euros), un dos por ciento del total del presupuesto de educación (Bothwell 2016; 2017). Recortes de estas dimensiones conmocionan la confianza de la gente y a las comunidades. La Universidad de Helsinki confirmó que recortaría personal en 1000 empleados al final de 2017, y más de 500 miembros de la Universidad de Copenhagen fueron despedidos (Grove 2016).

Los inviernos del Norte son típicamente sombríos. Y para luchar contra esa oscuridad, mucha gente ha desarrollado un sentido del humor negro. Si ha habido algo positivo en el año pasado, ha sido que no ha costado mucho esfuerzo encontrar chistes con este asunto. Para mí, ocurrió en mi primera visita a la recién renovada Biblioteca Nacional finlandesa. Renovada antes de los recortes, el edificio resultaba espectacular, pero cuando paseabas en los solitarios pasillos, parecía haber allí muy poco personal. Cuando buscaba algunos textos, di con un libro interesante. Sin embargo, al abrirlo, se desgajó en pedazos, y estaba en tal estado que no podía tomarse en préstamo. Llevé el libro al mostrador de información. La persona allí sentada parecía la única presente en todo el edificio. Miró el libro, y dijo "Lo siento, no puedo hacer nada. La persona responsable de reparar los libros ha sido despedida", dijo. El libro trataba sobre el ideal en las universidades, era una defensa de la universidad escrita en 1950.

Sin embargo ha habido momentos de éxito. Por ejemplo, al final de 2016 las negociaciones entre los institutos de investigación y educación superior de Finlandia y Elsevier and Wiley han permitido un acuerdo en el que tendremos acceso a todas las publicaciones electrónicas durante un año más (Tiedonhinta.fi 2016). Al menos hasta ahora, no necesitamos decidir qué hacer cuando no tengamos acceso a estas publicaciones editoriales. Pero también ha habido cosas horribles. Mucha gente se ha encontrado repentinamente sin empleo, y casi todo el mundo teme ahora que eso les ocurra. Los despidos se ejecutaron con crudeza. ¿Cómo va a ser leal alguien a una institución que lo trata de tan mala manera?

Hasta ahora, se desconoce qué pasara en el futuro. Muchas personas han decidido no esperar a que llegue. Hay signos de una severa fuga de cerebros en Finlandia, que señalan una catástrofe para la investigación finlandesa (Bothwell 2017). Los desti- 
nos típicos de los que se van son Suecia, Noruega, Alemania y Reino Unido. Personalmente, conozco a alguna gente que ya se han mudado o están pensando en ello. La movilidad internacional es normalmente algo positivo, pero lo desafortunado ahora es que no llega nadie a reemplazar a los que se van, hay muy pocas plazas que rellenar. No me sorprendería que resulte que los recortes hagan crecer el favoritismo en la academia. Estos aspectos, igualmente, significan que las oportunidades son cada vez menores para quienes provienen de grupos no privilegiados, para conseguir una plaza en la universidad.

En los asuntos concernientes al futuro, mi bola de cristal no es capaz de proporcionar una predicción $100 \%$ ajustada. No me sorprendería, sin embargo, si somos testigos en el futuro de la introducción de más firmes estrategias públicas nuevas orientadas al gerencialismo, y una más firme separación entre poder y ejecución. En Suecia, Mats Ericson, presidente de la Asociación Sueca de Profesores Universitarios (SULF) mostraba su preocupación por la desprofesionalización de la enseñanza y la investigación, y por las presiones para incrementar la financiación externa en las universidades del país (Ericson 2016).

Hasta donde sé, una descripción completa nos diría en qué áreas de investigación se produce una mayor afectación de los recortes en Dinamarca y Finlandia, y esa descripción no existe. Hasta ahora, solo hacemos adivinaciones cabales, y estimamos que los recortes probablemente han afectado más a las disciplinas más pequeñas y los proyectos pequeños, y que han dejado las áreas alineadas con las "prioridades estratégicas de las universidades" en mejor situación. En las universidades finlandesas, una gran parte de los recortes se dirigieron al personal de apoyo, un número sustancial de los cuales se consideraron innecesarios y sus contratos de trabajo fueron eliminados.

Previamente, en mi propia universidad, el personal de apoyo administrativo trabajaba en los Departamentos, a menudo eran personas con formación y habilidades investigadoras en las disciplinas a las que apoyaban. Ahora todos se han desplazado a una unidad central. Por ello, muchas cuestiones prácticas, como por ejemplo la información sobre páginas web, reserva de aulas, información a los estudiantes sobre cursos disponibles, requieren un considerable esfuerzo nuevo del personal docente e investigador. Previamente, el personal de apoyo administrativo se reunía en las cafeterías o para el almuerzo. Ahora se reúnen sobre todo para implementar tareas de comunicación de trabajo. Cuando el personal de apoyo está separado de los investigadores y docentes, o cuando la gente con beca no tiene despacho en un departamento, es quizás una cosa normal que no se sientan como parte integral de la universidad. Para la dirección, esto es cosa buena: los individuos aislados pueden ser controlados más fácilmente que los grupos. Con las adecuadas técnicas de gerencia eficiente, no tardarán muchos años en destruir el ideal de la colegialidad.

En una primera mirada, la idea de reaccionar al Manifiesto Académico desde la perspectiva nórdica parecía bastante fácil: hay muchas similitudes. Sin embargo, es difícil escribir sobre la evolución en todo el área del Norte. Las universidades y los gobiernos de universidad están cambiando actualmente a todos los niveles. Hay cambios en las disciplinas individuales, en los niveles de facultades y universidades, y hay diferencias entre países. Los cambios afectan a mucha gente, pero es difícil comunicarse entre sí en esos niveles diversos y oponerse a los desarrollos. En Finlandia, los recortes en los presupuestos han tenido impactos que han distorsionado la comunidad universitaria y que están disminuyendo el ideal de una comunidad colegiada. "Todo el mundo se juega mucho, si se queda solo buscando la excelencia y no 
interviene en el proceso administrativo", afirma Bill Readings (1997:33). Nos hemos quedados solos, como unidades aisladas. No es fácil luchar contra el proceso, pero merece la pena intentarlo. Creo que requerirá el apoyo activo de las comunidades universitarias, en las que el elemento en común es algo más que la competición constante y las divisiones estrictas entre grupos de personas.

\section{Referencias}

Bothwell, E. 2016. "Nordic Higher Education in Decline? The Region's Reputation for Excellence Could be Threatened by Funding Cuts and Restructuring." Times Higher Education, September 15, 2016. https://goo.gl/VxXYpg.

Bothwell, E. 2017. 'Finland Funding Cuts a 'Catastrophe' for Research: Scholars Fear Reputation of Country's Higher Education Sector will be Damaged as Evidence of Brain Drain Mounts." Times Higher Education, January 17, 2017. https://goo.gl/VcZtMv.

Ericson, M. 2016. "Academic Freedom Increasingly Restricted.” Accessed April 102017. http://sulf.se/en/leader/akademiska-friheterna-begransas-alltmer.

Grove, J. 2016. "University of Copenhagen to Cut More than 500 Jobs." Times Higher Education, 11 February 2016. Accessed April 10, 2017. https://goo.gl/cUxwRb.

Koskinen, I. 2016. “Objektiivisuus humanistisissa tieteissä” [Objectivity in humanities]. Niin et Näin 4: 35-42.

Readings, B. 1997. The University in Ruins. Cambridge: Harvard University Press.

Tiedonhinta.fi. 2016. "The Cost of Scientific Publications Must Not Get Out of Hand. Accessed April 10 2017. http://tiedonhinta.fi/en/english/. 


\section{Activismo contra acritud: sin mejoría pero más allá del marco de excelencia investigadora en Inglaterra}

Richard Watermeyer ${ }^{14}$

La inevitable rendición de los académicos -tanto en deferencia como por oportunismo- a la cultura de la excelencia en las universidades del Reino Unido es algo ya muy confirmado, como ha mostrado, muy reveladoramente, y paradójicamente con gran complicación, la transición desde la última evaluación nacional de resultados de investigación, denominada el Marco de Excelencia Investigadora (REF) de 2014, a su sucesora en el futuro, el REF 2021. Rectores, aspirantes a rectores, vicerrectores, decanos, jefes de departamento, directores de investigación, ejecutivos expertos en impacto y otro personal administrativo variado que puebla las universidades inglesas, no hace otra cosa que enviarse mensajes agitadamente porque en menos de 4 años deberán estar listos para su presentación ${ }^{15}$ institucional, y es que todos los académicos "elegibles" para ser aceptados en el REF 2021 -que de acuerdo con el consejo dado recientemente por la revisión Stern sobre el REF 2014 debe incluir a todo el personal "activo en investigación"- deben concentrar su atención absolutamente en conseguir que sus publicaciones y sus casos de estudio de impacto estén preparados para dicha inclusión en el REF. El REF es, junto con su hermano pequeño y menos prominente Marco de Excelencia Docente (TEF), el único juego al que se juega actualmente por aquí. Y vaya con el juego.

Para los que están al tanto, el REF es el sistema mediante el cual se evalúa toda la investigación financiada públicamente en las universidades inglesas por parte de paneles de expertos académicos y de asesores. Es la vara con la que se miden investigadores e instituciones que, afiliadas al mismo, se consideran personas u organismos de excelencia investigadora y que, por lo tanto, merecen una rodaja más grande, según sea la medida de sus resultados, de la financiación "Ajustada a la Calidad" del Gobierno (QR); se estima que aproximadamente 2 billones de libras anuales se manejan aquí para el sector de la educación superior. El REF, por lo tanto, es muy importante en los contextos binarios y de co-información para 1) la sostenibilidad de las universidades y 2) para la reputación institucional, el prestigio y la imagen comercial de las mismas. Su valor para las universidades inglesas es por ello incalculable. Por eso "en investigación, no hay más que el REF".

En un contexto así, quizás no es una sorpresa que todo tipo de tácticas, trucos y palancas de ventaja competitiva se produzcan y se denuncien en las universidades, porque estas hacen uso de las mismas para asegurarse de que la investigación que presentan al REF es la más competitiva, y consigue de los panelistas del REF la más favorable respuesta, y con ello los más generosos subsidios (QR) (Ajustados a Calidad). En el contexto del REF 2014 se jugaron varios juegos en las universidades; el más notorio de ellos quizás es el de la hiper-selección en la elección del personal académico en las instituciones, y los números de los excluidos en este sentido son realmente para echarse a temblar. De un total potencial de 145.000 académicos ele-

14 Richard Watermeyer es Profesor en Educación en la Universidad de Bath, UK. Es Sociólogo de la Educación (conocimiento, sciencia y pericia) y se especializa en Políticas de la educación, Práctica y Pedagogía. Específicamente trabaja sobre Sociologías Críticas de la Educación Superior y una nueva conceptualización de la praxis académica, así como en el papel actual y futuro de la universidad (pública) en el contexto de la marquetización, globalización y neoliberalización de la Educación Superior.

15 La fecha concreta de presentación todavía no está decidida. 
gibles para ser evaluados y aprobados por el REF, solamente 50.000 fueron aceptados, y 95.000 académicos fueron considerados no aptos para ser evaluados en el contexto de su potencial excelencia. En su lugar, se implementó una política de picotear la cereza mejor.

A mi juicio esto implica dos cosas. En primer lugar, que dos tercios de los investigadores universitarios de Reino Unido no tienen ningún respeto en sus instituciones de base. En segundo lugar, que la noción de excelencia articulada por el REF es más fatua aún de lo que parecía al principio - se basa en una presuposición aclamada y a priori sin ningún significado, del término "excelencia"-. Dicho con crudeza, y como sea que uno valore la noción de excelencia, lo que se hizo en el REF 2014 fue simplemente una selección parcial y muy estrecha de los resultados de los investigadores académicos británicos en un inmenso, carísimo y auto-cumplidor (y blindado) ejercicio que únicamente confirmó a los que ya se reputaban como excelentes en sus instituciones por parte de los panelistas de las comisiones del REF. Como resultado, el REF es atacado porque resulta ser una limitada demostración de fuerza de la investigación del país y con ello lo que está generando es una marginalización y encapsulamiento de amplísimas áreas de la comunidad académica, cuando lo que había que haber hecho, de acuerdo con la revisión Stern, es someter a evaluación toda la actividad investigadora, es un esfuerzo genuino para paliar, si no erradicar, los venenosos efectos sufridos por las "filas y columnas" académicas en un sistema tan agresivo como egregio, de gestión y auditabilidad de los resultados.

Cuando se recomienda que universalmente se presenten todos los resultados a evaluación no es quizás más que un sistema menor para intentar reducir o aplacar lo que muchos perciben como una castración de la autoridad académica y de la soberanía autónoma de los científicos a la hora de valorarse a sí mismos, en la intensificación del control y la regulación gerencialista del gobierno. Pero se hace de una manera sutil, y como a escondidas, diciéndoles a los académicos "Os podéis presentar todos". No podemos evitar recordar que esa recomendación opera como el gran sociólogo emigrado Herbert Marcuse (2002) describía la "desublimación represiva", en un espejismo de democracia participativa -si los académicos se sienten implicados en algo, seguramente lo aceptarán muy felizmente-. No es tan raro, así, que lo que se critica del REF tiene menos que ver con cómo entra en conflicto o corrompe el ideal ilustrado de ciencia, o de universidad humboldtiana, y en cambio más con el hecho de que niega a los académicos la oportunidad de participar en este juego.

He sido uno de los críticos que más intensamente ha pedido mayor inclusividad y participación equitativa de los académicos en el REF. Pero ahora estoy convencido de que dicho punto de vista es muy estrecho, que es reductivo y que nos distrae del verdadero contexto en que el sistema funciona. Quizás, de hecho, he sido víctima del tipo de mesmerización cuantitativa, el mismo acerca del cual frecuentemente prevengo a mis estudiantes y a mis compañeros- que reflexiona convincente y conclusivamente sobre el argumento de la no participación. Ahora, en cambio, cuando vuelvo a pensarlo, me doy cuenta de que el argumento contra el REF se ha enmarañado excesivamente, y se ha visto disimulado, con el asunto de la participación desigual.

Aunque no se puede negar que la no participación en el sistema REF 2014 ha sido perniciosa para la fábrica social de la academia, quizás es cierto que por un erróneo sentido de la colegialidad, de la ciudadanía y de la comunidad hemos abogado por 
una mayor participación de los académicos y hemos criticado exclusivamente esa no participación, aceptando implícitamente el compromiso con el sistema, y no la independencia del mismo. Además, la crítica, que en gran medida es una victimización, ni se ha desarrollado ni ha progresado. Ciertamente, no se ha traducido en ningún activismo sustantivo o significativo. Se ha centrado en observar lo que el REF hace a los académicos cuando los pone en cuestión o compromete su identidad y sus prácticas, de modo que la comunidad académica ha perdido ostensiblemente su visión para llegar a generar cambios positivos. En vez de esto, los académicos han preferido privilegiar la patologización de su profesión y de un modo cómplice se han inmovilizado ante la homogeneidad -en gran parte en el carácter indirecto -de su (pseudo) desaprobación. Sin duda la maldición del REF es algo que algunos académicos juzgan bello, e incluso perversamente, parecen disfrutar de ello, como una "legitima" oportunidad con la que lamentarse de su suerte y caer, masoquistas, en una nostalgia de épocas doradas que jamás fueron realidad.

Como objeto de su desafección, que aman y odian a la vez, el REF también representa el reproche a sus detractores, pues se detecta en su diatriba y en sus mitologías, no el grito de injusticia, sino el gemido del narcisista. Por supuesto, los críticos pueden explicar y defender esa casi ritual insatisfacción académica, basada en la cada vez mayor precariedad de los académicos en la era de la neoliberalización de la educación superior. Las universidades han rendido su estatus y su papel como santuarios de pedagogía crítica y han permitido, parece que con poca resistencia, la desprofesionalización y la despolitización de su comunidad académica, y ahora tienen que enfrentarse con el imposible desafío de reconciliar exigencias cada vez mayores de resultados con una cada vez menor autonomía. La co-emergencia de su sumisión, y de sus quejas, es quizá, por ello, aunque profundamente nostálgica de un ideal del deber académico, completamente inevitable.

Por tanto hay que poner en duda si insistir en la participación en el REF es el tema central o debe dejarse de lado. Es precisamente esa estrechez de miras la que ha convertido al REF en algo normalizado y hasta legítimo, por la incapacidad de un comentario crítico no distorsionado o embotado, incapaz de hacer otra cosa que ubicar al REF en el control de las vidas de los académicos británicos. Quizás el narcisismo se consolida y se exacerba con ese sistema, en la plaga que A.H. Halsey (1995) denominaba "la dominación erudita" y cuya percepción desde el exterior ha generado la desconfianza y ha justificado implementar este tipo de tecnologías de control público, diseñadas para instilar orden entre los académicos, como si fueran una bandada de gatos. Por ello, nos topamos con la "sumisión académica" al REF, tan ambivalente y dicotómica. Se lleva a cabo con un afectado desdén. El REF, en último término, revela quizás una tendencia, una actitud entre los académicos, que desean ser medidos en lugar de hacer lo que es inconmensurable.

La virtud del REF como oportunidad para los académicos de representar la medición de resultados es ampliamente criticada. Es un sistema gruesamente imperfecto que alimenta una multitud de conductas indeseables que a su vez causan la negligencia de los fines y funciones de la universidad como institución genuinamente pública. Sin embargo, los académicos no deben hacer muchos aspavientos con sus imperfecciones; más bien, deben empezar a valorarse a sí mismos. Si el REF es lo que otorga su identidad a los investigadores académicos del Reino Unido, éstos deben mirarse en ese espejo para coger impulso hacia el cambio. Si lo que ven en él no les gusta, solamente la trasgresión directa y activa de las reglas del juego 
puede producir una identidad que no sea la que ostensiblemente se esconde tras él. Es muy fácil decirlo y muy difícil hacerlo, desde luego. Pero sin duda algo hay que hacer.

\section{Referencias}

Halsey, A.H. 1995. Decline of Donnish Dominion. Oxford: Oxford University Press.

Marcuse, H. 2002. One-Dimensional Man. Oxford and New York: Routledge.

Stern, N. 2016. "Building on Success and Learning from Experience: An Independent Review of the Research Excellence Framework." https://goo.gl/StCAKi. 


\section{El manifiesto académico: la situación en los territorios flamencos}

Koen Bogaert, Valerie De Craene, Anton Froeyman, Karen Stroobants, and Sigrid Vertommen $^{16}$

En general, diríamos que a pesar de algunos matices o aspectos diferentes, la situación descrita en el Manifiesto Académico se aplica a los territorios flamencos como lo hace a Holanda. Desde el establecimiento del Acuerdo de Bolonia (2008), un plan político que planteaba crear un espacio de Educación Superior común y estandarizado, el panorama de investigación flamenco ha cambiado dramáticamente. Sin duda, como menciona el Manifiesto Académico, el argumento lógico de fondo es que no se puede confiar en las universidades. Así, la compartición de los fondos (competitivos) en sus montos segundo y tercero se fue haciendo más dura, en tanto el primer monto de financiación (la directa ayuda para las universidades) se reorganizó en un sistema competitivo, en el que las universidades debían luchar ${ }^{17}$ entre sí para conseguir financiación. Las armas con las que esa lucha debía sostenerse son parámetros de resultados cuantitativos, como el número de créditos ETCS impartidos, el número de doctorados conseguido, el número de publicaciones en revistas indexadas en la Web of Science, el número de citas en dichas revistas, etc. Desde entonces, las universidades están en una continua batalla por conseguir más dinero para ellas, y (por supuesto) menos dinero para las otras universidades. Esta lógica fue copiada por las universidades en un modelo interno, de manera que las diversas facultades de una misma universidad debían "luchar" cada una de ellas contra las otras por dinero, y muchas facultades imitaron este modelo en su interior para distribuir los presupuestos entre los distintos departamentos.

Así, esta lógica financiadora ha penetrado en toda la academia: las decisiones de contratación se basan casi únicamente en el dinero que pueden atraer (en forma de becas, de becas de doctorado, de publicaciones, citas, y demás), lo que determina fuertemente los tipos de conocimiento que se producen: la investigación de vanguardia, o la investigación cuyos resultados no son claros, se evita, mientras prevalece la investigación fácilmente publicable, incluso aunque la calidad sea mediocre, o las ideas no originales. El tipo de conocimiento que se produce en las universidades no es (o no es ya) el tipo de conocimiento que parece más interesante a los investigadores, o que es más beneficioso a la sociedad, sino el que sirve mejor a los intereses de quienes hacen o financian la política académica. Hablando en general, se ha extendido la idea de que la investigación académica, la educación o el servicio público no son nada más que medios para conseguir un bien mayor, que es más dinero para los departamentos/facultades/univer-

16 Koen Bogaert es Investigador postdoctoral en el Middle East and North Africa Research Group de la Facultad de Ciencias Políticas y Sociales en la Universidad de Gante, Bélgica. Valerie De Craene es estudiante de Doctorado en la división de Geografía y Turismo del Departamento de la Tierra y Ciencias Medioambientales de la Universidad de Leuven (Lovaina) en Bélgica. Anton Froeyman es un académico retirado (ahora ejerce de consultor académico libre), que hasta 2016 trabajó como Investigador Postdoctoral en el Centro de Lógica y Filosofía de la Ciencia en la Facultad de Artes y Humanidades de la Universidad de Gante. Karen Stroobants es Investigadora post-doctoral en el Centro de Enfermedades de Deformación de la Proteína en el Departamento de Química de la Universidad de Cambridge y anteriormente fue doctoranda en el Departamento de Química de la Universidad de Lovaina. Sigrid Vertommen es Asistente a la Docencia del Grupo de Investigación sobre Oriente Medio y África en la Facultad de Ciencias Políticas y Sociales de la U. de Gante en Bélgica.

17 El dinero que reciben las universidades se divide en diferentes "montos". El primero son donaciones directas del gobierno a las universidades. El segundo consiste en financiación competitive desde su base para investigadores individuales (p.ej. becas), y el tercero lo forma dinero que proviene de los proyectos indicados desde el poder (por el gobierno o la industria), y existe un cuarto monto (que en los países flamencos es el más pequeño con diferencia) y que se basa en donaciones a la universidad por parte de personas (por ejemplo alumni con dinero, etc). 
sidad. Las actividades que no generan dinero (como las conferencias o los artículos para el público general, la colaboración con las ONG o con los museos) se consideran una pérdida de tiempo. Esta situación empeora porque las universidades también tienden a gastar más y más dinero en publicidad, en administración empresarial, en comunicación y en proyectos inmobiliarios, en lugar de en docencia o en investigación. En este sentido, de nuevo, estamos de acuerdo con el Manifiesto Académico: la academia en el área flamenca se basa en la idea de que los académicos no son de fiar, de que se les debe controlar muy de cerca mediante los indicadores cuantitativos, y de que deben estar bajo una continua amenaza de perder su empleo, si se desea que consigan algo en absoluto.

Una cosa notoria es la estructura específica de personal de las universidades flamencas. Desde la introducción de la exención de tasas Dehousse para estudiantes de doctorado (en 1993), el número de doctorandos ha subido espectacularmente, de menos de 3.000 en 1993 a cerca de 10.000 en 2015. En cierto sentido, las universidades han utilizado la exención de tasas a los doctorandos del mismo modo en que las multinacionales envían sus fábricas a países de bajos salarios: es un modo de contratar a más empleados sin tener que gastar un dinero extra. La situación ha ido a peor por el hecho de que las universidades consiguen un bonus (de en torno a 50.000 euros) por cada Doctorado conseguido. Por supuesto, esto crea un incentivo para captar al máximo de alumnos de doctorado posible. Esto tiene dos consecuencias negativas.

La primera es que la calidad, y por tanto el valor, de un Doctorado está cayendo de manera constante, pues las universidades no tienen ningún interés en impedir que los estudiantes obtengan dicho grado. La segunda es que hay muchas oportunidades para doctorarse en el área flamenca, pero muy pocas posibilidades para los doctores, de integrarse en la universidad. Quienes hacen estas políticas replican que un doctorado debería proporcionar sus habilidades superiores al mercado de trabajo. Aunque esto suena en teoría muy bien, la práctica concreta de la trayectoria de los doctorandos es muy diferente. En primer lugar, los profesores tienen (debido al alza en los números de alumnos, el número de doctorandos y el incremento dramático del tiempo dedicado a la burocracia de solicitud de ayudas o becas) menos tiempo cada vez para enseñar realmente a los estudiantes de doctorado. En segundo lugar, las universidades, departamentos, y facultades solamente reciben dinero por sus resultados académicos en sentido muy estrecho (publicaciones, citas y doctorados). Por ello, nada que no conduzca directamente a uno de estos resultados (por ejemplo, invertir en transfrencia de habilidades, o en redes de cooperación fuera de la academia) es visto a menudo como una pérdida de tiempo.

Mientras tanto, el número de profesores en 2017 es virtualmente el mismo que había en 1993. Dado que los números de estudiantes de doctorado, de master o de grado, ha subido espectacularmente, en combinación con la siempre creciente necesidad de solicitudes burocráticas de financiación o de hacer otras tareas administrativas, los profesores sufren una enorme carga de trabajo, y están bajo una presión anormalmente alta.

Una diferencia importante con Holanda es que las universidades flamencas son dirigidas (en gran medida) por académicos, o para ser más precisos, por antiguos académicos, que pasan de la carrera de profesor a la de gestor en la administración universitaria. Sin embargo, ello no ha impedido la proliferación de la ideología de la Nueva Gestión Pública, como se vio rápidamente claro cuando estos académicos asumieron el modo de pensar absolutamente gerencial en términos de cuantificación, resultados mensurables, y "eficiencia" en su gestión.

Otra importante diferencia es la implicación de los estudiantes en las protestas contra la nueva gestión empresarial pública neoliberal en las universidades. En lu- 
gares como Reino Unido u Holanda, los estudiantes constituyen la fuerza de impulso y el grueso de las protestas del poder del pueblo (de hombres y mujeres). En la zona flamenca, sin embargo, los estudiantes y las asociaciones oficiales estudiantiles (por ejemplo la VVS, Sociedad Flamenca de Estudiantes) están muy notoriamente ausentes: protestan cuando les afecta una medida concreta a corto plazo, (por ejemplo la subida de tasas de matrícula o la obligatoriedad de un examen de ingreso) pero en la mayoría de los casos (con notables excepciones, como los estudiantes de Humanidades de Gante) parecen estar más o menos de acuerdo con el discurso general oficial de la nueva visión gerencial. La razón para ello es -paradójicamente- que los estudiantes tienen desde hace mucho tiempo voz institucionalizada en los debates sobre educación superior. Por ello, parece que estar en contacto con el establishment durante tanto tiempo los ha convertido efectivamente en parte del mismo.

Por último pero no menos importante, necesitamos prestar atención a la brecha de género en las universidades flamencas. A pesar del hecho de que la mayoría de los estudiantes de doctorado son mujeres, hay una gran brecha en lo que se refiere a las plazas académicas universitarias. El porcentaje de académicas en las posiciones más elevadas (hoogleraar) es uno de los más bajos de Europa. Por ello, en las universidades flamencas, son numerosas las redes de "amigotes" y la universidad neoliberal a menudo se da la mano con la cultura machista. Existe cierta consciencia sobre este tema: la "huelga de mujeres" en la Universidad de Gante en la primavera de 2017 recibió mucha atención y hemos visto la llegada de la primera mujer rectora desde hace mucho tiempo. Sin embargo aún hay mucho por hacer.

\section{Las afirmaciones del Manifiesto}

Estamos muy de acuerdo con el mensaje general del Manifiesto Académico: hay algo realmente malo en la universidad del siglo XXI, y los Lobos de mil cabezas de la administración gerencialista, de la eficacia, de la cuantificación y la mensurabilidad son los más importantes piélagos que se abren ante nosotros.

Sin embargo, dudamos de algún modo en compartir las expectativas del Manifiesto, de un cambio en las estructuras de decisión formal. Entendemos que, desde el punto de vista de Holanda, parece ser esa una buena solución. Sin embargo, en teoría, las universidades flamencas tienen un tipo de estructura semi-democrática: el rector y vice-rector (que tienen que ser ambos catedráticos) y los miembros del Consejo de Gobierno, se eligen por la comunidad universitaria mediante un tipo de sufragio ponderado (en el que los votos de los catedráticos cuentan mucho más). Este sistema, empero, no ha sido capaz de detener o combatir al lobo del mil cabezas gerencial. En la práctica, los académicos electos siempre parecen volverse cómplices del Lobo en cuanto se sientan en el despacho directivo. Y si no lo hacen, siempre hay fantasmas gerenciales no elegidos en el trasfondo y en los pasillos de la administración que a menudo consiguen que la decisión se adecúe a las exigencias de los que hacen las políticas. Sin embargo, estamos de acuerdo con las recomendaciones que se hacen en el Manifiesto. Y hay una que deseamos añadir al conjunto: se trata de la precariedad en las situaciones de trabajo de los investigadores. La razón principal por la que los investigadores y docentes siguen apoyando el sistema es porque lo necesitan para mantener sus empleos, y competir con colegas en situaciones igualmente precarias. Por eso, deseamos introducir un porcentaje mínimo obligatorio de personal estable en la comunidad académica. La ratio puede diferir de un campo a 
otro, dependiendo de las opciones de los doctores en el mercado laboral (que son muy elevadas en Química, por ejemplo, pero bajas en Humanidades).

\section{Acción y posibilidades de cambiar la situación a mejor}

En el área flamenca, las reformas de Bolonia y las universidades gerencialistas que surgieron de ellas han sido constantemente criticadas desde que nacieron en la segunda mitad de la década del 2000. Grupos de activistas como el Slow Science Movement y el Actiegroep Hoger Onderwijs (Grupo de Acción en Educación Superior) han ayudado a hacer público este tema. Hasta ahora, sin embargo, nada ha cambiado, a pesar de muchas opiniones manifestadas, artículos, libros o investigación en el tema. Con todo, hay que decir que en algunas universidades flamencas han salido elegidos nuevos Rectores por sus programas que muestran signos de una voluntad de sacar a la luz y de tratar estos problemas que destruyen la universidad. Sin embargo, todavía está por ver si esas ideas y promesas se ponen en práctica.

En este punto, la cosa más importante que hacer es vigilar a esa nueva generación de directivos académicos: ¿pondrán el dinero donde dicen? Si no, habrá que tomar, como dice el Manifiesto, otro tipo de medidas. Una huelga sería sin duda una muy buena idea, y tendría una influencia decisiva. Sin embargo, no sería fácil organizarla, pues puede ser difícil movilizar a un suficiente número de investigadores individuales, en parte porque existe una visión individualista por parte de muchos investigadores, y en parte por el miedo a las repercusiones por parte del gobierno universitario. Otra acción posible parece ser una combinación de "sabotaje" y de "rechazo", por ejemplo mediante "huelgas de publicación institucional". Como hemos dicho, el gobierno flamenco ubica parte de su financiación a las universidades de acuerdo con las publicaciones en ISI, que usa para comprobar la filiación institucional de los académicos. Si los académicos dejan de mencionar su filiación institucional en sus $p a$ pers, y las instituciones se hacen invisibles en dichos índices, no podrán ser utilizados como referencias. Cada artículo que no cuenta supone pérdidas de miles de euros a la universidad. Esto daría a los Consejos de Gobierno mucho mayor incentivo financiador para mejorar la situación de los académicos. El mayor problema con este tipo de acción, además del obvio peligro de repercusiones por parte del gobierno universitario, es que los profesores temerían perder dinero para sus departamentos. 


\section{La Universidad Complutense de Madrid y el Manifiesto Académico: Rasgos comunes de una crisis global en la educación superior \\ Eva Vico ${ }^{18}$}

El Manifiesto Académico llegó a la Universidad Complutense de Madrid en primavera de 2016, en medio del anuncio de un gigantesco Plan de Reestructuración de esta legendaria universidad española, en el que se preveía eliminar 9 de las 26 facultades de este centro, una de ellas la Facultad de Filosofía, donde José Ortega y Gasset, el célebre filósofo, tenía su cátedra en los años 20 del pasado siglo.

En los intercambios de correos que tras el anuncio de recortes y reestructuración general se empezaron a producir entre los profesores, un titular de la Facultad de Geología, condenada a desaparecer, facilitó a los miembros de la "Plataforma para la Reestructuración en la UCM" una copia en inglés del Manifiesto, que decidimos traducir al español para que fuera accesible a toda la comunidad académica Complutense.

El proceso de reestructuración en la Universidad Complutense anunciado en 2016 era un terremoto organizativo y administrativo que ponía patas arriba la organización colegiada y escalar de este centenario centro universitario. Los objetivos del plan, con la reducción de facultades y de departamentos, eran recortar los gastos en personal administrativo y de gestión, y creando un diseño megalómano de universidad, economizar igualmente en profesorado de nueva creación. Una de las "ideas" de este Plan era crear una inmensa Facultad de Ciencias de la Salud que aglutinara las actuales Facultades de Medicina, Enfermería, Odontología y Óptica, en una institución que albergaría a más de 10.000 estudiantes.

El Plan anunciado para la Universidad Complutense se presentó como un plan académico cuya finalidad era racionalizar recursos y aumentar la eficiencia y excelencia de esta universidad, mediante la supresión de la estructura articulada de los Departamentos y Facultades. El Plan, lejos de todo posible objetivo académico, era en realidad la culminación de un vuelco hacia una filosofía gerencialista y competitiva de la universidad pública, dañada en España por la virulencia de la crisis económica, y sometida a una pérdida general de criterios y horizontes. El Manifiesto Académico vino a describir con total exactitud lo que estaba sucediendo y lo que iba a suceder en el futuro.

El rector electo de la Universidad Complutense en el año anterior a esta crisis se alineó con rapidez en las posiciones del gobierno regional de Madrid, de derecha conservadora, gobierno cuyas decisiones a lo largo de su largo dominio temporal en esta comunidad han supuesto recortes, falta de apoyos y un general descuido del valor y el peso de la Universidad Pública en el conjunto de las universidades de la zona. La estrategia del gobierno local, y del gobierno central de España, ambos en posiciones de derecha tradicional, has sido hasta 2018 favorecer a las universidades

18 Eva Aladro Vico es Profesora titular en el Departamento de Periodismo y Nuevos Medios de la Facultad de Ciencias de la Información en la Universidad Complutense de Madrid. Ha sido Directora del Departamento de Periodismo III hasta su desaparición en 2017. Es especialista en comunicación, información y nuevos lenguajes digitales. Ha publicado los libros Teoría de la Información y la Comunicación Efectiva (1998), Comunicación y retroalimentación (2000), La información determinante (2010) y Las diez leyes de la Teoría de la información (2015), así como artículos de investigación, entre los cuales los últimos publicados son "El lenguaje digital: una gramática generativa" (CIC 22) y "Los mapas, la vida digital y los mundos que descubrimos" (Telos 2018). Dirige el Grupo de Investigación Estructuras Comunicativas e Interacciones en los distintos niveles de la Comunicación. Es también escritora de poesía, bloguera y activista cultural. Encabezó la Plataforma para la Reestructuración en la Universidad Complutense en 2016. 
privadas y reducir el peso de las universidades públicas en los presupuestos del Estado.

El rector de la Universidad Complutense, ante la contestación inmediata de sus planes, inició un despliegue hacia la fabricación de un consenso que, hasta estos momentos, ha tenido un éxito muy relativo. En la Universidad Complutense una estructura colegiada en Departamentos, Juntas de Facultad y Claustro protege la autonomía universitaria de decisiones arbitrarias tomadas desde el Gobierno de la universidad.

La oposición de académicos y administrativos a la reestructuración en la Complutense adquirió la forma de un movimiento activista mediante redes y correos electrónicos, en la Plataforma por la Reestructuración en la UCM, que organizó cobertura de medios, manifiestos y comunicados, reuniones y acciones en la calle, con considerable éxito. El proceso fue noticia de primera página en diarios nacionales y TV's.

En el proceso de discusión, debate y argumentación en el que se implicaron muchos profesores, el Manifiesto Académico sirvió para ayudar al establecimiento de un clima crítico de opinión, para llegar a todos los profesionales de la universidad, y para mostrar cómo en amplias áreas de Europa se estaba viviendo el mismo proceso.

En el contenido del Manifiesto pudimos reconocer a nuestro propio Lobo gerencialista, los recortes, las maniobras de manipulación, los ataques a los disidentes y acusaciones de "deslealtad", y toda la degeneración previa del sistema cuantitativista de medición de resultados, la presión a la excelencia, el mal uso de los índices, etc.

Uno de los principales sindicatos de profesores (USO) se hizo eco de estas acusaciones y difundió el Manifiesto a toda la comunidad universitaria Complutense, de más de 20.000 personas entre todos los sectores. Los sindicatos jugaron un papel importante sumándose a las comunicaciones y manifestaciones, aunque posteriormente su silencio ha servido para facilitar el "plan oculto" de reestructuración pactada fundamentalmente con muchos decanos.

La situación a día de hoy (y actualizada en esta versión en español del Informe Internacional que traducimos para $\mathrm{CIC}$ ahora) ha evolucionado de una manera que no podemos calificar de negativa. De la supresión de 9 Facultades, en otoño de 2016 el Vicerrector de Planificación anunció que solamente se suprimirían 4. Finalmente, y a un curso de las nuevas elecciones a rector, no se ha suprimido ni una sola Facultad de las condenadas a desaparecer.

El proceso tomó una forma que es muy interesante describir aquí, actualizando los datos de este Informe internacional. Una vez que la estrategia de oposición culminó en hacer aflorar este asunto en medios y prensa, la posición de Rectorado fue doble: primero, intentar presentar una cara más amable en la opinión académica, suavizando los planes. Otra, comenzar negociaciones y pactos de los que ha surgido un "plan oculto" cuyo resultado ha sido la fusión de Departamentos, pero no la de Facultades, y un mapa de la organización departamental que no es el que deseaban desde el Gobierno de la UCM, aunque a nuestro juicio tampoco es bueno para esta universidad.

Pensamos que el problema que en este Informe Internacional se describe tiene un origen muy grave en la propia universidad y en su personal académico y administrativo. Como el Manifiesto Académico afirmaba, "divide y vencerás funciona porque todos lo aceptamos". La historia del Plan de Reestructuración Complutense es un ejemplo de cómo la satisfacción de determinados intereses, y la ambición de gesto- 
res, profesores, centros o grupos, puede ser el arma que esté dinamitando la estructura de la Universidad Pública.

Como en este mismo documento indican nuestros colegas Jozef Hvorecky, Emil Višňovsky, y Matúš Porubjak ${ }^{19}$ de Eslovaquia, es la autenticidad de la esencia universitaria la que está en juego y la que se pone a prueba en estos procesos de reestructuración. En el caso Complutense, hubo vergonzosas retiradas de Facultades del frente oponente al plan de desaparición de centros, una vez que negociaron su salvación con el Rectorado. Muchos directores y decanos negociaron blindando su facultad a cambio de una estructura interna que fusionaba departamentos no afines y dejaba intactos a otros amigos. Algunos académicos inauténticos apoyaron el plan desde sus inicios para conseguir situaciones de privilegio. En el caso de la fusión en la Complutense, la habilidad negociadora de determinados grupos, y sus buenas relaciones con el gobierno UCM, ha permitido que subsistan secciones departamentales de en torno a una decena de miembros, dotados de secretaria administrativa propia, con voz y voto en sus Juntas de Facultad, en tanto se obliga a los opositores a formar Departamentos de hasta 180 profesores perdiendo amplia representación en las Juntas y los puestos administrativos necesarios. En el caos de una comunidad donde en un momento determinado gobiernan profesores y gestores movidos únicamente por el interés propio y la falta de ética, es fácil adivinar que los resultados académicos no son buenos para nadie.

En la situación actual, el rector de la universidad afirma haber "culminado" el proceso de reestructuración. En realidad, el fallo organizativo y el posible comienzo de recortes y de nuevos repartos de docencia a grandes grupos no especializados, no ha hecho más que empezar. Los nuevos Departamentos, muchos de los cuales superan los 100 profesores, son sacos donde se ha optado por agrupar a todos los profesores y que ahora mismo no tienen apenas capacidad organizativa. Ahora mismo se computan sus horas de trabajo y se les otorgan plazas de acuerdo con su capacidad de cobertura numérica. Los Consejos de esos Departamentos no pueden celebrarse ni en un aula de enseñanza, porque los profesores no caben en ellas. Habitualmente acude una cantidad de profesores a estos Consejos que no llega al quórum mínimo. En muchos casos, empieza a traslucirse una distribución de poder menos equitativa que la anterior, mayores injusticias y sobre todo, una organización que vela mucho menos por la calidad de la docencia.

Como hemos visto en los ejemplos de los países nórdicos, la resistencia es posible. El peor daño que puede causar el proceso de la productivización de la universidad es el daño anímico y en la estima de la comunidad universitaria, que en estos procesos cae muy baja y pierde toda fuerza de resistencia. Los sistemas de medición de la excelencia son realmente deprimentes para todos, y perdida la estima institucional y el respeto por uno mismo, se pierde el poder de autocontrol y de auto-organización como nos enseñan los psicólogos. El caos y la indefensión son la prueba diaria de estos planes "culminados".

19 Jozef Hvorecky, Doctor en Filosofía, es Profesor en Informática en la High School of Management/City University of Seattle en Trenčín, Eslovaquia, y Profesor Honorífico en la Universidad de Liverpool, UK. jhvorecky@vsm.sk.

Emil Višňovsky, PhD, es Profesor de Filosofía en la Comenius University en Bratislava, Eslovaquia, e Investigador Senior en la Academia Eslovaca de Ciencias. emil.visnovsky@savba.sk. Matúš Porubjak, PhD, es Profesor Asociado de Filosofía en la Universida de Ss. Cyril and Methodius in Trnava, Slovakia. matus.porubjak@ ucm.sk. 
Como decíamos, a nuestro juicio el principal enemigo de la universidad es la propia comunidad académica. Es ella la que conforma los gobiernos universitarios, la que figura en las comisiones de evaluación, la que evalúa de manera injusta y la que calla cuando se le negocia un trato de favor o la que hunde a una facultad rival para conseguir un puesto más en el Consejo de Gobierno. El proceso por el que ya no se valora a las universidades públicas comenzó cuando falsos académicos ocuparon cátedras inmerecidas y cuando académicos sin espíritu universitario auténtico comenzaron a gobernar los centros públicos, inventando sistemas de medición y de organización adaptados a sus propias carencias.

En un país como España, asediado por problemas de corrupción, una cultura de impostores genera instituciones sin horizonte, o busca en el dinero y en la ambición la única satisfacción a una carrera ficticia. De ahí surgen los ránkings fatuos, las evaluaciones caníbales y la desigualdad e injusticia en la medición del auténtico valor académico.

Creemos que somos muchos, como demostró el Manifiesto Académico, los profesores e investigadores que, agrupados, podemos mover la opinión pública y sacar a la luz este grave deterioro de la función educativa superior. Simplemente despertar la conciencia de los investigadores ya es tener la batalla muy ganada. Porque hasta ahora el Lobo venía disfrazado. Pero si conseguimos quitarle el disfraz de calidad y excelencia, y mostrar sus verdaderos fines, habremos acabado con su base fundamental.

La universidad productivista se ha impuesto a partir de una mentira esencial, y una inconsciencia general: que el conocimiento y los descubrimientos se pueden forzar y fabricar, y que es posible acumularlos matemáticamente. La única forma de elevar el conocimiento y aumentar la innovación en sociedad es la inversión constante, estable y a largo plazo en investigación y enseñanza libres e independientes. Fingir que esto no es así, o ignorar que esas condiciones no se dan, es un suicidio social y económico.

El Manifiesto Académico, y este Informe de Respuestas Internacionales, no podrán ser pasados por alto en las próximas elecciones a rectores y decanos en la UCM o en las futuras revisiones críticas de los procesos de evaluación y acreditación a todos los niveles. Si conseguimos despertar la consciencia global académica al respecto de esta situación habremos ganado la mitad de la batalla. Podemos usar para ello las propias publicaciones científicas y los sistemas de cita y de comunicación internacional entre las academias. Por lo tanto, podemos decir que gracias al Manifiesto Académico, los trabajadores de las universidades del mundo estarán (en el futuro, y con la difusión científica y el eco internacional en las revistas adecuadas) por fin unidos.

\section{Referencias}

Halffman, Willem and Hans Radder. 2013. "Het Academisch Manifest: Van een Bezette Naar een Publieke Universiteit." Krisis: Tijdschrift Voor Actuele Filosofie (3): 2-18.https://goo. gl/ZV79Jp.

Halffman, Willem and Hans Radder. 2015a. "The Academic Manifesto: From an Occupied to a Public University." Minerva 53 (2): 165-187.

Halffman, Willem and Hans Radder. 2016. "Manifiesto Académico: De la Universidad Ocupada a la Universidad Pública." [In Spanish.] Translated by Eva Aladro Vico. https://goo. gl/VSEQp6 CIC Cuadernos de Información y Comunicación, 22, 2017). 


\section{Problemas en las universidades francesas}

Christophe Charle ${ }^{20}$

Los problemas actuales en la educación superior francesa están relacionados con dos factores complejos. Por una parte, están los desequilibrios heredados desde hace largo tiempo a partir de una historia de reformas sucesivas, que intentaban corregir problemas en su origen, pero que no atajaron la raíz de los problemas, pues fuerzas ideológicas, sociales y políticas han resistido la implementación de políticas demasiado radicales para ellas. Las crisis repetidas que han sufrido ciertos gobiernos desde 1968 son testimonio de esta obstrucción. Por otra parte, los intentos de reforma han enfocado los objetivos que parecían más fáciles de reformar (investigación, instituciones no universitarias) y han usado las contradicciones internas entre las universidades (conflictos entre disciplinas, rivalidades entre regiones, y entre París y las provincias) para introducir cambios deseados por el gobierno, intentos que jamás fueron discutidos realmente por la comunidad académica, con el fin de evitar crisis o confrontaciones entre ellos. Esta es la estrategia adoptada en particular por las mayorías conservadoras, que deseaban meter a Francia en la competición internacional universitaria y proteger a su sector de élite, ya fueran élites sociales, o élites de reconocimiento intelectual (las "políticas de la excelencia").

Desde 2002, durante la década de gobierno político conservador y en los cinco años de François Hollande, las oportunidades políticas se han reducido a un puñado de reuniones y a la financiación externa, que han sido insuficientes para cubrir las necesidades crecientes de los cada vez más elevados números de estudiantes admitidos, que demandan mejor educación y perspectivas profesionales. Además, las universidades se han reorganizado con el objetivo de obtener mejores posiciones en los ránkings internacionales, en los que muy pocas universidades francesas tienen posiciones prominentes. Los problemas heredados del pasado y su agravamiento por todos estos motivos, no han hecho sino acentuar la situación, con la depauperación de las universidades más pequeñas y el ensanchamiento de la brecha entre disciplinas y entre instituciones.

Esta es la "política de la excelencia", la nueva carrera de coches internacional que nunca se ha definido en realidad (¿excelencia en qué, y para quién?). Esta política no pone en cuestión los privilegios del sector de las "grandes escuelas" (grandes écoles) y acentúa las desigualdades sociales, de financiación y de carrera académica entre el sector "selecto" y el sector "no selecto" académicamente. Podemos identificar cuatro problemas recurrentes en la Educación Superior en Francia.

\section{Financiación desigual}

Hay una desigual distribución de los recursos que contradice el principio de democratización, y que se viene advirtiendo desde 1990: los que ya tienen, reciben más.

20 Cristophe Charle, nacido en 1951, estudió en la Sorbonne y en la École Normale Supérieure (Ulm); Es Investigador Senior en el CNRS (1978-1991); Profesor de Historia Moderna en Lyon y en Paris 1 Panthéon Sorbonne University desde 1993; Director del Institut d'histoire moderne et contemporaine en 2000-2013; medalla de plata del CNRS (2001); Miembro Senior del Institut universitaire de France (2003-2013). Presidente de la Asociación para la Reflexión sobre la Enseñanza Superior y la Investigación (ARESER) (http://www.areser.fr). Sus libros más recientes son Histoire des Universités con J. Verger. Paris: PUF, 2012; Homo Historicus, Paris: A. Colin, 2013; La Dérégulation Culturelle, Essai D’histoire des Cultures en Europe au XIXe Siècle, Paris: PUF, 2015; editor de la Histoire de la Vie Intellectuelle en France (XIXe-XXIe Siècle) con L. Jeanpierre, Paris: Seuil, 2016, 2 volumes. Este texto se ha traducido del francés inicialmente por Willem Halffman. 
La escalera social con peldaños rotos se confirma por las cifras de abandono académico y de desempleo en los diferentes Programas de Grado, pero no se ha tomado medida alguna para reorganizar el sistema. El fracaso en la movilidad social es la consecuencia exacta de las desigualdades estructurales que estas "políticas de la excelencia" generan.

\section{Especialización Prematura}

Como remedio al desempleo, se ha abogado por una elección prematura de especialización a la que se la etiqueta de "profesionalización", cuando en realidad, las sociedades modernas demandan más polivalencia y "flexibilidad", y movilidad profesional a lo largo de toda la vida. Mientras las universidades de otros países asumen la importancia de la formación continua para rehabilitar a los trabajadores mayores que son víctimas de carreras truncadas por el paro, en Francia este papel no se está cumpliendo bien -excepto en el caso del personal más cualificado, de tipo ejecutivo, que sí se beneficia de formación adicional, y al que se lo pagan sus propios empleados (y este tipo de perfil es el que aparece con frecuencia en las écoles)-.

\section{El Espejismo de los reconocimientos internacionales}

La obsesión con los ránkings internacionales (como el de Shangai) que por sus métodos son lo menos adecuado para medir con veracidad la eficacia de un sistema universitario, viene de una analogía mal concebida con los ránkings deportivos. Los ránkings universitarios se centran en "reputaciones" académicas internacionales, o en unas pocas disciplinas estandarizadas, como las ciencias naturales, y por ello priman las investigaciones realizadas en una serie de universidades enormes, que dominan el paisaje académico francés hoy en día. La innovación pedagógica, la adecuación de la universidad a su entorno local, o la capacidad de integrar a nuevos grupos y nuevos temas, se ignoran, porque esos ránkings usan unos indicadores fijamente establecidos en el pasado. Pero esas cualidades nuevas son las que realmente muestran el dinamismo de una institución, y no su conformismo con un ideal obsoleto dominado por criterios que son extraños a la educación.

\section{Pérdida de Independencia}

Esta obsesión ha sido sostenida por los gobiernos de derechas y de izquierdas y se ha arbitrado en políticas de reestructuración, que han generado entidades burocráticamente ingobernables, como la PRES (Polos de Investigación y Educación Superior) o la COMUE (Comunidad de Universidades e Institutos Universitarios). Todo ello ha agravado las desigualdades entre universidades en su capacidad para conseguir recursos externos, lo que ha llevado a déficits financeros o a una sujección administrativa total. El control se ha concentrado en grupos exclusivos y reducidos, lo que ha abolido de hecho el principio de la educación independiente y de la libertad pedagógica. Las prioridades las fijan los "sellos de calidad" internacionales y los ránkings, no las necesidades reales o lo que los profesores y los estudiantes requieren.

En suma, todo lo que las universidades consiguieron en 1968 o después de 1984 (las dos leyes anteriores para Educación Superior) está siendo abolido. Las reformas actuales benefician exclusivamente a una minoría de instituciones, de académicos, y 
de estudiantes. Los gobiernos de Francia rechazan evaluar estas políticas inadecuadas, que vienen fijadas desde el extranjero, y que han mostrado sus carencias y falta de pertinencia para resolver los problemas académicos franceses. 


\section{La lucha por la Universidad Pública en Holanda}

Willem Halffman y Hans Radder ${ }^{21}$

Muchas cosas han ocurrido desde que publicamos la primera versión holandesa del Manifiesto Académico en la revista de Filosofía Krisis (Halffman y Radder 2013; la versión inglesa se publica en 2015). Desde entonces, se ha levantado una importante ola de resistencia entre el personal académico y los estudiantes en Holanda: algunos grupos de protesta han publicado una marea de análisis críticos, organizado numerosos debates, y se han implicado en muchas acciones políticas. A resultas de toda esta actividad crítica, hay algunas mejoras menores, pero desafortunadamente muchas de nuestras objeciones a la colonización de la Dirección Empresarial de la universidad siguen siendo agudamente relevantes hoy. Vamos a revisar con brevedad las varias formas de protesta e iniciativas de reforma de los pasados años y a describir los cambios en los principales mecanismos y políticas desplegadas por el "Lobo" gerencial.

\section{Resistencia y Acción reformista}

\section{Movimientos críticos}

En el curso del año 2013, se alzaron dos movimientos críticos: el grupo Ciencia en Transición y la Plataforma para la Reforma de las Universidades Holandesas. El objetivo del primero son los excesos de la actual cultura de investigación, especialmente en las ciencias naturales y de la vida (Science in Transition 2017). El grupo ha organizado una serie de talleres y de conferencias, dirigidas en primer lugar a los académicos y a los gestores de políticas científicas. Su principal argumento es que la ciencia está demasiado obsesionada con la producción de artículos de investigación, a expensas de la relevancia social, pero no cuestionan los rasgos fundamentales del gerencialismo del Lobo. Sin embargo, su tono razonable, en relación con las políticas gubernamentales de la ciencia, y su bien surtida página web ha atraído la atención de muchos. La segunda iniciativa (en la que los dos estamos implicados) se dirige críticamente a un amplio espectro de problemas concernientes a la investigación, la educación, la organización, la administración y a cualquier función pública de las universidades holandesas (Platform H.NU 2017) desarrollando actividades variadas. Una de estas fue ofrecer una petición de reformas radicales de las universidades al Parlamento Holandés en 2014. Esta petición fue respaldada por 17 importantes organizaciones sociales, entre ellas diversos sindicatos, claustros universitarios y asociaciones profesionales. Esta estrategia más confrontacional y política despertó atención, pero su principal efecto fue indirecto: puso presión en aquellos que quieren cambiar desde dentro el sistema.

\section{Los Sindicatos}

Uno de los sindicatos más pequeños, la Unión de Científicos (VAWO) siempre ha dado apoyo a la defensa de las condiciones de trabajo de los académicos. Sin em-

21 Willem Halffman es Profesor en el Instituto de Ciencia, Innovación y Sociedad en la Radboud University de Nijmengen.W.Halffman@science.ru.nl.

Hans Radder es Profesor (Emérito) en el departamento de Filosofía de la VU Universidad de Amsterdam H.Radder@vu.nl. 
bargo, los sindicatos principales deben de cambiar su énfasis constante en temas tradicionales de trabajo (salarios, pensiones, empleo) a una crítica más sistemática de las estructuras generales y las culturas académicas que los imponen. En este momento, el objetivo de los sindicatos son los problemas de precariedad laboral y de presión en el trabajo, pero estos problemas no son contemplados como efecto de sistemas más amplios relacionados con la financiación de la investigación, la burocracia gerencial o la jerarquía administrativa. Los sindicatos han obtenido algunas concesiones menores mediante negociaciones laborales, como por ejemplo la concesión para empleados académicos de una modesta reducción del empleo precario.

\section{Protestas de estudiantes y personal}

Al mismo tiempo, el activismo estudiantil ha explotado. Se han dado algunas acciones de estudiantes y una ocupación en la VU University de Amsterdam. Siguieron una serie de ocupaciones más prolongadas y numerosas en el Maagdenhuis, el centro administrativo de la Universidad de Amsterdam, a comienzos del 2015. Con el ímpetu de dichas ocupaciones se creó la organización de protesta estudiantil The New University, así como el grupo reformista Rethink-UvA (2017) con profesores de esta universidad. Después, se dieron acciones significativas, tanto de estudiantes como de profesores, en otras universidades, especialmente en Groningen, Maastricht y Utrecht. Todos estos movimientos críticos encontraron una respuesta significativa entre profesores, personal y estudiantes, como se vio por ejemplo en las dos "Noches en la Universidad" que tuvieron lugar en Amsterdam en 2014 y en Groningen en 2015. Más generalmente, todos estos acontecimientos generaron mucha atención mediática, local, nacional e incluso internacional. Estos movimientos levantaron un interés adicional importante en torno a un tema que habíamos dejado de lado en el Manifiesto, para nuestra vergüenza: la llegada de la diversidad étnica, de género y cultural, como tema político en las universidades holandesas, especialmente en la más diversa parte occidental del país.

\section{El gobierno y los partidos políticos}

Mientras tanto, el gobierno lo formaba una coalición entre el partido de derechas y neoliberal VVD y el partido socialdemócrata y de "nueva izquierda" PvdA. El primero era el de mayor poder, pero el Ministro de Educación, Cultura y Ciencia era Jet Bussemaker, un socialdemócrata. Hablando en términos generales, la política científica e universitaria no es un tema popular entre los políticos y el predominio de la ideología neoliberal solamente empeora las cosas. Por ejemplo el único tema que se trató, ocasionalmente, durante la última campaña electoral en la primavera de 2017 , fue el sistema de créditos al estudiante que recientemente ha reemplazado el sistema de becas. Aunque inicialmente varios partidos reconocieron los problemas de la universidad actual y del sistema científico, ese consenso pronto se desvaneció. Los únicos partidos con un interés consistente en, y una visión constructiva de los problemas, son los demócratas liberales (D66) y los socialistas (SP). Los líderes de estos partidos participaron frecuentemente en los mítines y en los paneles, criticando la presión laboral y la comercialización de la academia, y apoyando la importancia del autogobierno universitario. 


\section{Consejeros de políticas}

Organizaciones de consultores expertos y organizaciones de investigadores y académicos, han producido una serie de Informes sobre el Futuro de la Investigación y de la Educación Superior, muchos de los cuales han obviado sencillamente las críticas fundamentales y el descontento general. Entre las excepciones está un Informe del Instituto Rathenau que mostraba las diferentes prioridades para la educación superior y la investigación (Van del Meulen, Pont, Faasse, Deuten y Belder 2015). Aunque este informe recalcaba la posibilidad de alternativas en el núcleo de los círculos de políticas científicas holandesas, no proporcionaba un análisis incisivo de los rasgos fundamentales del régimen gerencialista actual. Otra excepción que también atrajo la atención entre los directores de investigación fue el Manifiesto Leiden, una breve pero poderosa declaración sobre la falta de sentido $y$ el significado real del uso de las valoraciones cienciométricas en la investigación (Hicks, Wouters, Waltman, de Rijke y Rafols 2015). Aunque no niega el valor de algunas mediciones de resultados, ofrece sin duda una visión de cómo el actual régimen debe ser reformado y regresar a lo razonable.

\section{¿Cambio de régimen?}

Bajo la presión de las protestas y la perspectiva de reformas, se dan pequeños cambios al dominio del Lobo en Holanda, de los cuales solo discutiremos los más notorios aquí. El Manifiesto Leiden está siendo apreciado por algunos líderes académicos del país y en algunos sitios observamos modificaciones al fetichismo de los indicadores en el ámbito de la investigación. La Facultad de Medicina de Utrecht, una unidad de investigación bien significativa en el panorama holandés y al mando de la cual está un miembro clave del grupo Ciencia en Transición, ha iniciado nuevos procedimientos de contratación de personal, que confían menos en los indicadores puramente cuantitativos de pseudo-realizaciones académicas, y prestan más atención a la relevancia social.

El Protocolo de Evaluación Estándar Holandés, que se usa generalmente para auditar periódicamente las unidades de investigación, prescribe ahora la evaluación por pares de la calidad de las mejores publicaciones, y ha desechado las mediciones puramente cuantitativas del número de publicaciones. Queda por saber cómo los nuevos comités evaluadores aplicarán las nuevas reglas -hay un riesgo en el proceso que hace que comience a parecerse al sistema REF inglés (el Marco de Excelencia Investigadora, vid. Watermeyer y Olssen 2016) con su transferencia al mercado de los puntuados como "top"-.

Otro desarrollo relevante es la articulación de "contramedidas" para las Humanidades: un conjunto variado de indicadores más flexibles que pueden ser utilizados en los Departamentos de Humanidades. Estos criterios para "Calidad y relevancia de las Humanidades" (qrih.nl 2017) se incluirán en el Protocolo Estándar de Evaluación. Incluso aunque ello no suponga eliminar los peligros del fetichismo del indicador completamente, al menos permite a las Humanidades escapar de la imposición de los indicadores de ciencias naturales, que a menudo no tienen sentido ninguno y son destructivos en esas disciplinas.

De todos modos, la idea de una competición permanente de todos contra todas como vía regia hacia la eficiencia y la excelencia sigue teniendo pujanza. La compe- 
tición por estudiantes entre universidades sigue tan intensa como siempre, y se ha expandido incluso con intentos de atraer a muchos más estudiantes extranjeros. Igualmente fuerte es la competición por el dinero de investigación y plazas de investigadores, con ratios cada vez menores de éxito en la competencia por las ayudas de investigación (Rathenau Institut, 2017). El problema relacionado de la desproporción en el enorme porcentaje de docencia temporal y contratos de investigación efímeros no está ni mucho menos resuelto. Además, hay un plan para acabar con el estatus de funcionarios del personal académico, que supondrá menor protección laboral y minará lo que queda de independencia académica.

Bajo el lema de que la gestión de la universidad es esencialmente la misma que la gestión de cualquier otra organización, algunos administrativos se han catapultado a las universidades desde la banca (Engelen, Fernández y Hendrikse 2014), o de otras instituciones completamente extrañas a la academia. Algunos de ellos no han tenido mucha fortuna, chocando con violencia con los órganos académicos, especialmente en la VU University de Amsterdam y en la Universidad de Amsterdam, donde ha habido incluso que forzarlos para salir de la institución. Parece haber cierto reconocimiento de que el trabajo académico es algo peculiar, y que, -quizá solamente- los académicos deben estar implicados en la gestión de las universidades. En este espíritu, el ministro Bussemaker ha incrementado la voz que estudiantes y juntas de facultad tienen en la política de las universidades. Incluso aunque su papel general es primariamente "consultivo", ahora al menos tienen voz en las decisiones sobre los grandes asuntos de la universidad, de las facultades y de los presupuestos de los departamentos.

Finalmente, no parece haber cambiado mucho el aspecto de salvación económica y el asunto extenso de la comercialización de la universidad (cf. Radder 2010). A pesar de las objeciones a estos temas, la política del así llamado Top Sector sigue siendo la misma. Es decir, una parte sustancial del presupuesto de la NWO, la Organización Nacional Holandesa para la Investigación Científica (550 millones de euros para los años 2016 y 2017, del cual un 35\% anual del presupuesto es para ayudas a la investigación) estará destinado a la colaboración investigadora entre académicos y empresas privadas y comerciales. Incluso en el debate sobre la Agencia de la Ciencia en Holanda, oficialmente publicitada ocmo una forma de ciencia ciudadana, la retórica de la salvación económica está presente por todas partes (De Graaf, Rinnooy Kan y Molenaar 2017).

\section{Activismo: ¿qué funciona?}

En la última sección del Manifiesto, dimos una lista de 11 estrategias para el cambio. Revisando las experiencias de estos dos años pasados en Holanda, una combinación de las siguientes estrategias parece haber funcionado mejor (al menos se ha conseguido algo): la inclusión de los sindicatos, que proporciona la posibilidad de acciones legales; las manifestaciones masivas (en debates y eventos a gran escala) y las contra-ocupaciones (en las que los estudiantes han tenido un papel significativo); los contra-indicadores, como por ejemplo el nuevo Protocolo de Evaluación Estándar y los nuevos criterios de valoración de las Humanidades; finalmente, la acción política y parlamentaria, en forma de intentos de implicar a los partidos políticos y al gobierno en la causa de la universidad pública. En términos generales, una combinación de presiones (de sindicatos, los estudiantes y académicos, partidos políticos, atención 
mediática) con el desarrollo de alternativas concretas para los directivos de la universidad han generado reformas discretas.

\section{Valoración: ¿hacia una universidad pública?}

En el Manifiesto, articulábamos un número de principios para la universidad pública. Desafortunadamente, aparte de la promesa de reducir la productividad cuantitativa como un criterio de valoración para la investigación, no se ha progresado mucho en dirección a medidas concretas para que la universidad sea más pública. La dirección gerencial ha debido retirarse en algunos terrenos, pero en general, la modificación de los dispositivos del Lobo ha sido muy marginal. Incluso si las promesas políticas actuales se cumplen, habrá solamente un poco menos de fetichismo de los indicadores ciegos, un poco de atención de más a las peculiaridades de las Humanidades, un poco menos de porcentaje de trabajo eventual y un poco más de terreno ganado para la democracia académica, así como ligera atención a los temas sociales adyacentes a las prioridades económicas de la investigación- esa sería la más optimista de las previsiones.

Sin embargo, algo ha cambiado. Cuando escribimos el Manifiesto argumentábamos que el Lobo era tan poderoso que toda crítica era sencillamente borrada del mapa por ser irrelevante, retrógrada o infantil. Las protestas se ignoraban: no era necesario razonar con la oposición. Esto ha cambiado. El ministro de Educación visitó a los ocupantes de la Universidad de Amsterdam. Incluso en la elevada nube de los gestores de política académica, ahora se habla del impacto social, además de la relevancia económica. Aunque la Agenda Nacional de Investigación ha evolucionado de un mal concepto de la consulta a los ciudadanos hacia la pura influencia de grupos de interés, al menos hay un reconocimiento de que la deliberación pública sobre la investigación científica y universitaria puede ser muy importante, y no simplemente un tema de inversión de banqueros (Halffman 2017).

En suma, se han hecho pequeños progresos. Han aparecido grietas y el disenso se está legitimando, pero las tensiones que encendieron ese disenso siguen presentes. La gran ola de activismo de 2015 se ha desvanecido, pero la resistencia es aún significativa y queda mucho por hacer.

\section{Referencias}

De Graaf, B., A. Rinnooy Kan, and H. Molenaar, eds. 2017. The Dutch National Research Agenda in perspective: A Reflection on Research and Science Policy in Practice. Amsterdam: Amsterdam University Press.

Engelen, E., R. Fernandez, and R. Hendrikse. 2014. "How Finance Penetrates its Other: A Cautionary Tale on the Financialization of a Dutch University." Antipode 46 (4): 1072-1091.

Halffman, W. 2017. "De Nationale Wetenschapsagenda: Leuk Geprobeerd.” https:/goo.gl/ hoFZwR.

Halffman, W. and H. Radder. 2013. "Het Academisch Manifest: Van een Bezette Naar een Publieke Universiteit.” Krisis: Tijdschrift voor Actuele Filosofie (3): 2-18. https:/goo.gl/ M5SEfx.

Halffman, W. and H. Radder. 2015. "The Academic Manifesto: From an Occupied to a Public University." Minerva 53 (2): 165-187.

Hicks, D., P. Wouters, L. Waltman, S. de Rijcke, and I. Rafols. 2015. “The Leiden Manifesto for Research Metrics.” Nature 520 (7548): 429-431. 
Platform H.NU. 2017. “Platform Hervorming Nederlandse Universiteiten.” Accessed July 6 2017. http://platform-hnu.nl/.

Qrih.nl. 2017. “Quality and Relevance in the Humanities.” http://qrih.nl.

Radder, H., ed. 2010. The Commodification of Academic Research: Science and the Modern University. Pittsburgh: University of Pittsburgh Press.

Rathenau Instituut. 2017. "Factsheet: aanvraagdruk bij NWO." https://goo.gl/4HZ1Eg.

Rethink-UvA. 2017. "UvA Staff for a New University." Accessed July 6 2017. http:// rethinkuva.org.

Science in Transition. 2017. "Science in Transition-English.” Accessed July 6 2017. http:// www.scienceintransition.nl/english.

Van der Meulen, B., P.M. Pont, P. Faasse, J. Deuten, and R. Belder. 2015. Keuzes Voor de Toekomst van de Nederlandse Wetenschap: Analyse van Beleidsopties bij Vier Scenario's. Den Haag: Rathenau Instituut.

Watermeyer, R. and M. Olssen. 2016. “'Excellence' and Exclusion: The Individual Costs of Institutional Competitiveness.” Minerva 54 (2): 201-218. 


\section{La universidad productivista se hace global (y también su resistencia)}

Willem Halffman y Hans Radder

El modelo de la universidad productivista se ha extendido por todo el globo como un incendio. Este modelo organiza el trabajo académico para conseguir un "output" máximo con el mínimo coste posible, en el espíritu de una empresa, aunque, en la mayoría de los casos, se aplica a entidades públicas. El modelo se vende y se apoya en un poderoso discurso que promete evaluar la eficiencia en los investigadores y en sus gastos mediante mediciones rigurosas e imparciales; pretende mejorar la calidad mediante la competición entre investigadores y sus instituciones; promete mejorar la "eficiencia" en la ubicación de los recursos de la Educación Superior; pretende alimentar la "excelencia" investigadora y la "élite" académica; pretende salvar económicamente mediante una corriente inacabable de "innovaciones", todas ellas dirigidas por ejecutivos profesionales que han ganado sus agallas en mundos más exigentes que los de los mullidos campus universitarios. Este modelo halla sus raíces en la Nueva Gestión Pública de los años 80 , en que se concebía la dirección de los servicios públicos como negocios, y que otorgó la gestión de servicios como el transporte, las instalaciones públicas, las inspecciones, los cuerpos reguladores, la educación, la sanidad pública e incluso en algunos casos las funciones policiales y las prisiones a entidades privadas.

El modelo de universidad productivista lo apoyan una variedad de creyentes. Están los que confían ciegamente en la competitividad dura, en los beneficios universales del libre mercado y en las maravillas de la libre empresa, también en el campus. Más a la derecha en el espectro político, están los que ven en esta forma de gestión una herramienta conveniente para conseguir que los rebeldes académicos estén bajo control, encadenados con toda seguridad a sus molinos de producción. Después están las facciones "realistas" que creen que esta es la única manera de salvar a las universidades públicas, de salvaguardar una educación superior e investigación sostenibles, atacadas como están por la masificación y por las políticas de austeridad permanentes. Y después están las filas bienintencionadas de los administradores universitarios, los académicos convertidos en gestores y en gerentes de políticas, que se han convencido de que no hay otra alternativa: así es como las universidades se gobiernan; este es el estándar profesional. Explican los detalles unos a otros en conferencias profesionales y el talleres formativos y aseguran así que el modelo se extiende a países "que necesitan modernizarse", como los que aspiran a entrar en la UE o los que están en la cola global.

El maremágnum causado por la universidad productivista nos rodea por todas partes. En la sombra de su retórica del gana/gana se esconden costes no expresados en los indicadores de excelencia y "efectos colaterales" inesperados pero no menos destructivos. Para los que no alcanzan los pináculos del reconocimiento y la excelencia, el empleo se ha vuelto precario y agotador. Los profesores asociados deben invertir su esfuerzo en cursos que no volverán a impartir, porque las dinámicas de producción obligan a un currículum de "más alta calidad". A pesar de todo, están marcados principalmente por sus resultados de investigación, a menudo en términos de indicadores reificados y distorsionantes. Los torpes sistemas de evaluación recompensan a investigadores e instituciones que han aprendido cómo jugar en el sistema, a través de publicaciones salami, reciclado de textos, círculos de cita y autocita, y otras vías de hacer subir los indicadores proxy. La autonomía de los consejos y órganos de decisión universitarios ha dejado sitio a los gestores profesionales "más eficientes", que han 
asumido el control del trabajo académico y creado relaciones más jerárquicas -especialmente conforme la "autonomía mayor" de la universidad se envuelve en la dependencia de la "responsabilidad" de los indicadores de resultados. Mientras tanto, la dirección parece obsesionada con los edificios, soñando un día con desarrollar una verdadera cartera de propiedades del estilo de las USIvy League Schools, lo que agrava la lógica de mercantilización que ha penetrado las políticas universitarias. Las Relaciones Públicas y los especialistas de marqueting esperan poder sacar partido del mercado internacional de estudiantes, trayendo "talento fresco" y especialmente dinero fresco, mientras organizan la fuga de cerebros desde países muy necesitados de ese talento. Para captar estudiantes, los recursos se retiran de la enseñanza o del apoyo a los alumnos, para pagar la publicidad y las instalaciones del "campus de verano". El crecimiento es imperativo, como la creencia en los beneficios a escala, con cada vez más grandes (y menos humanos) institutos de investigación, campus y aulas (vid. Batterbury y Byrne para el caso de Australia). En el pseudo-mercado global de "outputs" de educación e investigación, las contribuciones a lo local o a lo social no se recompensan, o a duras penas. La publicación habitual en periódicos, revistas o publicaciones académicas en habla no inglesa se ve como un hobby o señal de estar convirtiéndose uno en un perdedor académico. La importancia social se ha convertido en una etiqueta para adquirir financiación, sea corporativa o de otro tipo.

Cuando denunciábamos este modelo en nuestro Manifiesto Académico como una ocupación de nuestras amadas universidades por una fuerza alienígena, el "Lobo gerencial", sabíamos que el modelo de universidad productivista había estallado desde el mundo anglo-americano expandiéndose a Holanda. Pero no sospechábamos que nuestro iracundo Manifiesto fuera a resonar tan lejos y tan ampliamente. Recibimos correos de simpatizantes de cada rincón del mundo, incluidos países que presumíamos más resguardados de la locura de la maximización gerencial. Les pedimos a nuestros corresponsales que nos relataran su historia, para explicar lo que veían que ocurría en sus países y recibimos los 13 Informes, que hemos complementado en esta colección con nuestra descripción de los sucesos más recientes en Holanda. Estos Informes no son estudios sistemáticos con hipótesis cuantitativamente demostradas. Son reportes que provienen de la experiencia personal y se sustentan en estudios empíricos y argumentos convincentes. Hablan de colonización, de cómo se impone el modelo productivista; pero también, de resistencia y de protesta, que a veces lleva a victorias parciales. Tras ellos están las lecciones que hemos sacado de sus relatos, aunque la nuestra no es sino una perspectiva más en un conjunto rico de contribuciones de muy amplios y diversos contextos.

\section{El productivismo contextualizado}

Muchos autores de esta colección están de acuerdo con Michel Lacroix en que el análisis del Manifiesto Académico, recapitulado en términos de universidad productivista (tomando el término de Dagnino y Barbosa de Oliveira) desencadena un sentimiento poderosamente familiar. Al mismo tiempo, indican variaciones contextuales del modelo productivista. Como resultado de las específicas condiciones de los sistemas nacionales, de las regiones geopolíticas, o incluso de universidades específicas, la caja de herramientas del productivismo se aplica de manera selectiva y se adapta a las circunstancias locales. En algunos lugares, como España o Bélgica (vid. Aladro Vico; Bogaert, De raene, Froeyman, Stroobants y Vertommen) una representación académica relativamente fuerte sigue funcionando en forma de juntas decisorias o 
decanos electos, proporcionando cierto contrapeso para la resistencia. Sin embargo, incluso aunque los académicos estén formalmente al control, se sigue extendiendo esa caja de herramientas productivista, apoyando la incómoda observación nuestra de que, en parte, esto lo estamos causando desde dentro de la universidad.

Nuestro interés particular es el rol del modelo productivista en el contexto postcomunista de Europa del Este. Allí, la universidad productivista se presenta como el modelo moderno y profesional, que acaba con el clientelismo, que expulsa a los parásitos, pero al mismo tiempo mercantiliza el conocimiento a expensas de la cultura académica local: ver los Informes de Bosnia-Herzegovina (Hibert and Lešić-Thomas), Hungría (Wessely) y Eslovaquia (Hvorecky, Višňovsky and Porubjak). Particularmente en Hungría, el productvismo se alía con un estado fuertemente autoritario que está usando el discurso gerencialista para afirmar su poder sobre los académicos liberales (y por ello amenazadores). En nuestras comunicaciones con los académicos de Europa del Este -no explícitamente en estos reportes- quedamos sorprendidos por su percepción de las instituciones europeas como las verdaderas impositoras del modelo productivista, tanto bajo la excusa de facilitar el intercambio estudiantil ("Bolonia") o simplemente con el paradigma de actualizar la gobernanza de la universidad.

Sin embargo, la idea de que el productivismo es idéntico al buen gobierno, que es "la manera correcta de hacer las cosas", y que merece la pena emular a los países en la cumbre de la liga científica, se extiende también sin esa presión formal. De Brasil y España (Dagnino y Barbossa de Oliveira; Aladro Vico) llegan informes de cómo se copian modelos y herramientas como recetas de éxito seguro, eliminando las desventajas que conllevan, como si no tuvieran inconvenientes. En estas circunstancias, los relatos del lado oscuro del productivismo desde países aparentemente triunfadores como Holanda pueden servir para contradecir esos "hurra" de los rectores.

La legislación nacional y las políticas son un claro factor mediador en todos los casos, incluida la extrema interferencia del gobierno en las universidades japonesas (ver Katsumori), el infame Marco de Excelencia Investigadora británico (vid. Watermeyer), la peculiar posición de élite de las instituciones públicas en Francia (ver Charle) y las intrusivas reformas administrativas en Québec (vid. Lacroix). La masificación de la educación superior ha convertido los grados universitarios en algo asequible para las clases medias y altas. Al mismo tiempo, ante la incapacidad de los gobiernos nacionales de hacer coincidir ese crecimiento con el presupuesto designado, surge una fuente de grave tensión, para la que las recetas productivistas se presentan como una solución. Por encima de todo esto, el productivismo conduce a la Educación Superior hacia una (semi)privatización mediante matriculas más caras y mayor financiación de empresas, lo que a su vez detrae las inversiones públicas en el sector (vid. Brown y cómo describe esta lógica en USA). Estos rasgos apuntan a una cierta debilidad de nuestro análisis en el Manifiesto Académico. Aunque reconocíamos con brevedad en una nota al pie la importancia de una "amplia y extensa serie de desarrollos socio-culturales y políticos", nuestra metáfora primaria era el Lobo del gerencialismo. Dado que la noción de universidad "gerencialista" tiende a ignorar, o al menos subestimar, la importancia de factores más amplios, como las políticas neoliberales de gobierno, las de legisladores y las visiones generales del mundo, ahora utilizamos la más abarcadora noción de "productivismo" universitario.

Muy específica es también la posición de los países anglohablantes, que tienen un particular avance estratégico del "mercado" estudiantil internacional de grado. Entre estos países, Australia ha intentado volver la masificación estudiantil universitaria 
para su beneficio, atrayendo a estudiantes del Sureste asiático. Bajo la presión de las políticas de austeridad, los estudiantes extranjeros son saludados como una solución para preservar e incluso relanzar la posición de las universidades australianas, maniobra facilitada por el movimiento hacia el productivismo en dicha universidad (ver Batterbury y Birne). Aunque los países anglohablantes tienen a este respecto una ventaja estratégica, procesos similares se están dando en Holanda, como mencionábamos en nuestra contribución a esta colección. Así, la Universidad de Groningen anuncia orgullosa que será la primera universidad del centro de Europa en abrir un campus franquicia en China, en colaboración con la Universidad Agricultural de Beijing, y junto a la compañía de alimentación holandesa Friesland Campina (Universidad de Groningen 2017). Ven a China como "un enorme mercado de crecimiento de estudiantes" y esperan enviar a Groningen un número importante de los 450.000 estudiantes chinos que irán a estudiar fuera de su país y por supuesto, pagarán matrículas muchísimo más caras que las de los holandeses (dependiendo del programa de grado, pueden llegar a ser entre cuatro y seis veces más altas).

Además de estos rasgos contextuales, elementos similares siguen apareciendo cuando la universidad productivista se hace global. Como las reestructuraciones se desencadenan con los recortes de presupuesto, las crisis económicas y las políticas de austeridad, o incluso por las victorias electorales anti-intelectualistas, los gestores de políticas buscan alternativas y encuentran un modelo que tiene fama de eficaz en alguna Shangri-La científica, en lo alto del ránking de Shanghai. Los Informes de los países incluyen algunos ejemplos de políticas persistentes de austeridad que han destruido instituciones académicas y su colegialidad, como ocurre en Dinamarca y Finlandia (ver Välikangas), pero probablemente en ningún lado es tan dramático como en Brasil (Dagnino y Barbosa de Oliveira). Cuando el estado abandona a sus universidades, el capital privado parece la única vía de salvación, junto con las aventuras financieras

\section{Cómo resistir a la universidad productivista}

Teniendo en cuenta las especificidades locales, los informes sobre la llegada de la universidad productivista, sea parcial o en toda su deplorable gloria, han llegado a nosotros de muchas partes. A menudo, llegan de académicos que se sienten aliviados al ver que otros sufren el mismo ultraje; que no están solos en sus intentos de resistir. Justo como las especificidades de la universidad productivista se ven mediatizadas por las condiciones locales, así son las diversas formas de resistencia. Idealmente, la resistencia a este modelo tiene tres objetivos generales. Primero, la creación y el mantenimiento de solidaridad entre los estudiantes, los profesores universitarios y el personal de apoyo. Esto incluye la defensa o formación de estructuras democráticas que garanticen a todos los implicados tener voz y voto en estos temas de su interés. Segundo, los análisis en profundidad y la crítica del actual modelo de universidad, complementados por alternativas concretas y bien meditadas. Tercero, una variedad de actividades (lo primero, el debate y la acción) que conduzca a la realización de esas alternativas.

En el Manifiesto, identificábamos una larga lista de ejemplos de movimientos laborales para plantear posibles acciones contra el productivismo. ¿Qué modelos de resistencia podemos hallar en los Informes de los 14 países? Revisamos brevemente las diferentes formas de resistencia (y las razones para su ausencia). 


\section{Intervención democrática}

Los Informes de España y Bélgica muestran que la universidad democrática y las juntas de facultad y decanos electos puede que no impidan la introducción del productivismo. Sin embargo, el caso de España demuestra también que pueden ser plataformas críticas desde las que resistir sus más perniciosos efectos. Por esta razón, la pequeña extensión de los derechos democráticos de los estudiantes y los profesionales que resultó de las recientes protestas en Holanda contribuyó al menos un paso más en la dirección correcta.

Inversamente, los intentos por acabar con las instituciones y plataformas de deliberación de la democracia académica son la primera táctica para allanar el camino al productivismo, como ilustran los Informes de Japón y Hungría. Como en esos casos, el Informe eslovaco pone el acento en el valor de la democracia académica y argumenta en favor del retorno de la integridad personal y la libertad universitaria. El Informe bosnio aboga por revivir algunos elementos de la antigua Yugoslavia y su tradición socialista, especialmente las virtudes de la solidaridad y de la cooperación. En todos estos reportes, las oportunidades para un cambio sustancial parecen ser pocas o estar ausentes. De las razones para ello, dos sobresalen: el gobierno autoritario, aliberal nacional, y la cultura académica de la pasividad, la obediencia y el conformismo. El relato de Reino Unido argumenta que incluso intentos bienintencionados de hacer más inclusivo el actual sistema de evaluación investigadora, de hecho conforman y contribuyen a una manera intrínsecamente mala de evaluar los logros en investigación.

\section{Sindicalización}

El patrón más notable entre las estrategias victoriosas para defender la universidad del productivismo, en todos los informes que hemos recopilado, es la importancia de los sindicatos, las organizaciones de académicos, de administrativos de apoyo y de estudiantes. Brasil, Québec, España, USA, Australia y Holanda informan todos de cómo la sindicación ha sido vital para contrarrestar las estrategias del Lobo. Los sindicatos proporcionan una posición colectiva de negociación en las condiciones de trabajo, pueden investigar y reunir evidencias, y organizar movilizaciones masivas de protesta. Por ello, hay una cuestión empírica importante: ¿Cuántos miembros de la universidad, estudiantes o profesorado, son miembros de un sindicato? En Holanda, se trata de una pequeña fracción y tememos que la situación es similar en los países citados. Sin embargo, las informaciones sugieren que los sindicatos son un factor clave para una resistencia con éxito.

\section{Manifestaciones y acciones críticas}

Los objetivos de las manifestaciones y de las acciones públicas de crítica, por la comunidad universitaria, pueden variar. En algunos casos sirven para generar conciencia ante una serie de problemas, tanto entre los estudiantes, académicos, público en general, o entre los gestores de políticas y los políticos profesionales. Pueden dirigirse también a poner presión en los gestores o en los gestores políticos para resolver un problema particular del modo apropiado. Pueden intentar reforzar los principios básicos de la Educación Superior, en sus políticas y leyes. El papel y el 
impacto de estas formas de resistencia parecen diferir significativamente entre los países que están representados en nuestra colección. Los Estados Unidos informan de "muchos ejemplos prometedores de defensa eficaz de los valores e instituciones de la educación superior pública", especialmente el activismo estudiantil, que ha creado una conciencia pública mayor sobre el estado actual de la Educación Superior en USA. En Holanda hubo igualmente una gran oleada de resistencia, que comenzó en 2013, culminando en 2015, y que continúa con menor amplitud en estos momentos. Algunas modificaciones menores, pero significativas, en el productivismo, se han logrado proporcionando estrategias alternativas de gestión, como las reformas en el modelo de carrera académica nuevo que ha desarrollado la Facultad de Medicina de Utrecht.

Por el contrario, las movilizaciones de estudiantes y profesorado parecen más difíciles en Australia, debido al domino de una extendida visión y política neoliberal de la enseñanza. También en los casos de Canadá, Finlandia y Eslovaquia, las tácticas individualísticas del Lobo, que incrementan la competitividad y no la solidaridad, parecen tener mucho éxito. En Hungría, el primer y más importante desafío es acabar con ese "Pulpo", el gobierno antidemocrático y anti-intelectual, que usa sus tentáculos de modo tan destructivo. Sin embargo, hasta ahora, el impacto de las manifestaciones y acciones de protesta ha sido pequeño, en tanto la acción legal se considera pero no se contempla como muy prometedora.

\section{Huelgas y rechazo colectivo}

Se han producido unos cuantos casos de huelgas en Brasil, Canada y Bélgica a raíz de estos hechos. Sentimos que, frente a condiciones de trabajo que se deterioran, esta forma de resistencia puede explotarse más, especialmente si se organizan junto a los Sindicatos. En el Manifiesto Académico también planteábamos la posibilidad de una desobediencia civil administrativa, con estrategias de sabotaje contra las medidas de control administrativo menores. Desde Québec llega ahora un ejemplo eficaz de esta estrategia, cuando consiguieron la retirada de una tarea burocrática de control absurda mediante la sistemática estrategia de declarar en ella "Nada que declarar". Nuestros colegas belgas proponen acciones colectivas contra la financiación por resultados: la estrecha relación entre el número de publicaciones en revistas indexadas con la compañía comercial Thompson Reuters (recientemente vendida y rebautizada como Clarivate Analytics por parte de los inversores bancarios) y los fondos públicos otorgados a cada universidad. Si los académicos dejan de mencionar su filiación institucional en sus publicaciones y presentaciones, los resultados institucionales se verán subvertidos y sin dañar las carreras académicas. Estas acciones de no-cooperación son un poderoso recordatorio de las muchas herramientas que podemos utilizar en nuestra asistencia contra el productivismo. Al mismo tiempo, nos deben recordar también el hecho de que estas formas de resistencia sólo tendrán éxito si existe una sustancial cantidad de solidaridad: muchos, o si es posible la mayoría de las personas implicadas, deben estar dispuestas a participar.

\section{Contra-ocupaciones}

Las únicas ocupaciones contra el Lobo han tenido lugar en España y en Holanda. Sin embargo, de otras fuentes nos llega que se presentan a menudo en Brasil también. Es 
primeramente la más joven generación de estudiantes la que juega un papel indispensable en estos asuntos fuertemente físicos. Las ocupaciones española y holandesa han sido bastante eficaces a la hora de atraer la atención (de académicos, políticos y público en general) respecto a la situación de las universidades, pero no han aportado (todavía) soluciones a los problemas fundamentales.

\section{Salida}

La fuga de cerebros es una forma corriente de salida: dejar el país porque la situación en otro lugar se ve como más prometedora. Otra forma de salida puede darse con mayor frecuencia: los jóvenes académicos frustrados o resignados que deciden dejar la universidad tras el enésimo contrato de docencia breve y temporal o tras la enésima solicitud rechazada de financiación para investigar. Formas de salida que se han mencionado en Finlandia, Eslovaquia, y Australia, pero que seguramente aparecen en muchos otros países igualmente. Sin embargo, aunque las personas puedan tener sus razones para ambas formas de salida, la resignación individual no constituye una forma efectiva de resistencia, como ya establecíamos en el Manifiesto Académico.

\section{Contraindicadores y el poder del Humor}

Los únicos ejemplos de contraindicadores provienen de Holanda, en la forma de alternativas al índice h y a los criterios de evaluación específicos para las Humanidades. Sin duda que las muchas formas de argumentación en profundidad, debate serio y acción "intensiva" que hemos revisado, son necesarias para llevar a cabo un cambio significativo. Pero ¿serán suficientes para movilizar a la mayoría silenciosa? ¿Y serán suficientes para mantener viva nuestra propia motivación de cara a las (inevitables) barreras y contrariedades? Quizás no. Por ello, acciones más lúdicas pueden ser igualmente importantes, mostrando cómo el emperador está desnudo.

El año pasado, por ejemplo, la Plataforma para la Reforma de las Universidades Holandesas organizó un concurso de ránking de slogan (Platform H.NU 2016a). Recogimos todos los slogans de Relaciones Públicas de las universidades holandesas en nuestra página web y colocamos un botón para votar por el peor de todos. Al mismo tiempo, publicitamos en los periódicos y revistas universitarias la iniciativa para que fuera bien conocida. Finalmente, calculamos los puntos, publicamos los resultados del concurso y otorgamos los premios a los Consejos de Gobierno de las dos universidades ganadoras ${ }^{22}$. También ofrecimos un "generador de slogans al azar" basado en una selección arbitraria de los clichés de los slogans, para proporcionar a la dirección de la universidad una alternativa gratuita a las caras campañas de marqueting (Platform H.NU 2016b)

El objetivo serio subyacente a esta acción lúdica es, por supuesto, una fuerte crítica de la universidad como una empresa comercial cualquiera. Su particular fin es poner de manifiesto la costosa y forzada promoción de las universidades, mediante un extenso marqueting y departamentos de Relaciones Públicas y campañas de ima-

\footnotetext{
22 Votaron más de 3200 personas. La orgullosa ganadora fue la universidad de Groningen ("Born leaders reach for infinity" "Nacidos lideres para alcanzar la infinitud")) y la Universidad de Amsterdam ("We are the U" "Somos la $\left.U^{\prime \prime}\right)$ quedó en un honroso segundo puesto, mientras que la VU University SAmsterdam quedó cuarta con su profundo "Looking firther" ("Mirando más allá").
} 
gen de marca. Idealmente, esta acción debería verse acompañada de análisis cuantitativos sobre cuánto dinero público se destina a estas campañas. Los informes indican que las Relaciones Públicas y el marqueting son una cuestión crucial en las universidades de muchos países. Esta acción es una contribución esencial para llamar la atención pública sobre este hecho y para mantener alta nuestra moral.

\section{Conclusión}

Conforme la universidad productivista se hace global, la gente de las instituciones académicas está empezando a darse cuenta de que su lucha no es simplemente un fenómeno local. Las recetas productivistas se expanden rápidamente, pero las historias y los análisis de sus lados oscuros también se difunden con rapidez. Nuestro objetivo era extender no solamente el análisis de lo que está mal, sino también qué se podía hacer para evitarlo. Las descripciones desde 14 países ofrecen un panorama de formas eficaces de actuación. Los Sindicatos parecen tener un papel crucial, en muchos de los Informes, pero pensamos que sin duda deben apoyar las batallas que cada académico debe sostener en su propio entorno universitario.

¿Qué otros pasos podemos dar? Sin duda informes de más países serán de utilidad: informes sobre estrategias de resistencia seguidas y de tácticas comprobadas. Sería particularmente interesante conseguir más información del Sureste asiático, una rica y rápidamente floreciente cultura de la investigación y de la Educación Superior que hasta ahora ha permanecido aislada de nuestra visión. Oriente Medio y los países africanos tienen que resultar interesantes, por ejemplo en la cobertura informativa de la acción política extensiva en las universidades sudafricanas en recientes años. Quizás el siguiente paso sea desarrollar más comparaciones sistemáticas, pero por ahora una expansión geográfica de nuestra cobertura parece más útil.

Otra tarea fundamental será desarrollar un bosquejo de alternativa radical para el futuro, los rasgos de la universidad que sea profundamente pública, orgullosamente académica, pero también sostenible económicamente. No se trata de una cosa fácil, pero cuando llegue la siguiente oleada de reestructuraciones, quizás usted también se encuentre en necesidad de leer una visión más inspiradora que la de la universidad productivista.

\section{Referencias}

Platform H.NU. 2016a. "Rijksuniversiteit Groningen Heeft Domste Universitaire Reclameleus." Accessed July 10 2017. https://goo.gl/Q2s7bM.

Platform H.NU. 2016b. "University Slogan Generator.” Accessed July 10 2017. http://platform-hnu.nl/slogangenerator/.

University of Groningen. 2017. "University of Groningen to Start First Dutch Branch Campus in China." Accessed July 10 2017. https://goo.gl/EHFutJ. 